\title{
7 Liturgische Gattungen des Kurienzeremoniells im Palazzo Apostolico
}

Der Abschnitt in Cesare Baronios Annales über die Pflege des Grabes Christi, deren massgebliches Kennzeichen die Nähe zwischen begrabenem Leib und den instrumenta ad mortem ist, stellt innerhalb des Gesamtwerkes den Übergang von einer aus den Evangelien überlieferten Erzählung über die apostolische Pflege des Andenkens an das Leben Christi und seines Kreuzes- und Messopfertodes in eine Kirchengeschichte dar. Diese entscheidende Schwelle zwischen Historia Evangelica und einer Historia Ecclesiastica setzte ab 1572 mit den Arbeiten der Indexkongregation im Zusammenhang mit einer Neuausgabe der Vulgata ein. Die Überarbeitungen der Vulgata ermöglichten es der Kongregation zugleich, sich kontroverstheologisch mit der Kirchengeschichtsschreibung auseinanderzusetzen. Cesare Baronios Annales beziehen sich auf den zentralen Einfluss, den die Liturgie und ihr ritueller Vollzug im Zeremoniell auf die Kirchenhistoriographie ausübten. Eine solche Kirchengeschichte, die die Magdeburger Zenturiatoren und ihrer Ecclesiastica Historica erfolgreich zu widerlegen hatte, musste somit zwangsläufig aus einem liturgischen Verständnis des Kurienzeremoniells entstehen.

Die Gestaltung des Kurienzeremoniells für das anno santo erhob die indulgentiae in die Rangordnung der Sakramente. Damit gab die Verwaltung des göttlichen Gnadenerlasses eine wegweisende Richtung vor, in welche sich auch die Liturgie der kurialen Zeremonialkultur entwickeln sollte. Dieser rituellen Neuausrichtung des Zeremoniells nach liturgischen Vorgaben ging die Kurie in der bildprogrammatischen Ausmalung des Palazzo Apostolico nach. Die Forschung betrachtete die neueinsetzende malerische Ausstattung im Boncompagni-Pontifikat Gregors XIII. bislang getrennt von der Dynamik, die das Kurienzeremoniell mittlerweile aufzuweisen begann. Der folgende Abschnitt möchte sich dieser bildprogrammatischen Ausstattung des Palazzo Apostolico im Boncompagni-Pontifikat widmen und zeigen, wie eine neue Bildsprache zu einer Angleichung von römisch konnotierter Liturgie und ihrem rituellen Vollzug im Kurienzeremoniell wesentlich beitrug.

\subsection{Eine neue Bildsprache in der Cappella Paolina}

Es ist unbestritten, dass sich mit dem Pontifikat Gregors XIII. die römische Kunstproduktion, die bis dahin vorwiegend toskanische Maler dominierten, an eine Bildersprache anzupassen begann, die flämische und vor allem emilianische Wesenszüge trug. In die römische Bildproduktion drangen demgemäss regional unterschiedliche malerische Einflüsse ein, die es dem Boncompagni-Papst und seiner Kurie ermöglichen sollten, dem römischen Stadtraum eine sakrale Dimension zu verleihen. Ciappi bezeichnete diesen Einfluss Boncompagnis in seinem Compendio als eine „per ornamento 
della città e accrescimento del culto divino" charakteristische Eigenschaft. Am deutlichsten offenbarte sich dieser Einfluss im Frontispiz zu Diego de Simancas 1575 gedrucktem De Catholicis Institutionibus liber, auf dem die Gegenüberstellung zweier allegorischer Figuren - der Roma und der Ecclesia - gezeigt wird. Die beiden Personifikationen rahmen das im Bildzentrum aufgeführte Wappen der Stadt Rom ein. Der urbane Raum wird damit selbst als ein allegorischer Rahmen aufgefasst (Abb. 24). ${ }^{718}$ Die Übernahme einer Bildsprache, die sich allmählich von der Dominanz der toskanischflorentinischen maniera zu trennen begann und sich in eine bewusst römische Bildrhetorik wandelte, ging mit dem Bedürfnis Gregors XIII. und der Kurie einher, Rom und mithin die Ecclesia Romana als Heilsanstalt des göttlichen Gnadenerweises zu gestalten. Dementsprechend diente das urbane Architekturprogramm für die zeremoniellen Vorbereitungen zum Jubeljahr, weshalb es auch als Grundlage für die entsprechende Formulierung einer römisch-liturgischen Sprache genutzt wurde. Roms Stadttopographie bot gleichzeitig eine geeignete Fläche, auf der sich ein rhetorisches Bildprogramm der Ecclesia Romana abbilden liess, das dem römischen Stadtraum einen sakralen Charakter verlieh. Der Apostolische Palast sollte dabei selbst den zentralen Ort dieser sakralen Ausmalung Roms repräsentieren. Zu diesem Zweck wurde der päpstliche Segen ab der zweiten Jahreshälfte des anno santo über dem Belvedere-Hof und nicht mehr über dem Portikus der Petersbasilika gespendet. ${ }^{719}$

Im Verlauf des 16. Jahrhunderts wurde mit der innenarchitektonischen Ausstattung des Palazzo Apostolico diesem eine verstärkt zeremonielle Bedeutung verliehen. Ab dem Boncompagni-Pontifikat Gregors XIII. wurde der Palast dann zu einem einheitlichen Architekturorganismus des Papst- und Kuriensitzes umgestaltet. Den Kern dieser neuen zeremoniellen Palastarchitektur bildete die Cappella Paolina, die unter der Aufsicht des Bologneser Malers Lorenzo Sabatini zwischen 1573 und 1575 weiter ausgeschmückt wurde. Unmittelbar nachdem Giorgio Vasari die Sala Regia 1573 fertiggestellt hatte, beauftragte ihn Gregor XIII. ein Bildprogramm sowohl für die Decke als auch für die schmalen vertikalen Bildfelder auf den Seitenwänden der privaten Papstkapelle zu entwerfen. Das Bildprogramm Vasari sollte Michelangelos letzte Fresken in diesem Kapellenraum vervollständigen. Dabei bediente sich Vasari wieder der Kenntnisse seines engsten Briefkorrespondenten und Freundes aus Florenz, Vincenzo Borhini. In einem langen und bislang noch undatierten Brief an Vasari schlug Borghini ein geeignetes Bildprogramm für die Cappella Paolina vor. Borghinis Entwurf hob die Bedeutung der Fortführung der von Michelangelo mit der Kreuzigung Petri und der Bekehrung Pauli begonnenen Apostelgeschichte der

718 Ciappi, Compendio, S. 17. Vgl. auch das Urteil in Baglione, Vite, Bd. 1, S. 4: „[...] fece egli far molte fabriche non tanto per sua gloria, quanto per pietà cristiana [...].” Zu diesem Wandel des Künstlerklimas vgl. Kat. Venezia 1999, 132-143; Meijer 1999, S. 117-132; Kat. Bruxelles 1995, S. 35-55; Zuccari 1998, S. 262-281.

719 BAV, Chig.L.II.30, f. 345v-346r, 347v-348r, 349r-v, 354r. Dieselben Einträge finden sich ebenfalls in BAV, Bonc.C.5, f. 275r-281v. 


\section{ACOBI SIMANCAE \\ PACENSIS EPISCOPI, \\ DE CATHOLICIS INSTITVTIONIBVS \\ L I B $\mathbf{E}$, \\ Ad pracauendas \& extirpandas hrefes admodum \\ neceffarius, tertio nunc editus. \\ Cum Priuilegio, Elicentia Superiorum.

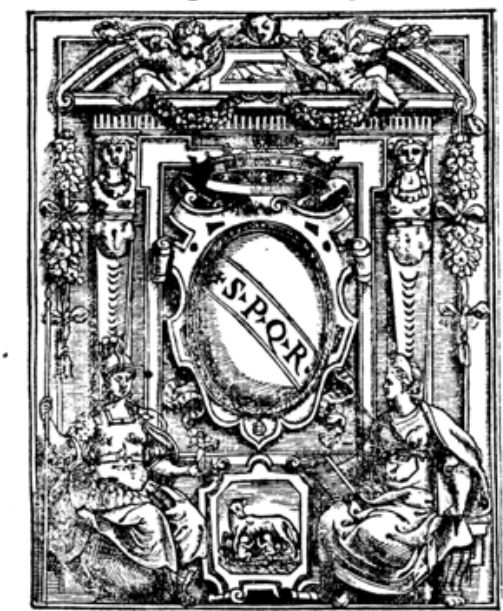

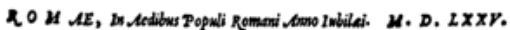

Abb. 24: Titelseite aus Diego de Simancas' De Catholicis Institutionibus liber, Rom 1575.

beiden Apostelfürsten Roms hervor. Deshalb schlug er für das links neben der Kreuzigung gelegene Bildfeld die Szene der Schlüsselübergabe vor, während auf der gegenüberliegenden Wand die Episode von Paulus vor Festus und Agrippa (Apg 26,1724) neben der Bekehrung angebrachten werden sollte. ${ }^{720}$ Beide Szenen sind in zwei Vorstudien Giorgio Vasaris überliefert, die er am 18. Juli 1573 mitsamt einem Schreiben an den Kardinal von Como, Tolomeo Galli, sandte (Abb. 25a \& 25b). Vasari erhoffte sich, dass seine Vorstudien, die dann Lorenzo Sabatini in Freskenmalereien

720 Frey 1923-1982, II, S. 800-805, bes. 801-803: „[...] da una parte metterei quando il nostro signor Gesù Christo dà le chiavi a San Pietro, per significare la potestà data a lui e suoi successori, col motto (se vi va parole, che a questo penserete vou del come e del dove): QUODCUMCQUE SOLVERIS etc. [...] Dall'altra parte della facciata da basso metterei quando egli si difende innanzi a Festo ed Agrippa (chè non solo contro la sapienzia umana, ma contro la potenzia ancora ebbono da fare assai), col motto: NON EST POTENTIA, che, legando insieme l'una e l'altra, viene a dire: non est sapientia, non est potentia contra Dominum, e chi non volesse sottintendere parole, nè appiccare insieme cosa che è separata di tanto spazio, potrebbe, e tornerebbe forse meglio al senso ed a una cotal proprietà di parlare, dire quivi: Non est sapientia contra Deum; e qui Non est potentia contra Dominum; come se dicesse: Contro al maestro non è sapere, e contro al padrone non è potere.” 
für die cappella parva ausführen sollte, wegen ihres Reichtums und ihrer Vielfältigkeit den Boncompagni-Papst ebenfalls zufriedenstellen würden:

Ecco che doppo molti dì che io per satisfare la mente di Nostro Signore, che mi chiese il disegnio et invenzione, per la volta e facciate della Pauolina (sic!), che avendolo finito io gniene mando; et il Reverendissimo Vescovo di Pistoi lo presenterà al Cardinale San Sisto, che è protettore di Lorenzo Sabatini Bolognese nostro che doverrà condurla. Arò caro che quando Sua Santità l'arà visto, poiché la Signoria Vostra Reverendissima mi scrisse che la lo vedrebbe volentieri, che io sappi dallei se a Sua Santità gli è sotisfatto o no; che per quel io conosco non m'è uscito di mano di quanti disegni feci mai né il più vario, né il più ricco, né il più artifizioso di questo. E se io in altro, seben son lontano e carico di fatiche, io posa far cosa che gli sia grata, mi sarà gloria che si degni comandarmi. ${ }^{721}$

Mit diesem Eigenlob verwies Vasari auf seine Fähigkeit, ein selbstgeschaffenes Bildrepertoire an Motiven und Modellen wiederverwenden und damit eine schnelle Ausführung des Bildprogramms für die Paolina gewährleisten zu können. In den Augen des Boncompagni-Papstes waren aber diese Bildlösungen Vasaris „den Zwecken der Cappella Paolina nicht dienlich“, wie es der Papstneffe Filippo Boncompagni Vasari am 1. August mitteilte. ${ }^{722}$ Die Gründe, weshalb dieses ursprüngliche Bildprogramm abgelehnt wurde, blieben bislang seitens der Forschung unbeantwortet. Eine wichtige Rolle spielte dabei sicherlich das von Vasari gewählte Dekorationsschema. Im Gegensatz zu Michelangelos Fresken sah es nämlich nicht mehr länger vor, die himmlische mit der irdischen Sphäre zu verbinden. Der bestehende Zyklus wäre dadurch deutlich gestört worden. Mit seinem Hinweis auf den Zweck der Kapelle scheint der Papstneffe sich jedoch nicht zwangsläufig auf die gewählte Gliederung bezogen zu haben. Filippo Boncompagni verwies damit vielmehr auf den Umstand, dass die Szenen mit den liturgischen Bedingungen der Cappella Paolina nicht mehr übereinstimmen würden. Die kurienzeremoniellen Voraussetzungen der Kapelle, die einen spezifisch liturgischen Rahmen vorgaben, bestimmten damit grundsätzlich die bildprogrammatische Ausschmückung. ${ }^{723}$ Es lohnt sich

721 Ibid., II, S. 808. Vasari hatte zuvor seine Zeichnungen auch dem Grossherzog Cosimo I. de' Medici und dessen Sohn Francesco I. de' Medici vorgeführt, worüber er Borghini in einem Briefschreiben vom 18. Juli 1573 berichtete. Vgl. hierzu ibid., S. 806-808: „Et quel disegno, che v’è inpastato le duo facciate con le 4 storie de dua Apostoli con quella architettura, gli a dato la vita, et è un disegnio chel Serenissimo Principe a detto che io son un teribile homo [...] Il Gran Duca ieri ebbe gran contento, che a veder quel disegnio vi staj 4 ore a trattenello."

722 Ibid., S. 811: „Nostro Signore ha ricevuto e letto la vostra lettera et ha anco visto e ben considerato il disegno, il quale, come bello et degno d'esser tenuto caro, non essendo stato al proposito per la Paolina, hà voluto, che lo servi appresso di me, restando sodisfattissimo della vosrta amorevoleza.“ Zu den beiden Zeichnungen vgl. Monbeig-Goguel 1982, S. 65-80; Kat. Saarbrücken 1997, Nr. 101; Kuntz 1999, S. 594-596.

723 Zumal dies auch einer der Gründe war, weshalb Michelangelos Fresken der Kreuzigung und der Bekehrung trotz aller Kritik hinsichtlich der expressiven Figurendarstellung und Komposition doch Aufnahme in die Paolina fanden. Vgl. hierzu insbes. Kuntz 2005, S. 156-166; Hemmer 2003, 
deshalb, Vincenzo Borghinis Vorschlag im Zusammenhang mit dieser liturgisch-zeremoniellen Bedeutung der Paolina auszuwerten.

In seinem Bildprogramm schlug Borghini eine Zusammenführung zweier bislang getrennter biblischer Erzählstränge vor, die Vasari dann in malerische invenzioni übertrug. Vasaris Bildlösungen verschränkten die eucharistische Heilsrealität bei der Aufbewahrung der Hostie mit einer Bilderzählung, die direkt aus der Apostelgeschichte entnommen wurde und die auf das apostolische Andenken an das Leben Christi verwies. Das Leben der beiden Apostelfürsten Roms hätte somit das Zentrum des Bildprogramms eingenommen. Während die Episode des Paulus vor Festinus und Agrippa auf eine solche Verschränkung ausgerichtet war, hatte die Schlüsselübergabe lediglich die Übergabe der spirituellen und temporalen Macht an Petrus und seine Nachfolger bestätigt. Diese Szene war jedoch, wie bereits beobachtet werden konnte, im Bildprogramm des Portikus der Petersbasilika enthalten und fest mit dem Zeremoniell des Festtags der Apostelfürsten verbunden. In seinem Briefschreiben an Giorgio Vasari hatte Borghini die Verschränkung der Apostelgeschichte mit der sakralen Heilsrealität der aufbewahrten Hostie im Zusammenhang mit dem Bildprogramm der Decke daher folgendermassen festgehalten:

\begin{abstract}
E perché nella volta vanzano dueo lunette, che vengono nelle teste, l'una sopra la cappella del Sacramento, l'altra alla porta che entra nella cappella, sopra lo spazio dove aveva da venire una finestra, che non vi è, sopra quella della cappella proverei la istoria di Melchisedech, quando panem et vinum obtulit, il che, oltre al proposito che torna del Sacramento, fa non poco a quest'altro, che il Nostro Signore fu detto: sacerdos in aeternum secundum ordinem Melchisedech, cosa piena di misterio, e nela volta della cappella propria, come bene dite, che hanno in disegno lo Spirito Santo. Nell'altra di riscontro a questa lo Agnello Pasquale, che, oltre al medesimo proposito del Sacramento, mostra che le figure e l'ombra della Legge sono terminate nella verità e luce dello Evangelio, e così viene terminata nelle sue facce e nella volta tutta questa cappella, lasciando gli altri ornamenti e considerazione particolari alla virtù e giudizio vostro, che ne siete buon maestro. Potevansi mettere altre istorie e considerazioni, e sarebbero state, per modo di dire, infinite, ché la materia è copiosa, e la Sacra Scrittura, vecchia e nuova, n’è piena. [...] E perché i gusti sono diversi, quando non piacesse mescolare queste istorie del Nuovo con quelle del Testamento Vecchio, e nel mezzo non mettere la Trasfigurazione, ma lo Spirito Santo o altra istoria, si potrebbono pigliare tutte da una parte dell'uno santo, e dall'altra dell'altro, con una certa similitudine o comparazione fra loro; come sarebbe negli angoli in quelle istoriette per S. Pietro, la morte di Anania e Safira; per S. Paolo, la accecazione d'Elimas mago. Per S. Pietro, quando sanò quello storpiato alla porta. Speciosa del Tempio; per S. Paolo, quando sanò quello infermo de’ piedi in Listris. Per S. Pietro, quando
\end{abstract}

\footnotetext{
S. 131-152 sowie die Einträge im Diarium des Zeremonienmeisters Biagio Baroni Martinelli während den vorgenommenen Umstrukturierungen des Palazzo Apostolico des Farnese-Papstes Paul III. in BAV, Barb. lat. 2799, f. 542v, 582r-v; BAV, Vat. lat. 8417, f. 20r-v. In diesem Zusammenhang wurde Perino del Vaga für seine Stuckarbeiten an der Decke der Kapelle bezahlt. Die Zahlungsbelege, die auf den 27. August und 16. Oktober 1542 datiert sind, finden sich in ASR, Cam. I. Mandati, b. 54/ 876, f. 81r-82r. Vasari selbst erwähnte diesen Auftrag in seiner Vita Perino del Vagas in Vasari, Vite, Bd. 7, S. 216, an deren Ausführung Frommel 1964, S. 32 noch zweifelte.
} 
suscitò Tabita; per S. Paolo, quando suscitò quel giovanetto. Per S. Pietro, quando vide la visione degli animali immondi, onde fu poi chiamato da Comelio Centurione; per S. Paolo, quando gli apparve in visione un uomo di Macedonia, pregandolo che passasse di là da loro ad aiutargli $\left[\ldots . . .7 .^{724}\right.$

Vincenzo Borghini war sich somit durchaus der malerischen Schwierigkeiten bewusst, die Vasari mit diesem Bildprogramm zu überwinden hatte. Jedoch vertraute er der Fähigkeit Vasaris, dass er diese Schwierigkeiten durch die Wahl der Bildinhalte und ihre malerische Realisierung bildsprachlich bewältigen konnte. Im Kupferstichkabinett der Staatlichen Museen zu Berlin findet sich ein weiteres modello Vasaris, das ebenfalls das Ensemble der Vorstudien, die der Maler Tolomeo Galli zur Begutachtung sandte, zeigt (Abb. 25c). Es handelt sich dabei um einen Entwurf des vorgesehenen Deckenfreskos für die Cappella Paolina, die Borghini in seiner invenzione ebenfalls angesprochen hatte. Jedoch unterscheidet sich dieses Blatt von Borghinis Ratschlägen, da Vasari die Szenen aus der Apostelgeschichte einer alttestamentlichen Erzählung der Vorsehung unterzuordnen suchte und das ursprüngliche Programm absichtlich umgestalten wollte. Der päpstliche Schatzmeister Alessandro Musotti teilte Vasari deshalb bereits am 31. Juli 1573 mit, dass nur die incrostature für den Fussboden ausgeführt werden sollten. ${ }^{725}$ Im Zahlungsbeleg für diese Ausführung wird ebenfalls erwähnt, dass dem Bologneser Maler Lorenzo Sabatini seine monatliche provisione ausbezahlt wurde. Dies sollte es ihm erlauben, die Ausmalung der Cappella Paolina abzuschliessen. Am selben Tag, als Musotti seinen Brief Vasari sandte, hatte der tesoriere Lorenzo Sabatini die Geldsumme für den Erwerb der Pigmente zurückerstattet. ${ }^{726}$ Dieser Umstand bestätigt, dass Sabatini ein neues Pro-

724 Frey 1923-1982, II, S. 804-805.

725 Vgl. ibid., S. 809-810: „Ho veduto il disegno et il discorso, che havete mandato all'illustrissimo San Sisto per l'impresa della cappella Paolina [...] Della incrostatura della medesima cappella si và pensando non farla altrimenti, ma solo il pavimento.“ Auch zit. in Baumgart/Biagetti 1934, S. 90. Hierfür wurde Matteo da Castello am 22. August mit fünfhundert scudi entlohnt. Der Zahlungsbeleg befindet sich in ASR, Cam. I. Tesoreria Segreta, b. 1301, f. 15r. Zur Zeichnung Vasaris für das Gewölbe der Paulina vgl. insbes. Kat. Saarbrücken 1997, S. 268-273; Kat. Berlin 2011, S. 9-10; Härb 2015, S. 609-612. Im Gabinetto Disegni e Stampe der Uffizi hat sich wiederum eine weitere Zeichnung Vasaris erhalten, welche für das zentrale Bildfeld der Gewölbedecke eine Auferstehung Christi vorsah. Vgl. hierzu insbes. Cecchi 1978, S. 58; Monbeig-Goguel 1982, S. 80; Härb 1994, Nr. 372; idem 2015, S. 613; Fairbairn 1998, Bd. 2, S. 517. Die Ablehnung des ersten Entwurfs kann ebenfalls damit begründet werden, dass das Kurienzeremoniell die Feierlichkeiten für den Festtag der Cathedra Petri, auf den sowohl die beiden Inschriften in Vasaris Zeichnung unterhalb der sitzenden Figur des Petrus als auch in der von der allegorischen Frauenfigur gehaltenen Kartusche links von der Szene der Cathedra verweisen, seit dem Carafa-Pontifikat Pauls IV. in der Petersbasilika abhielt. Vgl. hierzu den Eintrag im Diarium Francesco Mucanzios in BAV, Chig.L.II.30, f. 173r: In festo Romanae Cathedrae B. Petri fuit Missa solemnis in ecclesia D. Petri iuxtà ordinationem facta à Pauli Papae 4 introductam, ad quam Papa venit cum Tegno, et Cardinales in Cappis rubeis.

726 ASR, Camerale I. Tesoreria Segreta, f. 6v \& 11v. Vgl. hierzu auch Vaes 1928, S. 302. Zu Sabatini vgl. die biographischen Einträge in Vasari, Vite, VI, S. 147-148; Baglione, Vite, Bd. 1, S. 18; Malva- 
gramm für die Kapelle noch vor der Ablehnung des Entwurfs Borghinis und Vasaris entworfen haben musste. Auch wenn sich Sabatinis Bildkomposition nur geringfügig von derjenigen, die Vasari zu realisieren beabsichtigte, unterscheidet, weisen die neuen Fresken eine Bildsprache auf, die dem für die Cappella Paolina vorgesehenen Kurienzeremoniell weit mehr entspricht.

Es wäre irreführend, die Fresken Lorenzo Sabatinis in der Cappella Paolina als Indiz dafür zu betrachten, dass im Rom des Boncompagni-Pontifikates Gregors XIII. eine Konkurrenz zweier Malerschulen bestanden hätte. Bei den drei Wandfresken Sabatinis handelt es sich um eine organische Fortführung der in Giorgio Vasaris römischen Aufträgen dominanten toskanisch-florentinischen maniera, die dem Kurienzeremoniell hinsichtlich seiner Verwaltungspraxis der Sakramente diente. Mit der Abreise Vasaris nach Florenz anlässlich der Ausmalung der dortigen Domkuppel begann sich nach der Ablehnung seines Bildprogramms für die Cappella Paolina jedoch diese Anbindung des kurialen Milieus an eine toskanisch-florentinische Bildsprache aufzulösen. Lorenzo Sabatini fand mit der Steinigung des heiligen Stephanus, der Taufe des Saulus und dem Sturz des heiligen Simon Magus eine Bildformulierung für das Dekorationsschema der Paolina, mit welcher die liturgisch-zeremoniellen Rahmenbedingungen dieser Palastkapelle weiterhin erfüllt werden konnten. Dem Bologneser Maler gelang es mit seinen drei Fresken nämlich, die ästhetischen Grenzen zwischen theatralischer Figurenhandlung und der Öffnung des Bildhintergrundes in einen Kirchen- oder Stadtraum als eine durchlässige Dimension vorzuführen (Abb. 26a-c). Die Szenen der Steinigung und der Taufe rahmen auf der linken Seitenwand Michelangelos Bekehrung ein. Die Szene des Sturzes schliesst das gegenüberliegende Wandkompartiment mit dem Martyrium Petri ab. Erst 1580 sollte Federico Zuccari mit der Taufe des Cornelius Centurion die rechte Seitenwand hin zum Altar vollenden.

Mit seinen Bildlösungen für die Cappella Paolina stellte Lorenzo Sabatini eine sakramentale Raumbeschaffenheit her, die eine liturgische Symmetrie zur Cappella Sistina aufwies. War in der Ausstattung der Paolina während des Farnese-Pontifikats Pauls III. noch eine Spannung zwischen den beiden liturgischen Räumen festzustellen gewesen, so hatten Sabatinis Steinigung und seine Szene der Taufe ein zeremonielles Gleichgewicht zwischen Paolina und Sistina bewerkstelligt. Die Herwstellung eines solchen Gleichgewichts gelang Sabatini hauptsächlich mittels seines Rückgriffs auf eine chronologische Bilderzählung, die der im Neuen Testament überlieferten Apostelgeschichte entsprach. Dennoch überliess der Bologneser Maler in bildsprachlicher Hinsicht - den beiden Szenen Michelangelos das letzte Wort. Dieselbe chronologische Bildabfolge hatte Raffael bereits mit seinen Tapisserien für den

sia, Felsina pittrice, Bd. 1, S. 227-234; Missirini, Memorie, S. 18; Kat. Modena 1989, S. 49; DBI 2017, Bd. 89. Sabatini war bereits 1572 an Vasaris Dekoration der Sala Regia beteiligt, besonders an der Schlacht von Lepanto: Pillsbury 1976, S. 39-45. 
liturgischen Schmuck der Cappella Sistina dargeboten. ${ }^{727}$ Sowohl die Tapisserie der Steinigung des heiligen Stephanus als auch diejenige der Taufe des Saulus hingen in der Cappella Sistina an prominenter Stelle in unmittelbarer Nähe zum Papstthron. Raffaels Steinigung hatte dadurch die Figur des heiligen Stephanus direkt der des Apostels Paulus gegenübergestellt. ${ }^{728}$ Im Gegensatz dazu verzichtete Sabatini bewusst auf eine Darstellung des heiligen Paulus. Damit stimmte er bewusst die Szene der Steinigung als einen bildnarrativen Auftakt zur Bekehrung ab. Die Szene der Steinigung in der Cappella Paolina, von welcher eine Vorstudie im römischen Istituto nazionale di grafica überliefert ist und auf welche Orazio Samacchini für sein Ölgemälde in der Londoner Wellcome Library zurückgriff, reiht sich in die ikonographische Bildtradition der Steinigung ein. Die herkömmliche Bildüberlieferung zeigte ebenfalls Saulus in einer Gegenüberstellung zum heiligen Stephanus (Abb. 27a). Um 1563 hatte Sabatini für die Ausstattung des Palazzo Vizzani in Bologna erstmals das Bildmotiv der Steinigung als Ölgemälde ausgeführt (Abb. 27b). ${ }^{729}$ Wegen des in der Cappella Paolina engen Wandfeldes, auf dem Sabatini dasselbe Sujet in Fresko ausführen sollte, musste der Maler seine ursprüngliche Komposition ändern. Die im Ölgemälde diagonal aufgebaute Szene wandelte Sabatini dementsprechend in eine vertikal verlaufende Figurendramatik um. Die Bedeutung des Apostels Paulus, dem die linke Seitenwand der Kapelle gewidmet ist, verstärkte Sabatini dadurch, dass er den noch jungen Statthalter Saulus aus dem Bildhintergrund unmittelbar in die linke Ecke des Bildfeldes verschob: Weil Saulus die Mäntel der Mörder hielt, die Stephanus steinigten, war Saulus noch schuldiger als diese am Tode des Heiligen. In der Reihenfolge der drei Szenen auf der westlichen Seitenwand der Cappella Paolina vollzieht sich somit eine bildrhetorische Umkehr des Saulus persecutor in einen Paulus praedicator. ${ }^{730}$

727 Auch Michelangelo bezog sich in seiner Bekehrung auf Raffaels Teppiche für die Sixtinische Kapelle: De Tolnay 1947-1960, Bd. 5, S. 147; Fehl 2002, S. 52.

728 White/Shearman 1958, S. 193-221, 299-323; Shearman 1972, S. 21-44; idem 1986, S. 88-91; Weddigen 1999, S. 268-284; Pon 2015, S. 388-408.

729 Kat. Milano 2010, S. 84-85; Kat. Forlì 2018, S. 404.

730 Augustinus, Sermo CCLXXIX, De Paulo apostolo. Pro solemnitate conversionis ejusdem, in PL, Bd. 38, Sp. 1275: Nam et quando lapidatus est Stephanus primus martyr pro nomine Christi, evidentius aderat et Saulus. Et sic aderat lapidantibus, ut non ei sufficeret si tantum suis manibus lapidaret. Ut enim esset in omnium lapidantium manibus, ipse omnium vestimenta servabat, magis saeviens omnes adjuvando, quam suis manibus lapidando. Vgl. auch idem, Sermo CCCXV. In solemnitate Stephanis martyris II, in ibid., Sp. 1429: Saulus in Stephani caede saevior persecutor. Saulus a Saule dictus Paulus modicus, parvus. Stephanus pro inimicis fixo genu orat, quia petit indebitum. Quando iste exigebat debitum, Paulus apostolus cumulabat sibi debitum. Ille petebat debitum bonum: ille addebat ad debitum malum. Quid enim putatis, fratres? Quando lapidabatur Stephanus, audistis, sed forte non advertistis, posuerunt falsi testes lapidaturi Stephanum, posuerunt vestimenta sua ad pedes cujusdam adolscentis, nomine Sauli. Iste Saulus, et postea Paulus: persecutor Saulus, praedicator Paulus. Saulus enim nomen est a Saule. Saul persecutor erat regis David. [...] mutavit sibi nomen, et dixit se Paulum. Auch zit. in Fehl 2002, S. 62-63. Die innige Verankerung zwischen den drei Szenen hatte bereits Giulio Clovio in seiner Buchmalerei zu dem sich 
In den ersten beiden Wandfresken, die Michelangelos Bekehrung einrahmen, vollzieht sich eine rituelle Dynamik, in welcher zuerst der ungläubige Saulus in der Steinigung sinnbildlich fällt, um danach in der Taufszene zum Apostel wieder aufzusteigen. Sabatini verband diese rituelle Umkehr des Apostels Paulus im Bildnarrativ ferner mit der Raumarchitektur der Kapelle selbst, indem er im Bildhintergrund der Taufe eine für den Chorraum der Paolina gedachte und von Sangallo entworfenen Serliana einfügte. ${ }^{731}$ Sowohl in der Steinigung als auch in der Taufe verlieh Sabatini der Bildmitte, die im ersten Fresko eine landschaftliche Stadtvedute und im zweiten den Kapellenraum der Paolina zeigte, nicht dieselbe Bedeutung, die Michelangelo vor ihm in seiner Bekehrung präsentiert hatte. Sabatini verwendete den mittleren Abschnitt der beiden Wandkompartimente als ein Bildfeld, in welchem eine Übertragung der himmlischgöttlichen Heilskraft auf die irdisch-kirchliche Sphäre vorgeführt wurde. Diese neuartige Deutung des Stadt- beziehungsweise des Kapellenraumes als funktionaler Bestandteil der Bildarchitektur ist als bewusster Kommentar Sabatinis zu Michelangelos Bildlösungen zu deuten. Marcia Hall bezeichnete diese als eine malerische Gegenbewegung zur römischen maniera. ${ }^{732}$ Sowohl in der Steinigung als auch in der Taufe wird der Ort des Geschehens - Rom im ersten und die Cappella Paolina im zweiten Fresko - klar gekennzeichnet. Im Gegensatz zu Sabatini hatte Michelangelo mit seinen Fresken den Betrachter dazu herausgefordert, die Szenen der Bekehrung und der Kreuzigung überhaupt einem passenden Ort zuordnen zu können.

Des Weiteren stellte Sabatini in seinen beiden Fresken eine Wechselbeziehung zwischen der himmlisch gespendeten Heilskraft Gottes und der Stadt Rom her. Sowohl in der Steinigung als auch in der Taufe des Saulus öffnet sich im oberen Drittel des Bildfeldes das Himmelreich Gottes, das sich dem Betrachter sichtbar offenbart. Die Reihenfolge von Sabatinis Fresken auf der linken Seitenwand der Cappella Paolina führt mittels der Figur des Saulus/Paulus eine Bilderzählung vor, die den Übergang des in der Steinigung gezeigten Paares von Christus - deutlich der Skulptur

im Besitz des Kardinals Marino Grimani befindenden Kommentar zu den Paulus Briefen, die im Londoner Soane Museum aufbewahrt wird, vorausgeschickt. Vgl. Bradley 1891, S. 145-146; Millar 1914-20, S. 116-117; Cionini Visani 1993, S. 37.

731 Hemmer 2003, S. 137-138. Zu Sangallos Zeichnung aus dem Talman-Album des Ashmolean Museum in Oxford vgl. ferner Parker 1956, Nr. 468; Danesi Squarzia 2016, S. 91-92.

732 Hall 1999, S. 180. Der Begriff einer contra-maniera in Michelangelos Fresken für die Cappella Paolina scheint insofern berechtigt zu sein, als dass sich die römische maniera während des FarnesePontifikates Pauls III. hauptsächlich durch eine bewusste Eingliederung eleganter und anmutiger Bildelemente zu Gunsten einer bildsprachlichen grazia auszeichnete. Die Artikulation ornamentaler Figurengestaltung blieb als sublimes Vehikel für die Einbeziehung des Betrachters in das Bildgeschehen zentral, auf welche Michelangelo aber bewusst verzichtete, um sich zugleich in der Behandlung des Raumes von tradierten Bildformeln abwenden zu können. Vgl. Reinhardt 2010, S. 294-298; Vasari, Vite, IV, S. 9; Williams 1997, S. 73-122; Smyth 1963, S. 179-181; Shearman 1963, S. 205-206; Pinelli 1993, S. 94-116; Sohm 2001, S. 86-114; Brückle 2005, S. 115-121; Kat. Frankfurt 2016, S. 42-81, 114-133, 280-281. 
Michelangelos in Santa Maria sopra Minerva nachempfunden - und dem thronenden Gottvater in die sakramentale Spende des göttlichen Gnadenerlasses mittels der Taube des Heiligen Geistes in der Taufszene vollzieht. In der Taufe des Saulus bemühte sich Sabatini, die in der Apostelgeschichte enthaltene Überlieferung möglichst genau darzustellen, indem er den von Ananias getauften Saulus, dessen Wandel sich schliesslich erst im Augenblick der Spende des Taufsakramentes vollzieht, mit offenen Augen malte (9, 17-19). Die ikonologische Bedeutung dieser Szene wird somit deutlich gemacht: Nachdem Saulus das Sakrament der Taufe empfangen hat, erlangt er mithilfe der Kraft des Heiligen Geistes wieder sein Sehvermögen.

Mit dem letzten Fresko verwies Sabatini auf die sakramentale Heilsrealität, die sich in dem für die Cappella Paolina ausgearbeiteten Kurienzeremoniell vollziehen sollte. Diese zeremonielle Ordnung der cappella palatii spiegelte die organische Einheit zwischen dem Palazzo Apostolico und der Petersbasilika wider. In Sabatinis Bildprogramm markiert die Taufe des Saulus einen bildsprachlichen Wendepunkt innerhalb der Apostelgeschichte. Das Sakrament der Taufe verweist nämlich auf eine Umkehr von der jüdischen in eine christlich-apostolische Kirchengemeinde unter der Leitung des Apostelfürsten Paulus. Das Bildprogramm in der Paolina knüpfte damit an die Eingriffe Gregors XIII. zur Erneuerung des Lateranbaptisteriums und der dortigen Cappella di San Venanzio an. ${ }^{733}$ Die Bedeutung des Lateranbaptisteriums für das anno santo lag allen voran in der zeremoniellen Verwaltung und Spende des Taufsakraments an die catecumeni, welches ihnen an Ostern und Pfingsten gespendet wurde. ${ }^{734}$

Lorenzo Sabatini schloss mit seiner Taufszene in der Cappella Paolina die Umkehr des Saulus in den Apostel Paulus ab und hob die Wirkung des Taufsakraments

733 Diese Eingriffe am Lateranbaptisterium fanden zwischen Dezember 1574 und November 1576 statt, also im Zeitraum als Sabatini noch in der Cappella Paolina arbeitete. Vgl. hierzu neben den Zahlungsdokumenten in ASR, Camerale I. Tesoreria Segreta, b. 1302, f. 46v, 48v, 63r, 64r, 71v; ibid., b. 1303 , f. $5 v-6 r, 14 v, 16 v, 18 v, 48 v, 56 v$ \& ibid., b. 1304, f. 33v, auch die Beschreibungen in Ciappi, Compendio, S. 9; Rasponi, De basilica et patriarchio lateranensis, S. 214; Fleury 1877, S. 268; Lauer 1911, S. 318; Sodo, Compendio, in BVR, G 33, f. 45v: „[...] detto battisterio è in forma rotonda coperto di piombo circundato di colonne quale cala alquanti gradi dietro è li ve un pilo di porfido la suffitta è intagliata con una bella balaustrata di pietre fine è vi sono alcune pitture per adornamento fatter dalla santita di pp. Gregorio XIII. della sua bellezza et richetta quasi puo considerare essendo il luogo dove fu battezzato il sudetto imperatore.“ Zu diesen Eingriffen vgl. insbes. Freiberg 1991, S. 70-73.

734 Panvinio, De sacrosancta Basilica Lateranensis, in Lauer 1911, S. 465-466, nahm noch die Tradition auf, in welcher der Papst selbst diese Taufe der Neulinge ausführte. Danach hatte gemäss Ugonio, Historia delle stationi, c. $46 v$ der Suffraganbischof und vicarius Urbis diesen Ritus vollzogen. Vgl. hierzu bspw. die folgenden avvisi in BAV, Urb. lat. 1049, f. 152r; ASR, Camerale I. Tesoreria Segreta, f. 3r; BAV, Urb. lat. 1051, f. 176v. Vgl. auch Pientini, Pie narrationi, S. 58, am ausführlichsten jedoch Martin, Roma Sancta, S. 32, 82-83, 230. Jüngst hat sich in der Forschung wieder ein Interesse an Konversionen im Rom des Cinquecento gezeigt. Vgl. hierzu v. a. Broggio 2009, S. 173-197; Priesching 2013, S. 45-63; Matheus 2012; Mazur 2016, S. 18-42, 66-82. 
hervor, indem er das Taufwasser bildsprachlich betonte. Sabatinis Bildsprache behandelt das Taufwasser als sakramentales Mittel der heilsspendenden Kraft, welche die über Ananias und Saulus schwebende Taube des Heiligen Geistes enthält. Das Taufsakrament enthält damit ebenfalls die Kraft der göttlichen Gnade. Sabatinis Taufe des Saulus verband damit zwei katechetisch noch getrennte, aber im Kurienzeremoniell dann miteinander verbundene Dimensionen des heilsamen Eintritts von Neulingen in die päpstliche Kirchengemeinde, denn im Taufsakrament war auch unmittelbar das Sakrament der Firmung (confirmationis) enthalten. Bei der Osternachtliturgie wurden nämlich beide Sakramente den catecumeni gespendet. ${ }^{735}$ Die Bildsequenz auf der westlichen Seitenwand der Cappella Paolina verweist demnach bewusst auf den liturgischen Zusammenhang der Osterfeierlichkeiten, wodurch die liturgische Funktion der Cappella Paolina, die im Kurienzeremoniell als cappella parva zur Vorbereitung sowohl der Oster- als auch der Adventsliturgie genutzt wurde, offenbart wird. Sowohl Giorgio Vasari als auch seinem Briefkorrespondenten Vincenzo Borghini entging diese spezifisch liturgische Bestimmung der Paolina. Beide verstanden die Kapelle nämlich als den Raum, in welchem das Kardinalskollegium die Papstwahl in der apostolischen Nachfolge Petri durch ein Konklave vollzog. Diese petrinische Komponente sollte stets der Paolina eigen bleiben. Die entscheidende Neuerung, welche sich im Boncompagni-Pontifikat Gregors XIII. vollzog, war die zusätzliche Betonung des Stellenwerts des Apostel Paulus.

Die Forschung schlug eine Datierung von Lorenzo Sabatinis Bildprogramm, den Gregor XIII. im anno santo zum Leiter aller Ausstattungskampagnen im Apostolischen Palast berief, auf das letzte Lebensjahr des Bologneser Malers. ${ }^{736}$ Die Aus-

735 Aus römisch-kurialer Sicht, welche bereits im Tridentiner Dekret zur Taufe sowie zu den Sakramenten im Allgemeinen Resonanz fand, wirkte das Sakrament der Firmung als Abschluss des Bundes, in welches der Neuling mit der Taufe eintrat. $\mathrm{Zu}$ den Tridentiner canones über die Firmung vgl. $C O D$, S. 686. Luther und Calvin hatten die Taufe als Sakrament angenommen. Die Firmung wiesen sie aber bewusst als „müssige Zeremonie“ (otiosa caeremonia) zurück: WA, Bd. 6, S. 526-543; Calvin, Institutio christianae religionis, S. 324-330. Der Catechismus Romanus stellte dann die Unterscheidung zwischen den beiden Sakramenten her: Die Taufe besitzt die Kraft der Wiedergeburt und verhilft so dem Menschen zu neuem Leben, während die Firmung die schon Geborenen zu Männern mache, nachdem sie das, was des Kindes ist, ablegten. Das Sakrament der Firmung besitzt somit eine temporale Dimension, indem die Gläubigen zunehmend die vollkommene Stärke des Geistes erlangen. Vgl. hierzu insbes. CT, II, 3, 5. Zur Liturgie der Osternacht, welche dann in der Cappella Sistina zelebriert wurde, vgl. dann Sacrarum Caeremoniarum, S. 476-482; Cancellieri, Storia de' solenni possessi, S. 122-142; sowie Mucanzios Einträge in seinem Zeremonientagebuch in BAV, Chig.L. II.30, f. 211r-v, 322r-323v, 421r-422r.

736 Sabatini starb im August 1576. Vgl. Zuccari 2012, S. 71-77; idem 2016, S. 60-63; De Strobel/Rodolfo 2016, S. 208. Zuccari meinte vor allem, dass Sabatini die Cappella Paolina nicht als vorrangig im Zusammenhang mit den Arbeiten für die Sala Bologna und den Loggien Gregors XIII. erachtet habe. Die päpstliche Berufung zur Oberaufsicht der malerischen Ausstattung des Palazzo Apostolico geht auf Baglione, Vite, I, S. 17 zurück. Hess 1967, Bd. 1, S. 123, interpretierte dann diese Stelle im Zusammenhang mit den memorie aus BAV, Bonc.D.5, f. 240r-241r. 
malung der linken Seitenwand musste Sabatini jedoch noch vor seiner Ernennung zum Leiter der im Palazzo Apostolico tätigen Malerwerkstätten fertiggestellt haben, nachdem Matteo da Castello den Fussboden gegen Ende des Jahres 1573 ausführte. Für diese Datierung der Fresken auf der westlichen Seitenwand der Kapelle spricht Sabatinis Arbeit an der Dekoration der Kirchenfassade von San Pietro, die Szenen aus der Apostelgeschichte Petri enthielt. Die Fresken im Portikus der Petersbasilika dienten Sabatini daher als Vorlage für sein Bildprogramm in der Cappella Paolina, um dadurch den Bezug zum liturgischen Vorbereitungszeremoniell, das für diesen Kapellenraum gedacht war, herstellen zu können. Die chronologische Reihenfolge der Szenen war demzufolge vom rituellen Ablauf des Zeremoniells zur Aufnahme von Neulingen (catecumeni) in die christliche Kirchengemeinde abhängig.

Sabatini hielt in seinen beiden Bildlösungen für die linke Seitenwand sowohl an der konventionellen Einteilung der Bildfelder als auch an der Figurenaufstellung und deren bildsprachlicher Interaktion fest. Dadurch schaffte er es, eine besondere Klarheit in der bildnerischen Szenendarstellung zu vermitteln, ohne dabei Bildtituli hinzufügen zu müssen, wie es noch Vasari für seine Fresken beabsichtigt hatte. Dieses Merkmal der bildnarrativen Klarheit in der monumentalen Wandmalerei der zweiten Hälfte des Cinquecento hatte sich allen voran im Rom des BoncompagniPontifikates Gregors XIII. durchzusetzen begonnen, indem die Bildproduktion zur Ausstattung des Palazzo Apostolico die liturgischen Anweisungen, welche hauptsächlich durch das Kurienzeremoniell bestimmt wurden, befolgte. Spätestens ab 1574 trat die römische Monumentalmalerei in die Dienste der Kurie. Eine solche Entwicklung hatte zur Folge, dass das kuriale Mäzenatentum nicht mehr länger als ein Mittel zur Fürderung von Malern und ihrer Karrieren genutzt wurde, wie dies noch bei Michelangelo oder bei Raffael der Fall war. Die im Palazzo Apostolico tätige Werkstatt von Bologneser Malern begann mit dem Boncompagni-Pontifikat allmählich eine homogene Bildproduktion, die von emilianischen und flämischen Bildsprachen geprägt wurde, auszuführen. Diese Bildproduktion zeichnete sich dadurch aus, dass mit der Verschränkung zwischen Figurendarstellung und räumlichem Aufbau des Bildhintergrundes eine gleichmässige Aufteilung des Bildfeldes vorgenommen wurde. Die dadurch erzeugten Bilderzählungen büssten ihre bildrhetorische Sprache nicht mehr wegen komplexer Bildlösungen ein. ${ }^{737}$

Noch stärker als in der Steinigung des heiligen Stephanus hatte sich Lorenzo Sabatini in seinem Sturz des Simon Magus auf der gegenüberliegenden Seitenwand

\footnotetext{
737 Die Anfänge einer solchen Entwicklung der römischen Malerei können vornehmlich auf Girolamo Muzianos und Cesare Nebbias Dekorationen für den Duomo in Orvieto zurückverfolgt werden. Vgl. zu diesen Aufträgen insbes. Mack 1974, S. 410-413. Girolamo Muzianos Einfluss auf die römische Bildproduktion ab dem Boncompagni-Pontifikat Gregors XIII. ist nicht zu unterschätzen und wurde von Tosini 2008, S. 277-297 eingehend dargestellt. Vgl. in diesem Kontext auch die Bildproduktion Raffaellino da Reggios im römischen Stadtraum, allen voran in der Cappella Cesi der Kirche von Santa Maria dei Funari: bei Melograni 1989, S. 219-239.
} 
um die Ausarbeitung einer szenischen Dramatik bemüht. Die dargestellte Episode erzeugt ihre narrative Spannung durch die Unterscheidung zwischen Figurendarstellung und Landschaft. Dieses Spannungsverhältnis diente Sabatini dazu, um im Motiv des Sturzes das Schicksal allen häretischen Glaubens zu betonen. Zurecht wies die Forschung darauf hin, dass die Szene des Sturzes die einzige apokryphe Episode, die in der Apostelgeschichte auftaucht, innerhalb der Cappella Paolina sei. Deren Wahl ist aber keineswegs überraschend, wenn man berücksichtigt, dass in dem noch bis zu seinem Abriss im Jahr 1608 intakten Oratorium Johannes' VII. (705-707) von San Pietro dieselbe Szene bereits in Mosaik präfiguriert war. ${ }^{738}$ Das ursprünglich von Vincenzo Borghini und Giorgio Vasari vorgeschlagene Bildprogramm, das noch allein die petrinische Primatsidee vertrat und deren Höhepunkt im Gewölbeprogramm hätte erreichet werden sollen, wurde zu Gunsten einer im Hinblick auf das anno santo heilsgeschichtlichen Verbindung zwischen dem Palazzo Apostolico und der Petersbasilika aufgegeben. Diese sakramentale Zusammengehörigkeit zwischen Palast und Basilika wurde im kurienzeremoniellen Parcours der Osterwoche ebenfalls betont. In gewisser Weise kann die Cappella Paolina mit ihrem bereits von Michelangelo realisierten Freskenschmuck als eine Überführung der liturgischen Bedeutung, die dem verloren gegangenen Oratorium Johannes' VII. eigen war, in den architektonischen Organismus des Palazzo Apostolico verstanden werden. Ähnlich wie im gegenüberliegenden Bildfeld, in welchem die Steinigung des heiligen Stephanus dargestellt ist, bediente sich Sabatini im Fresko des Sturzes des Simon Magus wieder des bereits festgestellten Bildnarrativs des Absturzes. Die rechte Seitenwand der Cappella Paolina sollte jedoch nicht wie die Bildsequenz des Paulus zu einer Umkehr am Schluss führen. Stattdessen sollte die petrinische Szenenabfolge

738 BAV, Arch.Cap.S.Pietro.H.3, f. 122v-123r.Dieser Mosaikzyklus der Apostelfürsten, mit welchem das Oratorium ausgestattet wurde, wurde allerdings erst unter Innozenz III. realisiert, als die Verehrung des Schweisstuches der heiligen Veronika einen neuen Impuls bekam. Vgl. hierzu v. a. Pogliani 2001, S. 511-512; Ballardini/Pogliani 2013, S. 32. Wegen seiner unmittelbar hinter der Porta Santa gelegenen Position, musste Sabatini bei der Ausmalung der Kirchenfassade von diesem noch in Mosaik erhaltenem Schmuck der Petersbasilika Kenntnis gehabt haben. Im selben Oratorium waren auch Mosaiken der beiden Szenen der Kreuzigung Petri und der Enthauptung des Paulus nebeneinander angebracht. Sie sind in den Zeichnungen Grimaldis dargestellt und finden sich in BAV, Barb. lat. 2733, f. 89r; BAV, Arch.Cap.S.Pietro H 3, f. 113r-117v sowie in BAV, Vat. lat. 8404, f. 113v-114v überliefert. Vgl. hierzu auch Domenico Tassellis Album aus BAV, Arch.S.Pietro A 64ter, f. 12r, 18r, 30r-32r. Eine gründliche Rekonstruktion des 1608 abgerissenen Oratoriums bietet Kat. Roma 2016, S. 248-259. Vgl. ebenfalls die Beschreibung in Panvinio, De rebus antiquis in BAV, Arch.Cap.S.Pietro. G.10, f. $115 r-v$, der das Oratorium als erste Grabkapelle im alten Petersdom beschrieb. Am 7. Juli 1610, dem Oktav der Apostel Petrus und Paulus, wurde die Porta Santa in Anwesenheit des Kardinals und Präfekten der Bauhütte von San Pietro, Bartolomeo Cesi, sowie des Zeremonienmeisters Paolo Alaleone aus der abrissfertigen Fassade herausgelöst und in das Atrium der neuen Basilika gebracht. Vgl. hierzu die dokumentarische Überlieferung in BAV, Barb. lat. 2732, f. $74 r$; BAV, Barb. lat. 2733, f. 237v-238v sowie das avviso in BAV, Urb. lat. f. 513r. 
dazu beitragen, die dem Apostelfürsten eigene potestas im Zusammenhang mit der Verurteilung häretischen Gedankenguts zu affirmieren. ${ }^{739}$ Dem Protomärtyrer Stephanus wird ein Protohäretiker gegenübergestellt, nämlich der von dämonischen Gestalten umzingelte Magier Simon Magus. Der Magier stürzt über eine Menschgruppe, die sich vor einer städtischen Landschaftsvedute um den Apostelfürsten Petrus schart. Sabatinis Sturz des primum omnium haeresiarca knüpft damit bewusst an das Kurienzeremoniell, das zur päpstlichen Exkommunikation anlässlich der Verkündigung der Bulle In Coena Domini ausgearbeitet wurde, an. ${ }^{740}$

Giorgio Vasari hatte solche bildnarrativen Bezüge zum Exkommunikationszeremoniell an Gründonnerstag bereits mit seinen Fresken in der Sala Regia vorweggenommen. Jedoch scheint Sabatini bei der Ausarbeitung seines Bildprogramms für die Cappella Paolina von demjenigen in der Sala Regia bewusst abkommen zu wollen. Für den Bologneser Maler stand nämlich nicht mehr länger die politische Bedeutung der Bekämpfung von Häresie durch die römische Kurie im Zentrum. In Sabatinis Sturz des Simon Magus setzt sich stattdessen eine bildsprachliche Formulierung durch, die eine Verdammung des ersten Häretikers erstmals in einem Zusammenhang mit der kurialen Verwaltungspraxis der Sakramente vorführt. Das Bildsujet kann eindeutig mit derjenigen Gruppe von Bildern gleichgesetzt werden, die der Kardinal und Bischof von Bologna Gabriele Paleotti in seinem 1582 gedruckten Discorso als „apokryphe Bilder“ (pitture aocrife) klassifizierte. Paleotti schuf

739 Diese Thematik der Verdammung der Häresie auf der Grundlage des dem Apostelfürsten Petrus verliehenen potestas war eines derjenigen Bildsujets, denen Gregor XIII. seine grösste Aufmerksamkeit schenkte. Sowohl der Bilderzyklus der Bartholomäusnacht als auch die Exkommunikation Friedrichs II. durch Papst Gregor IX. in der Sala Regia hatten die Thematik der päpstlichen Verurteilung der Häresie zum Gegenstand. Vgl. Röttgen 1975, S. 100-104; Fehl 1974, S. 279; Böck 1997, S. 85-93; De Jong 2013, S. 148-154; Behrmann 2008, S. 137-141. Diese Freskengruppe Vasaris wurde aber bislang seitens der Forschung im Hinblick auf ihre bildnarrativen Verweise auf das Kurienzeremoniell zur Proklamation der Exkommunikationsbulle In Coena Domini noch kaum berücksichtigt. Vgl. zuletzt Jaser 2013, S. 374-524.

740 Die Magdeburger Zenturiatoren hatten die Verdammung des Simon Magus durch den Apostelfürsten Petrus als Ursprung des päpstlichen Missbrauchs der Exkommunikation gedeutet, deren ritueller Vollzug auf der Prämisse der Schlüsselübergabe fusste. Vgl. Ecc. Hist., II, Sp. 498. Für die zitierte Passage vgl. Ann. Ecc., I, a. 35, S. 252: [...] ut primum omnium haeresiarcham, ipso ortus sui principio, condemnaret [...]. Cesare Baronios Behandlung dieser apokryphen Episode der Apostelgeschichte sollte zeigen, wie der erste Häretiker Simon Magus eine „Synagoge des Satans“ hatte aufbauen wollen. Vgl. ibid., S. 251-252: Haec est [...] prima haeresis quae post Christum initium accepit, \& in nomine Christi non recte, neque facili ductu, sed iuxta adulteratam apud ipsos corruptionem praestigijs multos seduxit. Videas vero ex his antiqui hostis nequitiam \& fraudulentum dolum iterum repetitum: quippe qui non tantum in caelo Dei aemulatus est gloriam, sed \& in terra divinos sibi assumere honores studuit. [...] Tantae Christi gloriae invidus cum videret florentem Ecclesiam felicissime surgere: aliam huic simile quoque comparare statuit: \& ne quid minus haberet synagoga satanae, Ecclesia Christi, omnia quae in ea posita esse videret insignia, in suam quoquomodo transferre conatus etiam \& illa sua esse mentitus est. 
damit eine Klasse von Bildern, die mit der kategorischen Einteilung von Büchern in kanonische, hagiographische und apokryphe Schriften übereinstimmte. Die beiden ersten Bücherklassen dienten für die öffentliche Lesung. Dabei galten aber allein die hagiographischen Schriften als Autorität zur „Bildung der Gläubigen“ (edificazione de' fedeli). Diese hätten somit nicht dieselbe necessità wie die kanonischen Schriften aufgewiesen. Deshalb war die Gruppe der apokryphen Bücher - und damit auch der apokryphen Bilder - ausschliesslich für den privaten Gebrauch gestattet. $^{741}$

Lorenzo Sabatinis Bildsprache des von Dämonen umgebenen, stürzenden Magiers verweist auf die hoffnungslose Wiederaufnahme eines Häretikers in die Kirchengemeinde. Diese Hoffnungslosigkeit kommt im Vokabular des Kurienzeremoniells im Zusammenhang mit der sakramentalen Verwaltungspraxis der Enttäuschung des christlichen Heilsversprechens vor. So bleibt eine Aufnahme des Magiers Simon Magus in die Kirchengemeinde mittels der heilsspenden Kraft der Sakramente ausgeschlossen. Im Gegensatz zur westlichen Seitenwand wird in der Szene des Sturzes der liturgische Zusammenhang zwischen der Cappella Paolina und der Petersbasilika betont, indem sich Sabatini eines Mosaiks aus dem ehemaligen Oratorium Johannes' VII., in welchem dasselbe Bildsujet gezeigt war, bediente und für seine Bildlösung wiederverwendete. Der Bologneser Maler betonte damit die liturgische Verbindung zwischen der privaten Palastkapelle und der Kirche des Apostelfürsten Petrus. Die zeremonielle Bedeutung der Cappella Paolina, die als Privatkapelle allein dem Papst und der Kurie zur Feier spezifischer Feiertage im liturgischen Kalender diente, kam am deutlichsten beim rituellen Vollzug der zeremoniellen Schliessung der Heiligen Pforte, mit der auch das anno santo offiziell beendet wurde, zum Ausdruck. Die Vorbereitungen zur zeremoniellen clausura der Porta Santa begannen am Tag des vierten Adventssonntags. Einem Eintrag des Zeremonienmeisters Francesco Mucanzio in seinem Zeremonialtagebuch zufolge wies dieses Zeremoniell dieselben Züge wie dasjenige auf, das bei einer Kirchenweihe ausgeführt wurde. Die Schliessung der Heiligen Pforte bestätigt gleichzeitig die auf den Apostelfürsten Petrus aufbauende Ecclesia (Mt 16, 18). ${ }^{742}$ Demgemäss wird in Lorenzo Sabatinis Sturz des Simon Magus

741 Paleotti, Discorso, S. 285-286: „Ma quello in che più communemente pare che essi convengano è che di tutti i libri pertinenti alle cose della religione ve ne siano tre ordini: l'uno, che chiamano libri canonici; il secondo, libri agiografi; il terzo, libri apocrifi. Li primi hanno autorità e necessità, perché ci astringono a credergli nelle cose della fede, e questi sono i libri della Scrittura sacra, scritti non dagli uomini, da Dio per mano degli uomini. I secondi non hanno per l'ordinario necessità, ma autorità, onde si leggono publicamente ad edificazione de' fedeli. I terzi non hanno né autorità né necessità, ma però non sono con pena alcuna reprovati, onde non possono leggere publicamente, ma sì bene in privato con debita cautela; il che può essere nato o perché non si sappia l'autore certo di essi, o perché abbiano meschiate cose false con vere, o perché le cose che narrano non paiano così ben fondate come si doveria, o per qualonque altra causa [...].“

742 BAV, Chig.L.II.30, f. 360v-363r, hier 360v-362r: Finitis Vesperis Card.les et Praelati retinebunt Paramenta, et fiet Processio cum Candelis versus Portam Sanctam. Papa stans sine Mitra intonat 
eine Wechselwirkung zwischen der Cappella Paolina und der Petersbasilika betont. Dieser liturgische Zusammenhang entspricht ferner demjenigen, der vorhin zwischen der Privatkapelle und der Cappella Sistina festgestellt wurde. Die Paolina bildete dadurch einen zentralen Kontenpunkt, an dem zwei zeremoniell-liturgische Abläufe im Apostolischen Palast aufeinandertrafen. Lorenzo Sabatini verfolgte mit seinem Bildprogramm das Ziel, zwei rituelle Stränge des Kurienzeremoniells bezüglich der Verehrung des Sakraments der Eucharistie im bildnarrativen Verlauf miteinander zu verschränken.

Diese bildprogrammatische Angleichung der sakramentalen Verwaltungspraxis und des eucharistischen Heilsversprechens hatte sich somit zuerst in der päpstlichen Privatkapelle beweisen müssen, um danach auf die gesamte unter der Leitung Lorenzo Sabatinis stehende Ausstattung des Apostolischen Palastes nach dem anno santo überführt werden zu können. Lorenzo Sabatini setzte mit seinem Bildprogramm einen neuen Standard im Hinblick darauf, was die Bildproduktion, die dem kurialen Mäzenatentum diente, zu leisten hatte. Im Unterschied zu der von den Florentinern geförderten maniera, die sich allen voran auf die Ausgestaltung einzelner Figuren in ihren szenischen Momenten konzentrierte, gelang es den Malerwerkstätten im Palazzo Apostolico, die unter der Leitung Lorenzo Sabatinis standen, den apokryphen Charakter einer dezidiert römischen maniera wiederzubeleben. Das bildproduktive Element einer solchen apokryphen Auffassung, was die Malerei für die Kurie und somit unweigerlich auch für das Kurienzeremoniell selbst zu leisten hatte, bestand hauptsächlich in der Formulierung einer Bildsprache, mit welcher die kuriale Sakramentsverwaltung hinsichtlich ihres heilsspendenden Charakters bestätigt werden konnte. Diese bildsprachliche Formulierung wurde im Boncompagni-Pontifikat nicht nur durch eine innerhalb des Palazzo Apostolico arbeitende Künstlerwerkstatt geschaffen, sondern bildete auch die Grundlage dafür, wie das Verhältnis zwischen Gregor XIII. und seiner Heimatstadt Bologna, angemessen zu artikulieren war. Die Beschäftigung mit der Frage, welche Rolle Bologna für das Pontifikat und insbesondere für das Kurienzeremoniell einnahm, floss in die Ausmalung der am östlichen Ende der Terza Loggia angebrachten Sala Bologna ein.

\footnotetext{
Antiphonam [...] ut in Pontificali sub titulo de dedicatione, et Consecratione Ecclesiae. [...] Deinde aspergit aqua benedicta et adolet incenso: Tum Papa reasumpta mitra capit de manu primi Praesbiteri Card.lis cocleare cim calcio, et illam pro ijcit semel, aut ter in medietate liminis, postea ponendo primum lapidem submissa voco dicit. In fide, et virtute Jesu Christi filij Dei vivi, qui Apostolorum Prinipi dixit: Tu es Petrus, et super hanc Petram edificabo ecclesiam meam (Mt 16, 18-19), collocamus lapidem is tua primarium ad claudendum hanc Portam Sanctam singulo Iubilei anno reservandam [...]. Dasselbe Zeremoniell wiederholten die vier poenitentiarii der Hauptbasiliken. Vgl. hierzu die Einträge in ibid., f. 363r-366v.
} 


\subsection{Bologna als modulum argentum civitatis}

Die Ausstattung der Cappella Paolina hatte zur Folge, dass die päpstliche Privatkapelle während der liturgischen Advents- und Fastenzeit in eine zeremonielle Wechselwirkung mit der Cappella Sistina sowie mit der neuen Petersbasilika eintrat. Mittels ihres Bildprogramms wurde der Palazzo Apostolico als ein zentraler Organismus wahrgenommen, in welchem sich dessen liturgischen Funktionen während des Boncompagni-Pontifikates Gregors XIII. bestimmen und regulieren liessen. Als Sitz der Kurie und des Papsttums wurde der Apostolische Palast allmählich in einen lebendigen Architekturorganismus verwandelt. Mit Hilfe des Kurienzeremoniells wurde die architektonisch bedingte Trennung der einzelnen Räume und deren Innenausstattungen liturgisch aufgehoben. Die dafür eingesetzten Malerwerkstätten, deren Bildproduktion nicht mehr länger eine Manier der ausgeformten Figurendarstellung verfolgte, mussten eine Bildsprache finden, in der ein narratives Gleichgewicht zwischen Figurenhandlung und Szenendarstellung hergestellt werden konnte. Die römische Bildproduktion ging somit funktionell mit dem Kurienzeremoniell und dessen liturgischer Ausstattungsaufgabe des rituellen Vollzugs der sakramentalen Verwaltungspraxis einher. Die Grundlage zu dieser Wechselwirkung zwischen Bildproduktion und Kurienzeremoniell bewerkstelligten gerade diejenigen Orte des Palazzo Apostolico, die von den Zeremonienmeistern in ihren Tagebüchern kaum erwähnt wurden. Dies betraf in erster Linie den Ausbau und die damit verbundene malerische Ausstattung der Loggien, die Gregor XIII. über dem Cortile di San Damaso an der Nordfassade weiterführte. ${ }^{743}$

Die weiterführende Ausmalung der Palastloggien knüpfte bewusst an eine bestimmte Bildprogrammatik an, deren malerische Produktion bereits unter Pius IV. naturalistische Motive in Szenendarstellungen aus dem Neuen und Alten Testament aufnahm. Die Loggien wurden dadurch von einem Laboratorium für Grotesken in eine Malerwerkstatt umgewandelt, die eine Verschränkung zwischen den gemalten landschaftlichen Veduten und einer biblischen Exegese der darin eingefügten Figu-

743 Vier Zeichnungen des Architekten Martino Longhi il Vecchio, der seit 1573 Vignola als päpstlichen Architekten ersetzte, aus dem Archiv der Accadamia di San Luca zeigen, wie die architektonischen Eingriffe auf der Westfassade weitergeführt wurden. Vgl. hierzu die Zeichnungen in ASL, Fondo Mascarino, N. 2479r-v, N. 2480, N. 2481, N. 2489. Die Weiterführung des Baus sowie der Ausmalung der vatikanischen Loggien zeugen von einer bestimmten bildprogrammatischen Anknüpfung an die Bildproduktion während des Pontifikates Pius' IV. Zu den Loggien vor den Eingriffen des Boncompagni-Pontifikates vgl. die Studien von Redig de Campos 1974, S. 517-521; Dacos 2008; Davidson 1979, S. 385-404; eadem 1983, S. 587-602; eadem 1984, S. 382-389; eadem 1985; Dacos/ Furlan 1987, S. 101-107; Malesevic 2018b, S. 75-81. Der Ausbau der Loggien musste gemäss den Zahlungsbelegen zwischen 1574 und 1578 stattgefunden haben: ASR, Camerale I. Tesoreria Segreta, b. 1301, f. 53v, resp. b. 1306. Vgl. auch den Eintrag in Ciappi, Compendio, S. 8. Zu Martino Longhis weiteren Arbeiten im Vatikan vgl. dann Redig de Campos 1967, S. 169-171; Cornini/De Strobel/Crescenzi 1992, S. 151-154; Kat. Roma 1982, S. 16. 
ren anstrebte. ${ }^{744}$ Dieser bildprogrammatische Wandel setzte bei der Ausmalung der zweiten Loggia der Nordfassade im anno santo an und wurde 1577 abgeschlossen. Im Gegensatz zu den Jochen in der Seconda Loggia der Westfassade, die hauptsächlich Szenen aus dem Alten und Neuen Testament zeigten, enthielten einzelnen Gewölbeabschnitte an der Nordfassade quadri riportati, die Episoden aus dem Leben Christi präsentierten. ${ }^{745}$ Den einzelnen Figuren in den Bildfeldern wird nicht mehr länger dieselbe Dominanz verliehen, wie es noch Raffaels Werkstatt in der Loggia der Westfassade tat. Stattdessen nehmen detaillierte Landschaftsveduten und architektonische Schauplätze das Zentrum der Bildkomposition ein. Das Bildprogramm der elf Arkaden in der Seconda Loggia Gregors XIII. entwickelt ein Narrativ, das die Beteiligung der ersten Apostel am Leben Christi veranschaulicht und damit als incumbentia eines jeden Kirchenprälaten dienen sollte. Diese bildprogrammatische Wegweisung anhand der Vita Christi beginnt ab der achten Arkade mit der Bildgruppe der Verklärung des Herrn und der Schlüsselübergabe an Petrus, die sich in der Engelsgestalt mit Buch und Bischofsstab allegorisch vereinheitlicht. Das Bildprogramm der einzelnen Gewölbejoche endet schliesslich in der Fusswaschung Christi. ${ }^{746}$ Anhand einer im Städel Museum in Frankfurt aufbewahrten und in Aquarell ausgeführten Federzeichnung, die bislang als einzige Vorstudie zur Ausstattung der Seconda Loggia Gregors XIII. identifiziert werden konnte, kann ferner die enge Zusammenarbeit zwischen Lorenzo Sabatini und Raffaellino da Reggio beobachtet

744 Die Dekoration der Terza Loggia im Palazzo Apostolico, mit welcher bereits ab 1574 begonnen wurde, fiel auf eine équipe von Malern, die sich mit Lorenzo Sabatini deutlich als Bologneser Künstlerwerkstatt auswies und deren beiden wichtigsten Mitarbeiter der Maler und Architekt Ottaviano Mascherino sowie Baldassare Croce waren. Vgl. hierzu die Biographien in Baglione, Vite, I, S. 99100, 197-199. Nichtsdestotrotz hatte Sabatini für die Loggien auch Raffaellino da Reggia und Domenico da Formello in diese Werkstatt eingebunden. Sabatini kannte sie seit seinen Arbeiten für Vasari in der Sala Regia. Sodann waren auch Marco Marchetti da Faenza und sein Schüler, Giovanni della Marca, in den Loggien tätig. Vgl. hierzu ebenfalls die Biographien in ibid., I, S. 16-17 (Donato da Formello), 25-27 (Raffaellino da Reggio), 22-23 (Marco da Faenza), 46-47 (Giovanni della Marca). Mit den beiden letzteren Malern trat Sabatini wohl in der Werkstatt Vasaris im Palazzo Vecchio in Bekanntschaft, die vorwiegend für Grotesken eingesetzt wurde. Vgl. diesbez. insbes. Passignat 2013, S. 252-265; Cecchi 1977a, S. 24-54; idem 1977b, S. 6-26.

745 Das Bildprogramm wird komplett in Taja, Descrizione, S. 175-186, beschrieben. Zur Beteiligung der einzelnen Maler vgl. die entsprechenden Stellen in Baglione, Vite, I, S. 99, 17, 87-88, 26, 22, 18 , 46-47. Die gotteschi, für die hauptsächlich Marco da Faenza zuständig gewesen sein muss, unterscheiden sich deutlich von denjenigen Giovanni da Udines aus der Seconda Loggia an der Westfassade. Da Faenzas Motive lehnen sich dennoch an Giovanni da Udines Bildvokabular freskierter Miniaturen all'antica an. Jedoch führte er eine besondere Dichte sowie Bewegung im Zusammenspiel zwischen Figurenkomposition und Groteskenmalerei ein, um dadurch die horizontalen Brüche zwischen den beiden Motiven aufzuheben: Hess 1967, Bd. 1, S. 119-122. Dass Marco Marchetti für die Groteskenmalerei zuständig, war kann auch durch ein in Firenze, Uffizi, Gabinetto dei Disegni e delle Stampe, Inv. 4 aufbewahrtes Blatt belegt werden: Zuccari 2012, S. 73.

746 Taja, Descrizione, S. 183-185. 
werden (Abb. 28a \& 28b). Die Zeichnungen konnten Raffaellino da Reggio zugeschrieben werden. Die Federstudie belegt die Vermutung, dass der nach Sabatinis plötzlichem Tod am 2. August 1576 einberufene neue Leiter der Werkstatt - Sabatinis Sohn Mario - zu der Ausmalung der Loggien keinen entscheidenden Beitrag geleistet haben konnte. Hingegen war es der weitaus talentiertere Raffaellino da Reggio, der Lorenzo Sabatinis Bildprogrammatik angemessen umzusetzen im Stande war. ${ }^{747}$ Das Bildnarrativ in der Seconda Loggia verleiht insbesondere der Szene der Fusswaschung eine besondere Bedeutung, wenn diese im Zusammenhang mit dem Kurienzeremoniell an Gründonnerstag der Osterwoche ausgelegt wird. Dieser liturgische Tag im Kirchenkalender des anno santo war für den zeremoniellen Vollzug des Ritus der Fusswaschung für „dreizehn ausländische Arm[e]“ bestimmt. ${ }^{748}$ Die Malerwerkstatt Lorenzo Sabatinis konnte sich dadurch in ihrer bildproduktiven Praxis von

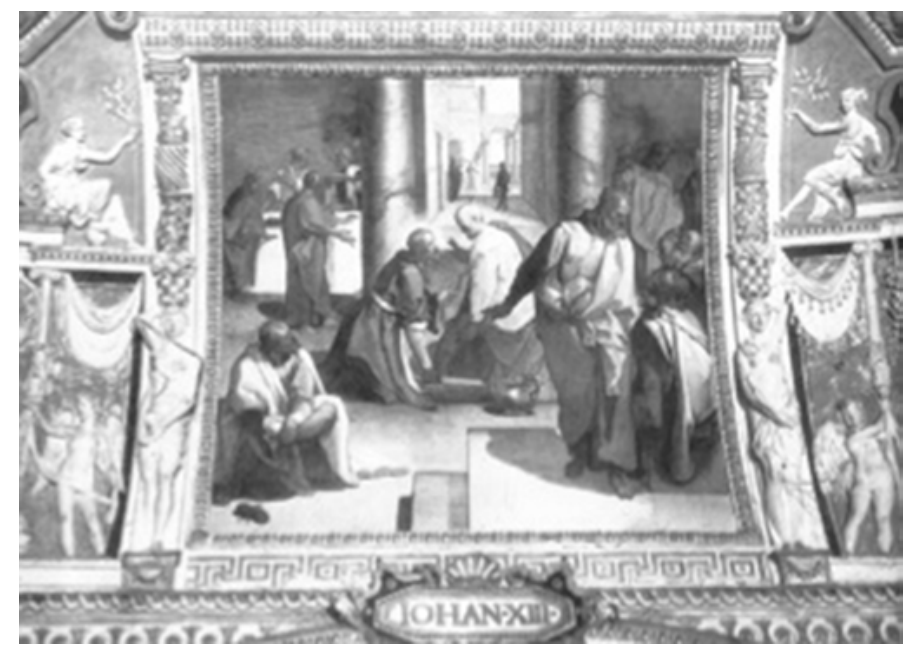

Abb. 28b: Raffaellino da Reggio, Die Fusswaschung Christi, Fresko, 1576-1577, Loggien Gregors XIII., Palazzo Apostolico Vaticano, Città del Vaticano.

747 Van Tuyll 2000, S. 291; Pulcini 2003, S. 109-110; Zuccari 2012, S. 75.

748 BAV, Chig.L.II.30, f. 316r: Post lectum Bullam Papa processit ad mandatum, et cum solito caeremonijs lavit pedes XIII Pauperum omnium ultramontanorum, quia sic placuit fieri Sanctitati Suae cum esset annus Jubilei, ut grationem sed redderet his, qui ex longioribus partibus religionis devotionisquae causa huc accaderent. Expleto huiusmodi actu, et exut Pontifici habuimus linteum quo se praecinxerat, qui nobis ex antiqua consuetudine obvenit. Vgl. zum Ritus, der während des Jubeljahres eine besondere Resonanz seitens römischer Bruderschaften - vorwiegend derjenigen des Gonfalone - erfuhr insbes. Pientini, Pie narrationi, S. 107-111. Raffaellino musste Livio Agrestis Fresko des Letzten Abendmahls im Oratorium der Gonfalone-Bruderschaft gekannt haben, da er selbst ebendort zwischen 1573 und 1575 - also kurz vor dem Auftrag für die Seconda Loggia - die Szene von Christus vor Kaiphas ausführte: Baglione, Vite, I, S. 26; Mancini, Considerazioni, S. 223. 
der dominanten Stellung der Bildprogrammatik Raffaels im Palazzo Apostolico lösen. Die Ausmalung der Loggien Gregors XIII. an der Nordfassade über dem Cortile di San Damaso wurde in einem engen Dialog mit dem sich im Innern des Apostolischen Palastes vollziehenden Kurienzeremoniell ausgeführt. Dieser Dialog zwischen Loggien und Kurienzeremoniell konnte aber erst dadurch bewerkstelligt werden, dass die Bildproduktion in den Loggien die architektonische Funktion derselben als essentielle Schnittstelle zwischen dem Apostolischen Palast als Innenraum und der römischen Stadttopographie als Aussenraum in ihrer Formensprache aufnahm.

Diesem Dialog zwischen Aussen- und Innenraum des Palazzo Apostolico widmete sich die Malerwerkstatt Sabatinis auch bei ihrer Ausmalung der Sala Bologna. Dabei entstand erstmals eine bildprogrammatische Vorstellung davon, wie die Loggien als organische Architektur und damit als essentielle Membran zwischen dem sich innerhalb des römischen Stadtraumes erfüllenden Heilsgeschehen und dem sich liturgisch innerhalb des Sacro Palazzo vollziehenden Kurienzeremoniell zu begreifen waren. Die Sala Bologna wurde am Ende der von Martino Longhi geplanten Raumaufteilung der Terza Loggia an der Nordfassade eingefügt (Abb. 29). ${ }^{749}$

Da sich dieser Raum am Ende der Terza Loggia befindet, war die Ostwand der Sala Bologna mit ihren drei von insgesamt fünf in Longhis Plan eingezeichneten Fenstern auf den Stadtraum Roms gerichtet. Aufgrund der unmittelbaren Nähe der Sala Bologna zu den beiden Räumen, die im Plan als cucina und dispensa bezeichnet sind, wurden die Terza Loggia und mit ihr die Sala Bologna als Speisesaal Gregors XIII. genutzt. ${ }^{750}$ Die Sala Bologna kann zurecht als päpstliche Hommage an

749 ASL, Fondo Mascarino, N. 2480, 2481; Wassermann 1962, S. 28-29; Sambin de Norcen 2011, S. 26.

750 Eindrücklich an Ciappis Beschreibung der Mahlzeiten im Sommer, die in luogo aperto stattfanden, ist auch die Erwähnung des päpstlichen Verhaltens während der liturgischen Fastenzeit der quaresima. Vgl. Ciappi, Compendio, S. 100-101: „Venendo l'hora die pranso (sic!), s'apparecchiava un tavolino ornato di verdure, \& fiori in luogo aperto, \& arioso, massime l'estate, godendo molto Sua Beatitudine dell'aere. La mensa era parca di numero di vivande, \& quelle poche erano semplici, \& se ne passava sobriamente: potendosi dire veramente di Sua Santità, che mangiasse per vivere, non vivesse per magiare [...] Nella Quadragesima, della quale fu osservantissimo, solendo dire, che dalli dodici sin' all'ultima età di ottantatre anni, che si trovava, non l'haveva rotta giamai, usava le medisme minestre di herbe passate con latte di mandorle, ò pignoli, ò seme di melone in luogo d'ova, \& poi alcun gustativo di buon pesce ò di tartaruche, ò pesce lesso, ò fritto, benche poco, come sarebbono state quattro triglie, ò sardelle, overo qualche grancio tenero." Ein avviso vom 30. Juli 1580 in BAV, Urb. lat. 1048, f. 226r hält diesen Brauch der Mahlzeiten Gregors XIII. ebenfalls fest. In dieser Hinsicht steht noch eine Untersuchung darüber aus, ob diese Mahlzeiten im Bereich der päpstlichen ricreazione ein bestimmtes Spannungsverhältnis zu den villegiature Gregors XIII. aufwiesen, die in den memorie aus BAV, Bonc.D.5, f. 73r, 131v, 139r, 177r-v dokumentiert sind. Vgl. diesbez. Coffin 1988, S. 40-41, 54-59; Ehrlich 2002, S. 58-68; Courtright 2003, S. 17. Zur architektonischen Einordnung der Küchenräume in der Palastarchitektur des zweiten Cinquecento vgl. allen voran Pagliara 2001, S. 39-91; Fiorani 2011, S. 14. In den nachfolgenden Pontifikaten Sixtus' V. und Clemens' VIII. wurden die Fensteröffnungen an der Ostwand der Sala Bologna zuge- 
den Herkunftsort Gregors XIII. betrachtet werden, weshalb die Dekoration ausschliesslich den beiden Malern aus Bologna, Lorenzo Sabatini und Ottavio Mascarino, anvertraut wurde. Die Würdigung seiner Heimatstadt, an deren Universität Ugo Boncompagni das Studium der Rechte mit einem Doktorat in utroque jure abgeschlossen hatte, sollte sowohl in den kartographischen Darstellungen des städtischen und ländlichen Territoriums Bolognas als auch in den Sternenhimmel im Gewölbe einfliessen. Die zeitliche Nähe zu der ein Jahr zuvor im Palazzo Farnese in Caprarola ausgeführten Sala della Cosmografia erlaubt es, eine Verwandtschaft mit der Entstehung des Sternenhimmels in der Sala Bologna zu vermuten. Der Vergleich mit der farnesianischen Sala della Cosmografia zeigt aber, dass in der Sala Bologna eine weit präzisere Darstellung der Sternenkonstellation im Vordergrund gestanden haben muss, denn die Gewölbedekoration in Caprarola lehnte sich an eine allegorische Repräsentation des Sternenhimmels an. ${ }^{751}$ Der Sternenhimmel in der Sala

Bologna sollte damit nicht wie derjenige in der Sala della Cosmografia von Caprarola eine schicksalshafte Vorsehung des Boncompagni-Pontifikates darstellen, sondern lediglich die bildproduktive Synthese zwischen Himmelsdarstellungen und Kartographie vollenden. Metaphorisch handelte es sich beim Gewölbe der Sala Bologna um eine Öffnung des Palastes zu den Sternen und zu der von den Loggien bewerkstelligten ariosità. Dementsprechend wurde die Gewölbedecke als illusionistische quadratura von Ottaviano Mascarino konzipiert. Lorenzo Sabatini fügte in dieses Dekorationsschema zehn berühmte Figuren der Astrologie und der Geografie ein. ${ }^{752}$

mauert, um sie in die Architektur des neuen Palastes Sixtus' V., der an die östliche Loggia angrenzte, einzugliedern. Das Projekt nahm sehr wahrscheinlich seinen konzeptuellen Anfang zwei Jahre nach der Wahl von 1585, wie es im avviso vom 18. April 1587 notiert wird: BAV, Urb. lat. 1055, f. 150r. Domenico Fontana konnte aber gemäss den in ASR, Cameral I. Fabbriche, b. 1527, f. 25r; ivi., b. 1528, f. 115r erhaltenen Zahlungsbelegen mit dem Bau des Palazzo novo erst 1589 begonnen haben. Vgl. hierzu insbes. Fontana, Della trasportatione (1603), c. 11r; Wassermann 1966, S. 32-33. Bezüglich der Ausführung für das Mauerwerk in der Sala Bologna vgl. den Zahlungsbeleg in ASR, Camerale I. Giustificazioni di Tesoreria 24, b. 3, f. 5v, das auf den 18. April 1596 datiert ist. Clemens VIII. nutzte die Sala Bologna dann als sein privates Schlafgemach. Vgl. auch die Beschreibung der Sala Bologna in Taja, Descrizione, S. 497-498.

751 Lippincott 1990, S. 3-20; Hess 1967b, S. 406-409; Partridge 1995, S. 413-444; McGrath 1997, S. 1045-1100; Warner 1971, S. 336-337; Fiorani 2005, S. 145-147; Urban 2011, S. 59-60; Malesevic 2018a, S. 135-141. Die besondere Bedeutung, welche die Heimatstadt des Boncompagni-Papstes für die Kurie und damit auch für das Kurienzeremoniell einnahm, kann aus Mucanzios Tagebucheintrag für den 9. Februar 1578 zur vierten Feier der quadragesima entnommen werden, an welchem Gregor XIII. der Ecclesia Bononiensis die goldene Rose überreichte: BAV, Chig.L.II.30, f. 523r-525v. Der Eintrag Mucanzios führt auch die Instruktion an den Bologneser Nuntius Vincenzo Bolognetti auf.

752 Wie die einzelnen giornate der Restaurierungsarbeiten von 1939 gezeigt haben, führte Sabatini seine Figuren innerhalb eines ganzen Tages aus. Vgl. Biagetti 1940, S. 240; Ceccarelli/ Aksamija 
Die Sala Bologna ergänzt damit die Loggien in der architektonischen Ordnung des Palazzo Apostolico, indem sie als essenzielles Bindeglied zwischen den unter Pius IV. ausgeführten Darstellungen von Weltkarten in der westlichen Terza Loggia und ihrer ekklesiologischen Auslegung hinsichtlich der potestas papalis wirkte. Die Bildprogrammatik der Loggien unter Pius IV., an welche die Malerwerkstatt Sabatinis anknüpfte, zeigte, wie sich diese potestas papalis über den gesamten orbis Christianum erstreckte. Rom nahm dabei das Zentrum ein. Beim Betreten der Sala Bologna durch die an der Südwand gelegene Tür präsentierte sich auf dem Wandkompartiment der gegenüberliegenden Nordwand zwischen den beiden Fensteröffnungen eine Allegorie der Bononia. Über diese allegorische Personifikation der Heimatstadt des Boncompagni-Papstes wurde eine Stadtvedute aus dem Blickwinkel von San Giovanni in Bosco angebracht (Abb. 30). Es ist die einzige Personifikation im Raum, die sitzend und in Begleitung von Büchern präsentiert wird. Auf der gegenüberliegenden Wand eröffnet sich dem Betrachter mittig im Bildfeld ein kartographischer Prospekt Bolognas, der links von der Übergabe der Dekretalen Gregors IX. und rechts von der Übergabe der Dekretalen Bonifaz VIII. an die Bologneser Juristen eingerahmt wird (Abb. 31). Entlang der westlichen Seitenwand wird entsprechend durch die Dominanz der kartographischen Abbildungen Bolognas die Administration des contado gezeigt, der wieder von zwei allegorischen Personifikationen der Pax und der Annona eingerahmt wird (Abb. 32). Die einzige nach den sixtinischen sowie clementinischen Eingriffen an der Ostwand noch übriggebliebene Allegorie der Securitas schliesst diesen Rundgang ab (Abb. 33). ${ }^{753}$ Mit diesem Bildprogramm auf den Seitenwänden der Sala Bologna wird eindeutig auf die territoriale Verwaltung Bolognas unter der päpstlichen Schutzherrschaft der Boncompagni-Familie verwiesen, deren Grundlage die kirchliche Rechtsprechungspraxis bildet.

Die Bildsprache der beiden Szenen der Dekretalien lehnt sich bewusst an Raffaels Übergabe der Dekretalen und Pandekten in der Stanza della Segnatura an. Deren ikonologische Auslegung muss daher vor dem Hintergrund der kurialen Arbeiten an den Revisionen am Corpus Iuris Canonici und am Decretum Gratiani von Seiten der Correctores Romani stattfinden. Fiorani schlug jüngst vor, dass die beiden Fresken der Übergaben der Dekretalen und besonders diejenige Bonifaz’ VIII. auf die Fi-

2011, S. 154. Die Korrespondenz zwischen der Figurendarstellung und der illusionistischen Architektur der einzelnen Loggienöffnungen lässt stark eine Anlehnung Sabatinis an Pellegrino Tibaldis Bildlösung für die Ausmalung des Palazzo Poggi in Bologna vermuten, die Sabatini selbst gekannt haben musste. Vgl. hierzu Marinig 1999, S. 188; Kiefer 2000, S. 304-308. Eine Vorstudie Mascarinos zur volta celeste der Sala Bologna befindet sich im Codice Resta der Biblioteca Communale in Palermo: Kat. Palermo 2007, S. 92. Für eine vollständige Zeichnung der quadratura aus der Albertina vgl. auch Knall-Brskovsky 1984, Taf. 7.

753 Nur noch der Kopf der zweiten Personifikation, die eine Allegorie der Iustitia dargestellt hatte, ist überliefert. Zur Identifikation dieser Figur vgl. die Beschreibung in Ceccarelli/Aksamija 2011, S. 185-186. 


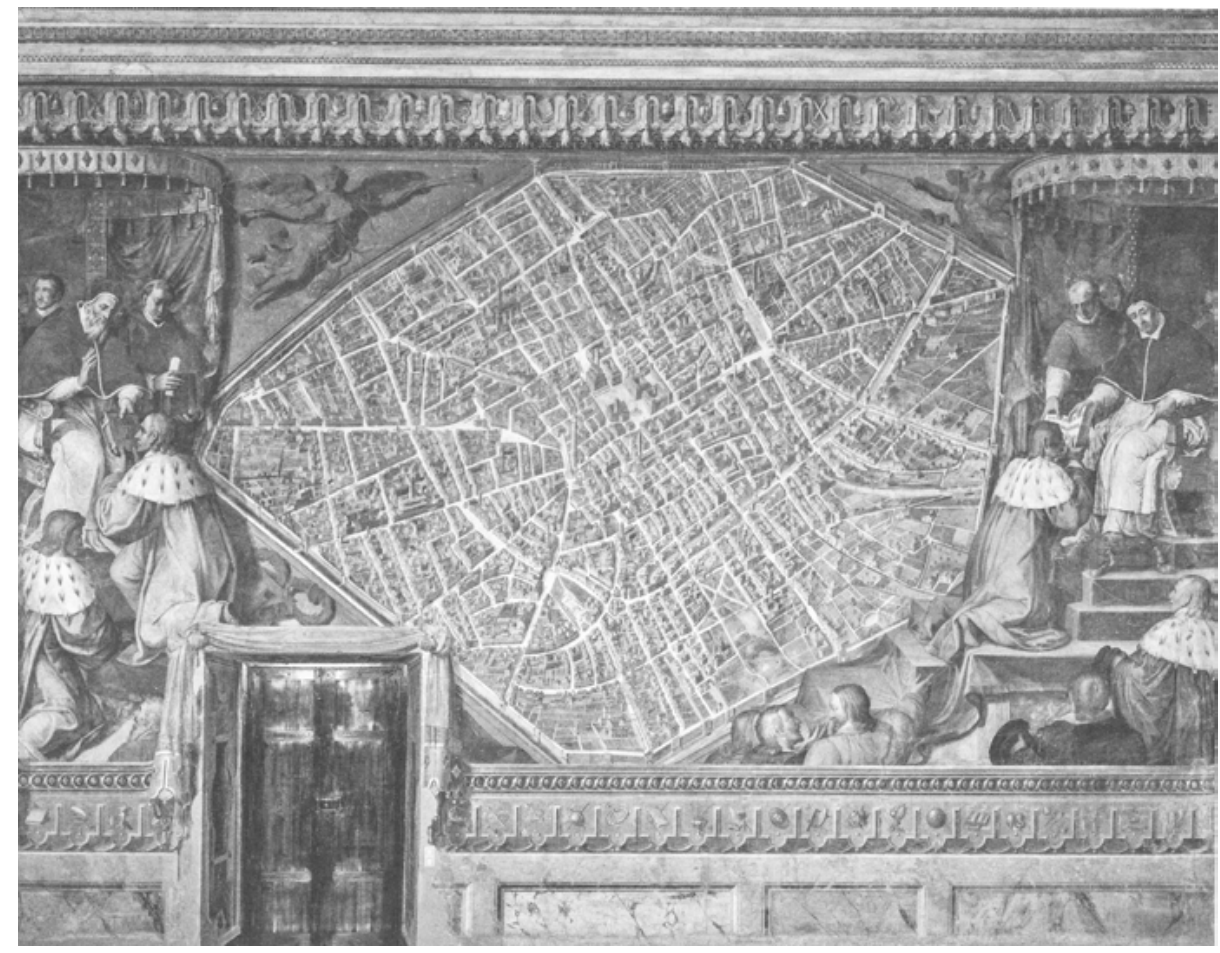

Abb. 31: Lorenzo Sabatini, Südliche Stirnwand mit Stadtprospekt Bolognas, eingerahmt von der Übergabe der Dekretalien Gregors IX. und Bonnifaz' VIII., Fresko, 1575, Sala Bologna, Palazzo Apostolico Vaticano, Città del Vaticano.

nanzpolitik Gregors XIII. hinweisen würden, insbesondere auf die Rückforderung der päpstlichen Lehensgüter an die Camera Apostolica. ${ }^{754} \mathrm{Da}$ aber die Ausmalung der Sala Bologna noch vor dem anno santo fertiggestellt wurde, kann eine solche Interpretation nicht zutreffen. Der Boncompagni-Papst Gregor XIII. ordnete nämlich erst mit der am 1. Juni 1580 erlassenen Bulle Ad Romani Pontificis an, dass die feudatarios ihren Lehenszins bis zum Festtag der beiden Apostelfürsten Petrus und Paulus an die Camera Apostolica entrichten sollten. ${ }^{755}$ In der Sala Bologna findet

754 Fiorani 2011, S. 19-21; eadem 2005, S. 226-227; Ciappi, Compendio, S. 41-43. Zur päpstlichen Finanzpolitik Gregors XIII. gegenüber Spanien vgl. weiter Dandelet 2001, S. 31-39 sowie die beiden avvisi in BAV, Urb. lat. 1045, f. $444 r$ und BAV, Urb. lat. 1046, f. 260r, welche über den zeremoniellen Empfang der chimera berichten. Pius V. hatte bereits mit der 1566 erlassenen Bulle Admonet nos neue Lehen aus dem Territorium des Kirchenstaates untersagt: Bull. dipl. rom., VII, S. 560-564. Vgl. dazu Fattori 2004, S. 97-107.

755 Bull. dipl. rom., VIII, S. 336-342. Vgl. hierzu neben Santori, Autobiografia, S. 368 und Pastor 1893-1933, Bd. 9, S. 759-760 auch die entsprechenden avvisi in BAV, Urb. lat. 1049, f. 69r, 83r, 131r, 271r, 307r, 333r-v. 


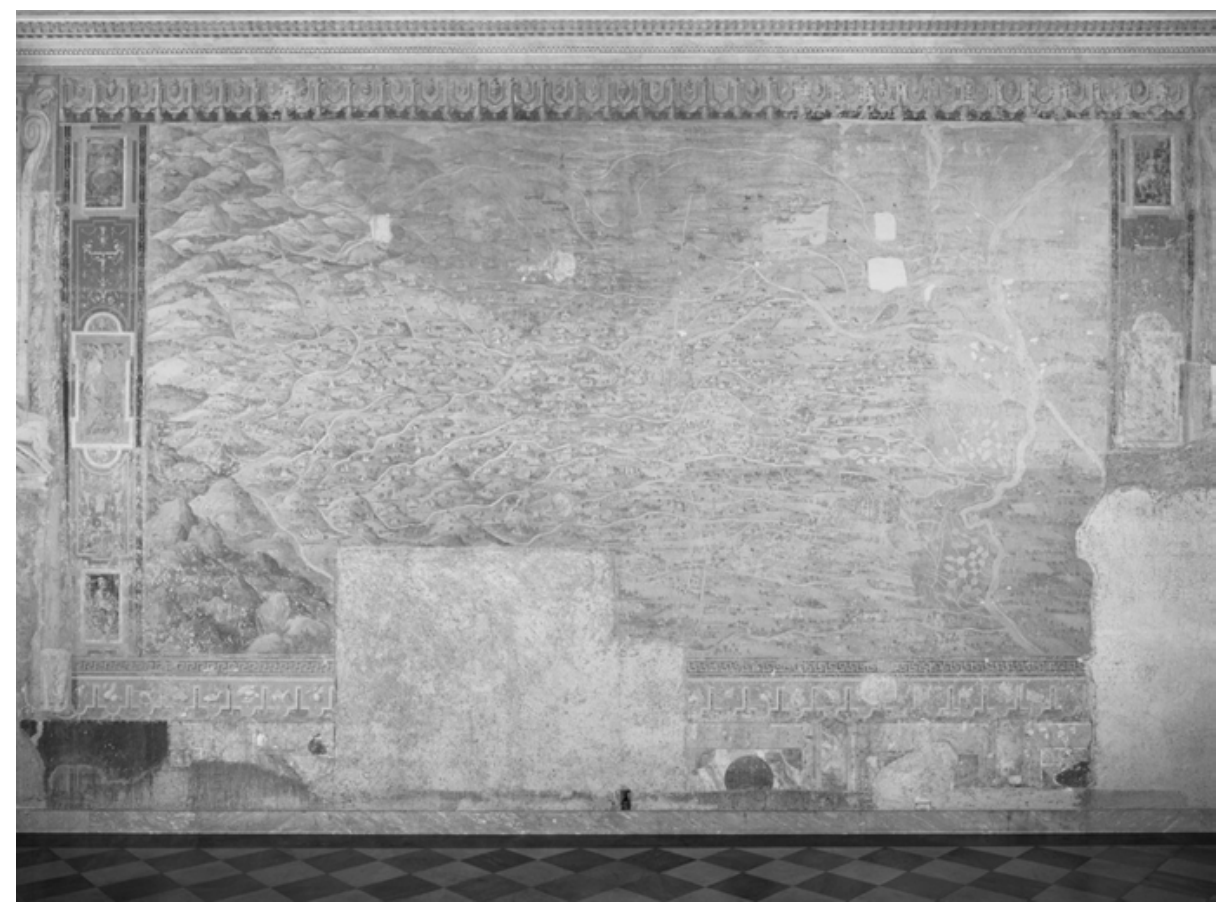

Abb. 32: Lorenzo Sabatini, Wandkompartiment der westlichen Seitenwand mit Chorografie Bolognas, Fresko, 1575, Sala Bologna, Palazzo Apostolico Vaticano, Città del Vaticano.

sich somit eine bildsprachliche Formulierung der Thematik, wie die Bedeutung der bischöflichen Stadtverwaltung Bolognas durch ihren Kardinalbischof Gabriele Paleotti mit der kirchlichen Rechtsprechungspraxis zu vereinbaren war. Im Gegensatz zu dem bereits geschilderten Fall der Bemühungen Carlo Borromeos, für die Mailänder Diözesanverwaltung eine rituelle Unabhängigkeit der ambrosianischen Liturgik aufrechtzuerhalten, war Paleotti vor allem darum bemüht, die liturgische Diözesanverwaltung Bolognas in Einklang mit der kirchlichen Rechtsprechung zu bringen. ${ }^{756}$ Diesbezüglich nimmt die links über der Eingangstür dargestellte Szene der Übergabe der Dekretalien Gregors IX. einen gewichtigen Platz in diesem Bedeutungszusammenhang ein. Der unter einem zeremoniellen Baldachin thronende Papst trägt hier eindeutig die Gesichtszüge Gregors XIII. Dies kann dadurch erklärt werden, dass der in der Sala Bologna tätige Maler Lorenzo Sabatini die Porträtmalerei der Bildhauerei anzunähern beabsichtigte. Der Bologneser Bildhauer Alessandro Menganti hatte nämlich den Boncompagni-Papst sowohl in seiner für den Palazzo Pubblico in Bologna

756 Zum Verhältnis Mailands und der kirchlichen giurisprudenza vgl. Prodi 1957, S. 195-199, 201; Bereta 1977, S. 51; Bendischioli 1926, S. 241-280, 409-498; Unterburger 2013, S. 76-77. 
vorgesehenen Büste als auch in einer monumentalen Bronzestatue verewigt (Abb. 34a \& 34b). ${ }^{757}$ Bis zur Ausmalung der Sala Bologna fanden sich demnach nur die von Bartolomeo Passerottis zwischen 1572 und 1573 ausgeführten Ölgemälde vor (Abb. 34c). Diese folgten der überlieferten Bildtradition von Papstbildnissen, weshalb Sabatini diese auch über zwei weitere überlieferte Zeichnungen Passerottis gekannt haben musste (Abb. 34d \& 34e). ${ }^{758}$ Neben dem thronenden Papst steht eine in Dreiviertelporträt gemalte Figur, die dem Bildnis des 1574 zum Kardinal berufenen Filippo Guastavillani gleicht. Jedoch bleiben die neben Papst Gregor IX. stehende und einen Kodex haltende Figur sowie derjenige Kurienprälat, der seinen Kopf hinter dem roten Vorhang verbirgt und sich mit Guastavillani im Gespräch befindet, unbestimmt. Allerdings meinte die Forschung in diesem Prälaten die Gesichtszüge des Kardinals Guglielmo Sirleto erkannt zu haben. ${ }^{759}$

Die Übergabe der Dekretalien Papst Gregors IX. in der Sala Bologna folgt nicht einer herkömmlichen Darstellung des Papstes im Umkreis seiner Nepoten. Das auf der Südwand angebrachte Fresko zeigt vielmehr Lorenzo Sabatinis Bestreben, eine geeignete bildsprachlichen Formulierung dafür zu finden, wie die engsten Kurienprälaten des Boncompagni-Papstes bezüglich ihrer Revisionsarbeiten an einem neuen Corpus Iuris Canonici darzustellen waren. Aus den erhaltenen Sitzungsberichten zur Congregatio generalis der Correctores Romani, die unter der Leitung Kardinal Francesco Alciatis stattfanden, lässt sich feststellen, dass das Decretum Gratiani bis zum Frühjahr 1575 beinahe vollständig revidiert wurde. ${ }^{760}$ Es kann daher davon ausgegangen wer-

757 Kat. Bonn 2005, S. 189-190; Kat. Bologna 2002, S. 28-45; Kat. Roma 2014, S. 104. Zwischen 1575 und 1577 scheint sich im Bereich der Bildproduktion von Papstporträts Gregors XIII. eine Verknüpfung der Bildhauerei und Porträtmalerei zu manifestieren.

758 Kat. Bonn 2005, S. 190; Ghirardi 1990, S. 179-181; Fiorani 2011, S. 14; Malesevic 2018a, S. $140-141$. Am 25. Mai 1577 wurde die von Pietro Paolo Olivieri ausgeführte Bronzestatue feierlich in der Aula Consiliare des Senatorenpalastes auf dem Kapitol eingeweiht. Vgl. hierzu Pecchiai 1950, S. 97-99; Butzek 1978, S. 280-294, 475-487; Pastor 1893-1933, Bd. 9, S. 825, 870-871; Freiberg 2009, S. 41-43 sowie das auf den 25. Mai 1577 datierte avviso in BAV, Urb. lat. 1045, f. 299r. Zur Kenntnis Sabatinis von den Vorstudien zu Passerottis Bildnissen Gregors XIII. vgl. Malvasia, Felsina pittrice, I, S. 181: „Mi sono poi fatto introdurre da Sua Santità papa Gregorio XIII [...] e circa del suo ritratto, del quale umilmente lo supplicai, dandomi licenza e contentandosi per una volta da me e dal Passarotti, che da altri non vole esser ritratto.“ Am 3. Juli 1990 versteigerte das Londoner Auktionshaus Christie’s eine weitere und sich bis dahin in der Zürcher Galerie Kurt Meissner befindende Zeichnung.

759 Sambin de Norcen 2011, S. 110. Ein Porträt Sirletos ist in BAV, Stamp.Cappon.IV 97; Stampe.I.2 (1-64) überliefert, das allerdings erst 1625 von Claude Pernet als Kupferstich ausgeführt wurde. Die Zuschreibung der neben dem Papst stehenden Figur als Papstneffen Filippo Boncompagni schlug erstmals Rubbini 2001, S. 46 vor. Jedoch scheint dieses Bildnis noch von demjenigen Passerottis weit entfernt zu sein: Ghirardi 1990, S. 184.

760 BAV, Vat. lat. 4892, f. 204v-211r enthält die Kommentare Thomás Taxaquets zu Corp. iur. canon., D.5 c.1, welche sich dem Sakrament der Taufe widmen. Aus einem Briefschreiben Pietro Galesinis an Carlo Borromeo vom 14. Januar 1574 kann darüber hinaus auch im Zusammenhang mit der Ausmalung der Cappella Paolina festgestellt werden, dass sich auch die Arbeiten zur Distinctio 5 mit der Spende 


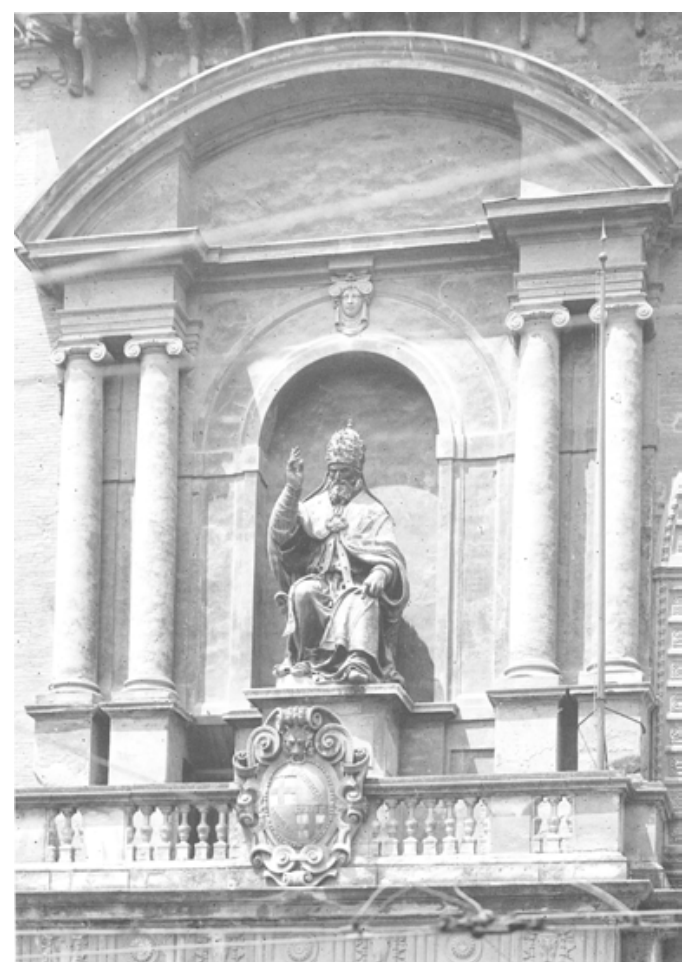

Abb. 34b: Alessandro Menganti, Statue Papst Gregors XIII., Bronze, 310 cm, 1579, Palazzo Publico, Bologna.

den, dass die weiterführenden Revisionen zur fünften distinctio während des anno santo gleichzeitig mit den Revisionen sowohl am Liber Extra Gregors IX. als auch am Liber Sextus Bonnifaz' VIII. durchgeführt wurden. Damit könnten die beiden Szenen der Übergabe der Dekretalien in der Sala Bologna, welche die kartographische Darstellung der Stadt Bologna einrahmen, durchaus ein Indiz dafür sein, dass sich beim nahen Abschluss der Revisionen am Decretum Gratiani die Idee eines Liber Septimus anbahnte. $^{761}$

des Taufsakramentes gegenüber den neofiti hatten auseinandersetzen müssen. Das Briefschreiben ist enthalten in BAV, Vat. lat. 4913, f. 56r-v. Vgl. deisbez. auch Sommar 2002, S. 51-53.

761 Eine eigenständig dafür eingesetzte Kommission, die von den Kardinälen Carafa, Alciati und Flavio Orsini wurde 1580 eingesetzt, auch wenn Alciati am 12. Mai desselben Jahres starb. Dementsprechend kann der Todestag dieses Kommissionsmitglieds als terminus ante quem der offiziellen Einsetzung dieser Kardinalskommission gelten. Vgl. hierzu Sentis, Decretales Clementis Papae VIII, S. VIII sowie die avvisi vom 13. Juli und 23. September 1583 in BAV, Urb. lat. 1051, f. 297r, 418r-v. Für die neusten Forschungen zum Liber Septimus, das erst unter Clemens VIII. herausgegeben wurde, vgl. Dickerhof-Borello 2002, S. 99-216. 


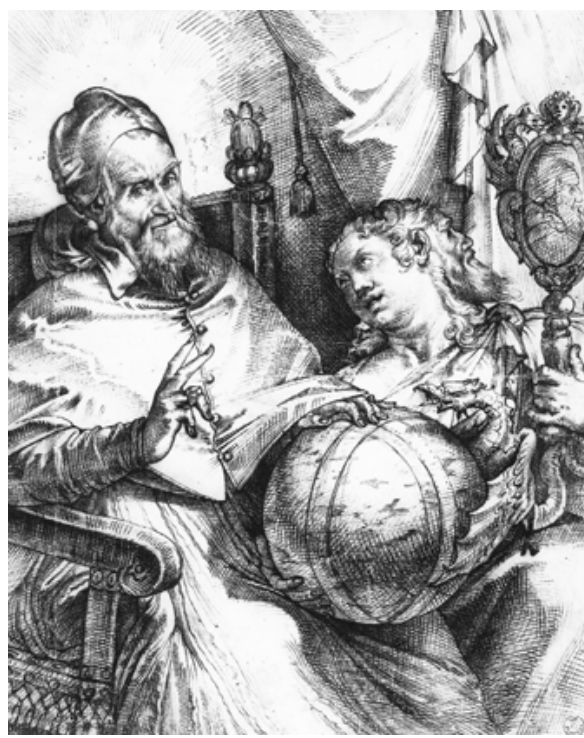

Abb. 34d: Bartolomeo Passerotti, Allegorisches Bildnis Papst Gregors XIII., Federzeichnung in Brauntinte, 1572, 46,1 x 39,7 cm, Privatsammlung.

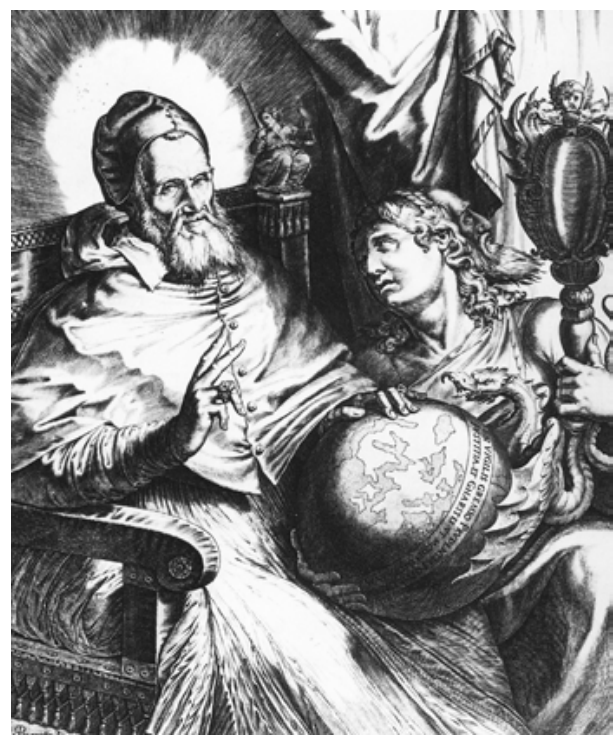

Abb. 34e: Bartolomeo Passerotti, Allegorisches Bildnis Papst Gregors XIII., Federzeichnung mit Tinte, 1572, 46,1 x 39,7 cm, Gabinetto Disegni e Stampe degli Uffizi, Florenz.

Die Forschung vertrat bislang die Ansicht, dass die Correctores Romani ihre Arbeiten an den beiden weiteren Büchern des Corpus Iuris Canonici nicht aufzeichnete. Diese Arbeiten am Liber Sextus können jedoch anhand Antonio Augustíns 1576 in Lérida gedruckten Antiquae Collectiones Decretalium rekonstruiert werden. Augustins Antiquae Collectiones legten ebenfalls eine Edition der ersten vier Compilationes antiquae vor. ${ }^{762}$ Die dritte, vierte und fünfte Compilatio enthielten Dekretalien über die Verwaltungspraxis der Sakramente. Damit hatte sich in den Arbeiten der Correctores Romani ein Weg angebahnt, die Sakramentsliturgik und ihren ritu-

762 Für eine Untersuchung bezüglich der Bedeutung dieser Schrift für die weiteren Editionen der Quinquae compilationes antiquae vgl. insbes. Kuttner 1977, S. 3. Seit 1558 war Augustín an den Dekretalien interessiert, denen er erstmals in Worms, später dann auch in Verona begegnete und sie kopieren liess. Vgl. diesbez. die Briefschreiben an Panvinio vom 11. April und 25. Juni 1558 in Andrés, Antonii Augustini Archiepiscopu Tarraconensis Epistolae Latinae, S. 313, 320. Diese Edition der Dekretalien, von denen sich ein Exemplar in BAV, Stamp.Racc.I: II.376 befindet, liess Augustín ebenfalls 1576 in Lérida drucken und widmete sie Gregor XIII. Ein weiteres Exemplar konnte in BCR, E.V.53 aufgefunden werden, das sich ursprünglich in BVR, S.BOR.D.IV.17 befunden haben muss. Dass Augustin auch einer sich im Escorial befindenden Handschrift während seiner Zeit als Bischof von Lérida begegnete, kann hierdurch angenommen werden: vgl. Augustín, Opera omnia, II, S. 42; ibid., VII, S. 97. 
ellen Vollzug im Zeremoniell auf der Grundlage des Kirchenrechts verpflichtend zu formulieren. ${ }^{763}$

Indem die beiden Dekretalien-Szenen in der Sala Bologna die kartographische Darstellung der Heimatstadt Gregors XIII. einrahmen, stellten sie zugleich mit ihrer Übergabe die auf dem Feld des Kirchenrechts stattgefundene Übertragung der sakramentalen Verwaltungspraxis aus Rom nach Bologna dar. Dadurch wurde ein besonderer Austausch zwischen der römischen Kurie und der Diözese Gabriele Paleottis innerhalb des Kirchenstaates vergegenwärtigt. Bildprogrammatisch realisierte sich dieser Austausch aus einem Dialog zwischen der an der Nordwand angebrachten Personifikation der Bononia docet und der planimetrischen Darstellung des Bologneser Stadtraumes auf der Eingangswand. Sabatini und Mascarino hatten dadurch innerhalb des Palazzo Apostolico einen für den päpstlichen Empfang von Botschaftern aus Bologna angemessenen Raum während des Boncompagni-Pontifikates geschaffen. Mit ihrer Bildprogrammatik knüpft die Sala Bologna an die Ausstattung von Audienzräumen an. Mittels der beiden zentralen Episoden wird die territoriale Diözesanverwaltung Bolognas in einer organischen Entwicklung des Kirchenrechts ausgelegt und dadurch mit der kurialen Sakramentsverwaltung in Übereinstimmung gebracht. Dadurch wird in der Sala Bologna die Verwaltung des Stadtraumes unter der kirchenrechtlich begründeten potestas des Boncompagni-Papstes subsumiert. Gemeinsam mit dem Diözesanbischof Paleotti wollte Gregor XIII. seine Stadt in ein Modell des sakramentalen Raumes schlechthin verwandeln. Der Palazzo Apostolico verwandelte sich durch die Sala Bologna und die Loggien an der Nordfassade des Cortile di San Damaso zu einem Laboratorium der Modellierung diözesaner Verwaltungsstrategien. Bildprogrammatisch hatte die Sala Bologna somit dem Palazzo Apostolico in seinem architektonischen Aufbau die Merkmale eines Stadtpalastes verliehen. ${ }^{764}$ Die Dekretalien-Szenen sind allerdings nicht als Modi der Selbstdarstellung des Boncompagni-Papstes zu betrachten, denn sie zeigen, wie die allegorische Personifikation Bolognas auf dem gegenüber-

763 Diese Fortführung auf der Basis der sakramentalen Verwaltungspraxis kann ebenfalls entlang der Abschnitte aus Augustíns Recollecta in iure canonico, in BAV, Vat. lat. 4895, f. 11r-12v beobachtet werden, die sich den Riten der Taufe, Busse und der Altarweihe widmen: idem, Antiquae Collectiones Decretalium, S. 38, 101, 177 (Firmung), 199 (Eucharistie), 124, 201 (Taufe), 144 (Krankensalbung).

764 Dieser Prozess der Einverleibung kann durch die päpstliche Verordnung, den Palazzo Comunale in Bologna zu vergrössern, erklärt werden: BAV, Urb. lat. 1044, f. 476r. Vgl. zu den weiteren Eingriffen in Bologna auch Ciappi, Compendio, S. 84-95; Pastor 1893-1933, Bd. 9, S. 840 sowie zum Wandel der Palastarchitektur die jüngsten Forschungsergebnisse in Alonzi 2003, S. 39-43; Ricci 2012, S. 17-20. Ebenfalls gewichtigen Anteil an diesem Laboratorium der Stadtverwaltung Bolognas, das sich in der Sala Bologna des Palazzo Apostolico bildprogrammatisch verwirklichte, hatte der Botschafter Filippo Carlo Ghislieri eingenommen. Er war der zentrale Vermittler zwischen Lorenzo Sabatini und dem Senat in Bologna für eine kartographische Darstellung der Stadt und deren contado. Vgl. diesbez. die Briefkorrespondenz aus dem Archivio di Stato Bologna, Assunteria di confini, aque e fiumi, zit. in Ceccarelli/Aksamija 2011, S. 182-185. 
liegenden Wandkompartiment bildrhetorisch in eine narrative Szene umgewandelt werden kann. Die päpstlichen Eingriffe in den urbanen Stadtraum der Diözese Paleottis oszillieren nämlich zwischen kanonistischer Belehrung (doctrina) und gelehrter Modellierung (doctus) des urbanen Sakralraumes. Der Boncompagni-Papst setzte deshalb eine Bologneser Erzbruderschaft in Rom sowie eine Sakramentsbruderschaft in Bologna ein, deren Leitung er dem Kardinalsbischof Paleotti anvertraute. Die Sakramentsbruderschaft in der Heimatstadt des Papstes verfolgte vor allem das Ziel, den Status der Adelsfamilien Bolognas und den der Papstfamilie der Boncompagni auszugleichen. Die Adelsfamilien Bolognas versuchten sich im Verlauf des Cinquecento immer stärker vom Bürgertum abzusetzen, indem sie sich als eine vom Bürgertum separate senatorische Klasse stilisierten. Sie bemühten sich nämlich darum, von den Päpsten die formelle Erbschaft von Senatorentitel zu erlangen, auch wenn sie dafür die heftigen Konkurrenzschwierigkeiten um die Neubesetzung vakanter Sitze bewältigen mussten. ${ }^{765}$ Die Herstellung eines solchen Gleichgewichts zwischen Papst- und Adelsfamilie hatte die Bildprogrammatik in der Sala Bologna bereits ideologisch vorformuliert, indem die Darstellung des contado von den beiden bereits angesprochenen Allegorien der Pax und der Annona eingerahmt wurde. Beide Personifikationen verwiesen auf eine erfolgreiche Bekämpfung - oder zumindest Eindämmung - des Banditenwesens des Boncompagni-Papstes. ${ }^{766}$

Zum Zeitpunkt des anno santo beanspruchte die Dekoration der Sala Bologna, die Bindungen des Boncompagni-Papstes zu seiner Vaterstadt in die Organik des Palazzo Apostolico mittels der bewussten Anlehnung an den kirchenrechtlichen Prototyp der Übergabe der Dekretalien herzustellen. Lorenzo Sabatinis Bildproduktion führte in den weiteren Ausgestaltungskampagnen zugleich eine sublime Dimension der kurialen Sakramentsverwaltung ein. Dadurch liess sich der Apostolische Palast letztendlich zum eigentlichen Zentrum einer sakramentalen Verwaltungspraxis, die im Kirchenrecht begründet war, ausstatten. Aus der kirchenrechtlichen Grundlage der Sakramente folgte, dass sich die Correctores Romani bei ihren Revisionsarbeiten am Liber Extra sowie am Liber Sextus der Sakramentsverwaltung widmen mussten. Die Correctores Romani hatten aber bis dahin noch keineswegs die Sakramente, die bereits Christus einsetzte, von denjenigen, die erst die Apostel selbst installiert hatten, unterschieden. Diese Unterscheidung wurde auch nicht im Bereich der kirchlichen Jurisprudenz hergestellt, sondern vollzog sich auf dem Feld der kontroverstheologischen Kirchenhistoriographik. Indem sich anfänglich eine Historia Ecclesiastica aus einer katechetischen Kirchenlehre

765 Gardi 1994, S. 241-253, 347-396; Fanti 1961, S. 159; Giacomelli 1980, S. 63-64; idem 1990, S. 192-197; Capanni 2017, S. 27-38; Vitali 2003, S. 104-105.

766 Albergati, Trattato, S. 7, 595-596, 598-600; Vulpelli, Tractatus de pace; Morone, Tractatus aureus; Blastenbrei 2000, S. 363-364. Gregor XIII. scheiterte aber an einer Herstellung einer solchen sinnbildlich fabrizierten pax: BAV, Urb. lat. 1643, f. 2r-3v, 4v; BAV, Urb. lat. 1050, f. 252r, 261v, 371v, 385v; BAV, Urb. lat. 1051, f. 10r, 85r, 106r, 113r, 152r, 156v, 164v, 183r-v. 
der Sakramente ergab, konnte eine kirchenhistoriographische Rekonstruktion der Entstehungsgeschichte der Sakramente vorgenommen werden. ${ }^{767}$

Bevor die Kurie jedoch eine solche Formulierung zu Stande bringen konnte, bedurfte es einer ausführlichen Beantwortung der Frage, wie die Ordnung des ,allerheiligsten" und damit obersten Sakraments der Eucharistie, in der sich die heilsgeschichtliche Wirkung der übrigen Sakramente einzugliedern hatte, nun kirchenhistoriographisch angemessen erfasst werden konnte. Sowohl in Bezug auf die zeremonielle Organisation und Durchführung des anno santo als auch hinsichtlich des liturgischen Ritenvollzugs im Kurienzeremoniell während des Boncompagni-Pontifikates nahm das Sakrament der Eucharistie das Zentrum des sakramentalen Heilsuniversums ein. Die Heilswirkung der Eucharistie leitete sich aus der heilsversprechenden Theologie des Kreuzes- und Messopfertodes Christi ab. Ein kirchenhistoriographisches Verständnis dieses Sakramentes fusste zwangsläufig auf der Grundlage von dessen rituell vollzogener Heilswirkung im Kurienzeremoniell. Die Verknüpfung zwischen der heilsspendenden Wirkung der Sakramente und ihrer Verwaltung im Kurienzeremoniell hatte sich erstmals in der Bildprogrammatik der Sala delle Carte Geografiche manifestiert. Das Dekorationsschema dieses Verbindungskorridors im Palazzo Apostolico zeigte nämlich eine vertiefte Auseinandersetzung der Kurie mit der kirchengeschichtlichen Bedeutung der Sakramentsverwaltung, da die Sakramente in einem perspektivischen Bezugssystem zur Eucharistie dargestellt wurden. Die sieben Sakramente wiesen in ihrer temporalen Heilswirkung einen ekklesiologischen Aufbau auf, den die Kirchenhistoriographik in der Entwicklungsgeschichte der Ecclesia Romana zu rekonstruieren hatte.

\subsection{Die sakramentale Entwicklung des eucharistischen Heilsgeschehens}

Die Ausführung des Bildprogramms für den 120 Meter langen Verbindungskorridor im dritten Obergeschoss über der ehemaligen Hofanlage des Belvedere schliesst an die Ausgestaltungskampagnen der Seconda Loggia, der Sala dei Foconi und der

767 Diese Unterscheidung hatte sich hinsichtlich der Auslegung des Sakraments der Firmung, die vorhin bereits im Kontext der Ausmalung der Cappella Paolina im Zusammenhang mit dem Kurienzeremoniell besprochen wurde, am deutlichsten artikuliert. Die Magdeburger Zenturiatoren führten in ihrem dreizehnten und letzten Band, welcher 1574 gedruckt wurde, eine ausführliche Diskussion darüber, weshalb dieses Sakrament nicht zu Lebzeiten Christi eingesetzt worden sein konnte, sondern erst durch die Apostel einberufen worden sei. Vgl. hierzu Ecc. Hist., XIII, Sp. 406: Duo sacramenta à Christo instituta. [...] Sed duo instituit per se ipsum scilicet, sacramentum baptismi, quod est maxime necessitatis \& efficaciae: \& sacramenti Eucharistiae, quod similiter propter quotidianam infirmitatem est maximè necessarium, tanquam reparativum quotidianae infirmitatis. Sacramentum verò confirmationis \& extremae unctionis dedit per Apostolos, nisi fortè intelligatur, quod impositione manus facta parvulis intelligatur confirmatio. 
Sala dei Paramenti an. Die im Gewölbe der Sala delle Carte Geografiche angebrachten Episoden entwickeln ein Bildnarrativ, das die vorhin besprochene Darstellung einer apostolisch begründeten Vita Christi um eine kirchenhistoriographische Dimension erweitert. Dadurch wurde die Verbindung zwischen einer apostolisch überlieferten Lebensgeschichte Christi und der Sakramentsverwaltung der Kurie im rituellen Vollzug der Liturgie mittels des Kurienzeremoniells betont. Das Resultat dieser bildprogrammatischen Ausarbeitung der kirchenhistoriographischen Verankerung des sakramentalen Heilsgeschehens in der Galleria delle Carte Geografiche war die am 20. September 1579 an den Oratorianer Cesare Baronio monatlich entrichteten Auszahlung von sechs scudi. Diese monatliche Auszahlung an Baronio bestätigt, dass die kuriale Verwaltungspraxis der Sakramente grundlegend für eine kirchenhistoriographische Rekonstruktion der sakramentalen Entwicklung der Ecclesia Romana in den Annales Ecclesiastici sein musste. ${ }^{768}$ Das Dekorationsschema für das Gewölbe der Galleria delle Carte Geografiche präsentierte, wie sich zeigen sollte, ein gänzlich auf die potestas papalis bezogenes Bildnarrativ der Sakramentsverwaltung und ihrer kirchenhistorischen Entwicklung. Im ersten Band seiner Annales Ecclesiastici bemühte sich der Oratorianer Baronio um eine angemessene Darstellung des rituellen Vollzugs derjenigen officia, die dem Sakrament der Eucharistie zugeordnet werden. Dabei zeigte er die Unterschiede zwischen einer Ecclesia Occidentalis und einer Ecclesia Orientalis anhand der lateinischen Patristik auf. Das Bildprogramm in der Galleria über der Belvedere-Hofanlage ging jedoch davon aus, dass die sakramentale Verwaltungspraxis von einer Universalkirche geleitet werde. ${ }^{769}$ Dieser Unterschied zwischen Baronios Arbeit an seinen Annales und dem Bildprogramm der Galleria delle Carte

768 ASR, Camerale I. Tesoreria Segreta, b. 1037, f. 36r. Die architektonischen Arbeiten für die Galleria, deren Leitung Ottavio Mascarino übernahm, mussten im Herbst 1578 begonnen haben. Vgl. hierzu den Bericht vom 28. Oktober von Giovanni Antonio Odescalchi in Pastor 1893-1933, Bd. 9, S. 874 sowie Smith 1977, S. 6, 27. Die Nutzung des Cortile del Belvedere durch Gregor XIII. wird in einem avviso vom 22. Juli 1578 in BAV, Urb. lat. 1046, f. 288v festgehalten: „[...] per due hore (ha) dato aud(ien)za caminando sempre indefessamente“. Zur Hofanlage des Belvedere vgl. dann Ackerman 1954, S. 103-107; Wasserman 1966, S. 146-148; Redig de Campos 1967, S. 174-178; Almagià 1952, S. 1-11; Prinz 1970, S. 50; Büttner 1972, S. 154; Frommel 1973, Bd. 1, S. 78-79; Denker Nesselrath 1992, S. 217-222; Pinelli 1994, S. 9-71; Courtright 2003, S. 51-59. Die Zuschreibung an den Architekten Mascarino lässt sich aus BAV, Bonc.D.5, f. $240 v$ bestätigen.

769 Ann. Ecc., I, S. 474-476. Wie später noch zu zeigen sein wird, musste Baronio sich mit dieser Differenzierung zwischen lateinischem und griechischem Ritus bereits ab 1576 im Zusammenhang mit der Translation der Reliquien des heiligen Gregor v. Nazianz auseinandergesetzt haben: infra, Kap. 8.2. 1577 empfing der Boncompagni-Papst den an der Universität Louvain tätigen Rechtsprofessor, Jean de Vandeville zu einer Audienz, während der Vandeville eine Handschrift zur Einberufung einer neuen Kongregation präsentierte, welche sich später zur Sacra Congregatio de Propaganda Fide - allerdings erst nach 1622 - festigen sollte. Vendeville hatte bereits 1567 in einer Audienz gegenüber Pius V. dieselben Pläne präsentiert. Gregor XIII. wandte sich dann an den Jesuiten Antonio Possevino, der Vendevilles Vorschläge bearbeitete und entsprechend ergänzte. Vgl. hierzu Donnelly 1988, S. 181-188; Fiorani 2005, S. 234-235. 
Geografiche schliesst eine Beteiligung des aus Sora stammenden Oratorianers an der konzeptuellen Formulierung dieses Dekorationsschemas aus.

Die Galleria delle Carte Geografiche verband den Palazzo Apostolico mit der Anlage des Belvedere und zählt somit noch zum päpstlichen Appartement. Die Inschrift über dem Nordeingang erklärt, wie die an den Seitenwänden angebrachten Landkarten und deren Chorographien mit dem ungewöhnlichen Bildprogramm im Gewölbe zusammenhängen: Der Anspruch Italiens, „vornehmstes Gebiet des Weltkreises“ (regio totius orbis nobilissima) zu sein, wird durch die darauf bezogenen Heiligenszenen, in denen die „frommen Taten heiliger Menschen“ (pia sactorum virorum) gezeigt werden, unterstützt. Das Bildprogramm folgt einer ähnlichen Konzeption wie das der Sala Bologna, denn die geographischen loci werden an die dort stattgefundenen „Begebenheiten“ (res) angepasst. Das Bildnarrativ des Gewölbeprogramms musste allerdings noch vor dem der Landkarten und den Chorographien fertiggestellt worden sein, da am 24. Dezember 1580 der Dominikaner Ignazio Danti dem Kosmographen Abraham Oertel von den achtzig Szenen, die das Gewölbe schmückten, berichtete:

Havendo divisa l'Italia p. il mezzo del Mo(n)te Apennino o posta da una banda della Galleria quella parte che è bagnata dal Mare Ligustico, et Tirreno, et dall'altra, quella che è cinta dall'Adreatico, e dall'Alpi, dividendola poi seco(n)do gli stati et le prefetture de governj in quara(n)ta parti, seco(n)do che la Galleria è divisa in .40. quadrj di tanta grandezza che sono andati 64 . fogli di carta reale per quadro nel fare i caronj. Hora vo riducendo ogni cosa in un libro, ove le parti d'Italia sara(n)no fino a .48. et vi saranno apresso da .80. storie di figure, che sono dipinte nella volta della Galleria sop(ra) ciascuno quadro rapprese(n)tando qualche segnalato miracolo occorso in quella provincia. Ne ho voluto dare aviso a V. signoria, accio se lej havesse volunta a farmj intagliare questo libro che me lo faccia sapere, che io operej co(n) il papa che ci porgesse qualche aiuto, et nova annotatione, co(n) le inscrittioni che in essa Galleria io ho fatte, et sono state tutte riviste et racco(n)cie dal S. Moreto, dal S. Bargeo, et dal Frizzolio [...] resta ancora che le dicha, che ho messo insieme fra città, et altre terre grosse d'Italia ritratte in pianta dal naturale fino a cento pezzi, che sar(an)no co(n) il medesimo libro. ${ }^{770}$

770 Abrahami Ortelii Epistulae, S. 241-242. Aus dem Zahlungsbeleg vom 7. August 1580, der den Transport zerbrochener und den Kauf neuer Gefässe für das Dach des Corridore nuovo dokumentiert, kann abgeleitet werden, dass der architektonische Rahmen im Spätsommer 1580 vollendet gewesen sein musste: ASR, Cam. I, Tesoreria Segreta, b. 1308, f. 21r. Vgl. dann auch die avvisi vom 13. Juli und 24. Dezember 1580 in BAV, Urb. lat. 1048, f. 212r-v, 452v. Am 26. Januar bewunderte Michel de Montaigne während seines Rom-Aufenthaltes la belle galérie. Zit. n. Montaigne, Journal, S. 179. Gemäss dem Bericht des venezianischen Botschafters sind die Galerie und ihre Dachterrasse im Sommer 1581 schliesslich sowohl begehbar als auch fertig. Vgl. hierzu Albèri, Le relazioni degli ambasciatori veneti, IV, S. 274: „Le stanze poi aggiunte al suo appartamento sono molte e con bellissimi ornamenti, e tra gli altri vi sono due galleria da passeggiare, l'una sopra e l'altra coperta di sotto a quella, lunghe quanto è il Cortile d Belvedere: la coperta è tutta messa a stucco e oro con diverse storie pie, e nelle pareti tra le finestre vi è descritta l'Italia compartita in 32 provincie, e le due prossime città nell'uscire della stanza l'una di qua l'altra di là della porta sono Venezia e Genova, quella come capo del mare Adriatico, e questa del mar Tirreno.” 
Das Briefschreiben des Dominikanertheologen Danti zeigt, dass er nur für den Entwurf der kartographischen Darstellungen an den Seitenwänden verantwortlich war. Die kunsthistorische Forschung hatte sich bislang der Frage, wem der Entwurf für das Gewölbeprogramm zugeschrieben werden könnte, gewidmet und dabei Cesare Baronio, Guglielmo Sirleto und Fulvio Orsini als Programmentwerfer vorgeschlagen. ${ }^{771}$ Bis zur dokumentierten Zahlung seiner monatlichen sechs scudi im selben Jahr als das Programm für den Korridor im Belvedere entworfen wurde, konnte Baronio seine Annales Ecclesiastici noch keineswegs soweit fertiggestellt haben, wie sie zehn Jahre später im Druck erschienen. Zudem ist es unwahrscheinlich, dass dem seit 1578 in der Vallicelliana weilenden Oratorianer ein Auftrag übergeben wurde, der für die Ausstattung eines noch päpstlich-privaten Korridors innerhalb des Palazzo Apostolico gedacht war. Beim bildprogrammatischen Entwurf für die Sala delle Carte Geografiche muss es sich um eine Zusammenarbeit von Kurienprälaten gehandelt haben, die sich um den Papstneffen und Kardinal Filippo Guastavillani scharten. Der Kardinal Guastavillani wird nämlich im aufgeführten Zahlungsbeleg vom 5. Juli 1578 genannt. $^{772}$

Die Stellung, welche die Galleria delle Carte Geografiche im Palazzo Apostolico einnahm, lässt sich am deutlichsten aus der Beschreibung des Zeremonienmeisters Francesco Mucanzio, der den Korridor als ein deambulatorium bezeichnet, ableiten.

771 Fiorani 2005, S. 184-186; Schütte 1993, S. 16-18; Milanesi 1994, S. 117; Cheney 1989, S. 34; Pinelli 1994, S. 152-153; Watts 2005, S. 174; Götze 2009, S. 376. Für die Rekonstruktion der beteiligten Künstlerwerkstatt an der Ausführung des Gewölbeprogramms vgl. einerseits die memoria aus BAV, Bonc. D.5, f. 240v sowie andererseits dann Borghini, Il Riposo, S. 577; Mancini, Considerazioni sulla pittura, I, S. 280 und Baglione, Vite, I, S. 51, 116. Wie Pinelli 1994, S. 136-140 anhand einiger Entwurfszeichnungen Cesare Nebbias nachweisen konnte, kann dieser als eigentlicher Verantwortlicher für die Ausführung der Fresken betrachtet werden, während Girolamo Muziano für das dekorative Rahmensystem sowie die narrative Gestaltung der einzelnen Bilderzyklen zuständig gewesen sein muss. Zur Problematik der Identifizierung der einzelnen Maler vgl. auch Fiorani 2005, S. 176-181.

772 ASR, Camerale I, Tesoreria Segreta, b. 1306, f. 9r: „Al dì 5 lug.o 20 m.ta di mente N.S. e ordine del Ill.mo Car.le Guastavillano pagati a Ottaviano Mascarino pittore Bol.e al quale si sono pagati scudi 20 ciascheduno messe come per mandato quale firmato di N.S. questo dì." In seiner Relazone della corte di Roma von 1574 bezeichnete ihn Fabio Albergati als denjenigen Kardinal, der „in atto ad esser proposto a tutte le facende et negotii importanti“" war. Zit. n. Pastor 1893-1933, Bd. 9, S. 871. Ein weiterer Discorso sopra la corte di Roma, den Albergati für Filippo Boncompagni ebenfalls 1574 verfasst haben musste, befindet sich in BAV, Vat. lat. 9435, f. 57r-109v. Zum Kardinal Guastavillani, der bereits in der Sala Bologna in der Szene der Übergabe der Dekretalien Gregors IX. porträtiert wurde, vgl. DBI 2003, Bd. 60, S. 489-493. 1575 wurde er zum Protektor des Ordens der Ritter von Malta ernannt und 1578 hatte ihn der Boncompagni-Papst zum Protektor des Franziskanerordens nominiert. Vgl. diesbezüglich. Maffei, Degli Annali, I, S. 97 und das Dokument in Biblioteca Comunale dell'Archiginnasio di Bologna, Gozzadini 279, fasc. 41 (Rubbini 2001, S. 43). Guastavillani war ebenfalls an der Reform des neuen Kalendarium Romanum beteiligt, wie dies sein Briefschreiben vom 17. September 1580 an Sirleto in BAV, Vat. lat. 6181, f. 57r belegt. 
Sie sollte hauptsächlich als Verbindung zwischen Palast und Belvedere ad privatam animi oblectationem, et frugem, quam ad publicam utilitatem dienen. ${ }^{773}$ Die Galleria schloss damit eine entscheidende Lücke im Verhältnis zwischen Palast und Belvedere. Die Architektur der Sala delle Carte Geografiche nahm nämlich die im BoncompagniPontifikat stark verankerte villegiatura auf und schrieb sie in die architektonische Ordnung des Palazzo Apostolico ein. Am Bildprogramm der Galleria lässt sich daher neben der Beantwortung der Frage, wie die Sakramentsverwaltung kirchenhistoriographisch zu erzählen sei, auch ein Einfluss, den die villegiatura auf das Vokabular römischer Bildrhetorik im Palazzo Apostolico ausübte, ableiten. Die Bedeutung der Galleria als Verbindungskorridor zwischen Palast und Belvedere wurde nach deren Fertigstellung sowohl in Giovanni Battista Stellas Ambulatio Gregoriana als auch in weiteren panegyrischen Beschreibungen betont: Während nämlich der südliche Eingang die Besucher willkommen hiess, blieb ihnen der gegenüberliegende Eingangsbereich versperrt, da sich in diesem die Privatgemächer des Papstes befanden. ${ }^{774}$ In dem für die Galleria entworfenen Bildprogramm liess sich dieser besondere Schwellencharakter einer Verbindung zwischen Palast und Belvedere mit einem Korridor nur dadurch gewährleisten, dass man in das Bildprogramm dekorative Merkmale integrierte, die gemeinhin aus dem Bildvokabular stammten, das für repräsentative Räume des Rückzugs eingesetzt wurde. Die Herausforderung für die in der Galleria delle Carte Geografiche tätige Malerwerkstatt lag somit darin, dass sie eine Bildsprache zu entwerfen hatte, in welcher der Rückzugscharakter nicht vollständig von den zeremoniellen Bedingungen des Palazzo Apostolico zu trennen war. Das Bildprogramm war wiederum vom Kurienzeremoniell abhängig.

Ähnlich wie im Falle der Dekoration der Sala Bologna, in deren Ausgestaltung die Thematik des buon governo im Zusammenhang mit der kirchlichen Diözesanverwaltung Bolognas einfloss, musste die Galleria delle Carte Geografiche in ihrer Bedeutung als Verbindungskorridor einen Bildergang erzeugen, durch den ein kirchenhistorischer Weg der Ecclesia Romana und ihrer Sakramentsverwaltung ersichtlich werden sollte. Diese Entwicklung sollte sich dem Betrachter besonders auf dem Weg durch die Galleria vom südlichen Eingang bis zur nördlichen Stirnwand als Bildnarrativ enthüllen. Die Villenausstattung, die seitens des Papstneffen Filippo Guastavillani unternommen wurde, beeinflusste die in der Galleria tätige Malerwerkstatt. Unmittelbar nachdem Guastavillani zum Kardinal ernannt wurde, beauftragte er Mascarino mit dem Bau seiner Villa in Barbiano, die zwischen 1577 und 1581 ausgemalt wurde. In diesen Zeitraum fällt auch die Ausführung des Bildprogramms für das Gewölbe der

773 BAV, Bonc.C.6, f. 343r-v.

774 BAV, Bonc.D.8, f. 153r-156r: [...] (Q)uam altera vulgo/ Invia, sacra sui reserat penetralia Regia. Auch zit. in Ferri 1994, S. 73-81, Z. 65-69. Die Ambulatio kann über ASV, Fondo Boncompagni, Indice, VII, f. 30v an Giovanni Stella zugeschrieben werden. Vgl. diesbez. auch Fiorani 2005, S. 173. Zwei weitere Beschreibungen in BAV, Bonc.D.46, f. 97r-115v (De Gregorij XIII Beneficentia Panegiricus) und in BAV, Bonc.D.5, f. 312r-313r (Beatissimus Pater) halten dasselbe Verhältnis fest. 
Galleria delle Carte Geografiche. ${ }^{775}$ Die Villa Guastavillani steht für den sozialen Erfolg, den der Papstneffe Gregors XIII. innerhalb der Kurie ab seiner Kardinalswahl verbuchen konnte und den er eifrig in der bildprogrammatischen Innenausstattung zum Ausdruck bringen wollte. Obwohl Guastavillani ähnlich wie der Kardinal von San Sisto Filippo Boncompagni bei seinem Eintritt in das Kardinalskollegium keine Sonderstellung innerhalb der Kurie besass, wurde er nichtsdestotrotz 1577 in jene Kommission einberufen, die sich mit der Frage beschäftigte, ob für die Herstellung des Friedens in den Spanischen Niederlanden ein päpstlicher Legat entsandt werden sollte. ${ }^{776}$

Sowohl für die Empfangsräume als auch für die Privatgemächer des Kardinalnepoten in seiner Villa auf der Barbiano-Höhe wurde ein Bildprogramm ausgeführt, das sich erstmals in einem Durchlauf zu einem einheitlichen Narrativ organisch zusammensetzte. Dabei nahmen sowohl die Sala del Cardinale als auch die Sala dell'Antico Testamento im piano nobile, die an die zentrale Loggia angrenzten, eine besondere Stellung auch im Zusammenhang mit dem Gewölbeprogramm der Galleria delle Carte Giografiche ein. Die Ausmalung der Sala dell' Antico Testamento präsentiert einen Fries von Episoden, die dem Alten Testament entlehnt wurden und die eine allegorische Exegese der Taten biblischer Figuren dem Betrachter vor Augen führt. Moses, Isaak, Jakob und Jonas werden als biblische Helden in ihrem Gehorsam gegenüber dem göttlichen Willen dargestellt. Ihre Handlungen finden inmitten einer idyllischen Landschaftsszenerie statt. Der zyklische Parcours in diesem Raum umkreist die über der Kaminanlage angebrachte Szene der Verbrennung häretischer Bücher, welche mit der Inschrift FERRO NON PUDIAS auf die Verbrennung ketzerischer Bücher als notwendigen Reinigungsakt verweist (Abb. 35). ${ }^{777}$ Die zent-

$775 \mathrm{Zu}$ den Plänen Mascarinos aus ASL, Fondo Mascarino, N. 2526-2533 für die Villa Guastavillani vgl. Matteucci Armandi 2001, S. 63-75; Wasserman 1966, S. 169-171; Scannavini 1998, S. 257-268. Als besonderes Vorbild für die Villenanlage des Kardinalnepoten Guastavillani diente die zwischen 1573 und 1575 erbaute Villa Mondragone des Kardinals Marcus Sittichus von Hohenems, wo sich sowohl der Boncompagni-Papst als auch Guastavillani selbst regelmässig im Herbst und Sommer aufhielten. Vgl. diesbez. die entsprechenden avvisi in BAV, Urb. lat. 1044, f. 300r, 443r; BAV, Urb. lat. 1046, f. 176r. Im Gegensatz zur Villa Mondragone war die Villa Guastavillani keineswegs eine für die Papstresidenz gedachte Architektur, da sie keinerlei Merkmale der Hybridität aufweist, die auf die Struktur des früheren Palazzo Apostolico zurückzuführen sind. Das prominentestes Beispiel bez. solcher Hybridformen der Villenarchitektur stellt Bartolomeo Ammanatis Villa Giulia dar. Vgl. hierzu Coffin 1979, S. 150; Azzi Visentini 1997, S. 159.

776 Maffei, Degli Annali di Gregorio XIII, I, S. 267: „Ma il Papa vedendo le cose precipitate di male in peggio, per non lasciare prova intentava vi fece fare sopra una Congregazione di sette Cardinali Morone, Como, Granvela, Sforza, Orsino, Madruccio, e Guastavillani, i quali considerate e deplorate insieme tante calamità risolverono, che si ritornasse a mandare in Fiandra personaggio d'importanza, il quale a nome di Gregorio colla compagnia de' medesimi, o di altri Commissari dell'Imperadore trattasse di nuovo la composizione, rimuovendo le difficoltà dove si trovassero.“ Vgl. dazu insbes. Pastor 1893-1933, Bd. 9, S. 416.

777 Baldini 1984, S. 22-23 berücksichtigte diese Szene noch als eine allegorische „Erfindung des Feuers“. Vgl. auch Winkelmann 1987, S. 658 und Righini 2001, S. 112. Eine Beschreibung dieser Szene hat 
rale Szene tritt somit bildsprachlich in einen Dialog mit dem Fresko in der Sala del Cardinale, das ebenfalls über dem Kamin angebracht wurde und den Heiligen Eligius inmitten der Beredsamkeit und Notwendigkeit präsentiert (Abb. 36). Die beiden Räume treten ebenfalls über ihre malerische Innenausstattung in einen Dialog: drei Figuren und ihrer sind im letztgenannten Fresko über der Inschrift PLVS SVPREMA VIRTUS angebracht. Diese Figurengruppe verweist auf das allegorische Tripel der suprema virtus. Im Zentrum der Bildkomposition wird eine Feuerflamme - der fuego revolto - gezeigt, die der heilige Eligius mit derselben Gestik, welche die Personifikation der Necessitas besitzt, segnet. Dieses ikonographische Merkmal wurde im Zusammenhang mit den Bemühungen des Kardinals Guastavillani, den Frieden in den Spanischen Niederlanden mittels der Einführung eines spanischen Inquisitionstribunals wiederherzustellen, interpretiert. ${ }^{778}$

Diese Deutung stimmt aber nicht mit den kurialen Arbeiten zur Beendigung der Wirren in den Niederlanden überein. Der besondere Stellenwert, der der Flamme und damit dem Feuerelement im Bildprogramm der Villa Guastavillani zugeschrieben wird, kann als Resultat der Arbeiten der Kardinalskommission, die am 30. Juli 1578 eine Papstbulle entwarf, betrachtet werden. Ein avviso vom 9. August desselben Jahres berichtet, dass der Boncompagni-Papst damit sowohl ein allgemeines Jubeljahr für Rom verkündete als auch Prozessionen und Gebete für die quarant'ore anordnete:

Gozzadini, Una scorsa a Barbiano, S. 24 nach seiner „piacevole giornata“ in Barbiano hinterlassen: „Più ricca è la composizione dell'ultima pittura. Un giovine genuflesso con verga di ferro attizza il fuoco d'alcuni pezzi di legno accatastati, se pur non vi pone la verga a fine d'arroventirla. Presso quelle fiamme veggonsi una testa di giovinetto, ed un'altra di vecchio, che mostrano d'attentamente osservare. Due figure indietro si danno a rapida fuga, ed altre si stanno spettatrici. Nel fondo architettura alla tibaldesca. Quivi alcune teste son molto belle, e vi si ammira del pari quel largo stile che spicca negli altri due affreschi.“

778 Righini 2000, S. 110. Vgl. zur ikonologischen Auslegung des fuego revolto dann Cecchini 1976, S. 459 sowie Cairo 1979, S. 132: „Per contrario la fiamma capovolta si dipingeva sugli abiti di penitenza dei relapsi, del Tribunale dell'Inquisizione di Spagna (fuego revolto), a indicare dannazione.“ Für eine ikonographische Beschreibung vgl. Gozzadini, Una scorsa a Barbiano, S. 23, der die Feuerflamme gänzlich ausser Acht lässt: „In altro affresco vedi a sedere sotto un arco un vecchio che allunga il destro braccio verso lo spettatore. Ed ha la sinistra armata di martello: a dritta gli sta una donna che il garda, accenna in alto, tiene nella manca un libro, ed altro, pur chiuso, preme col destro piè. Dall'opposta parte è una vecchia che la parola volge al vegliardo, ed ha allato la conocchia, e'l fuso. Queste figure più alte del vero sono grandiose, e benissimo pennelleggiate: quella specialmente tutta neda del vecchio è grandiosamente delineata, ha una testa di carattere grave [...].“ Tatsächlich hatte der Nuntius Bartolomeo Portia die Überzeugung gewonnen, dass nur der Einsatz von Waffen die Ordnung in den Niederlanden wiederherzustellen vermöge. Vgl. hierzu $N B D$, I, S. 205, 214, 255. Die Bekämpfung der Aufstände richtete sich auch gegen die römischen Justizbehörden in den Spanischen Niederlanden, wie es ein avviso in BAV, Urb. lat. 1045, f. $524 \mathrm{v}$ festhielt. 


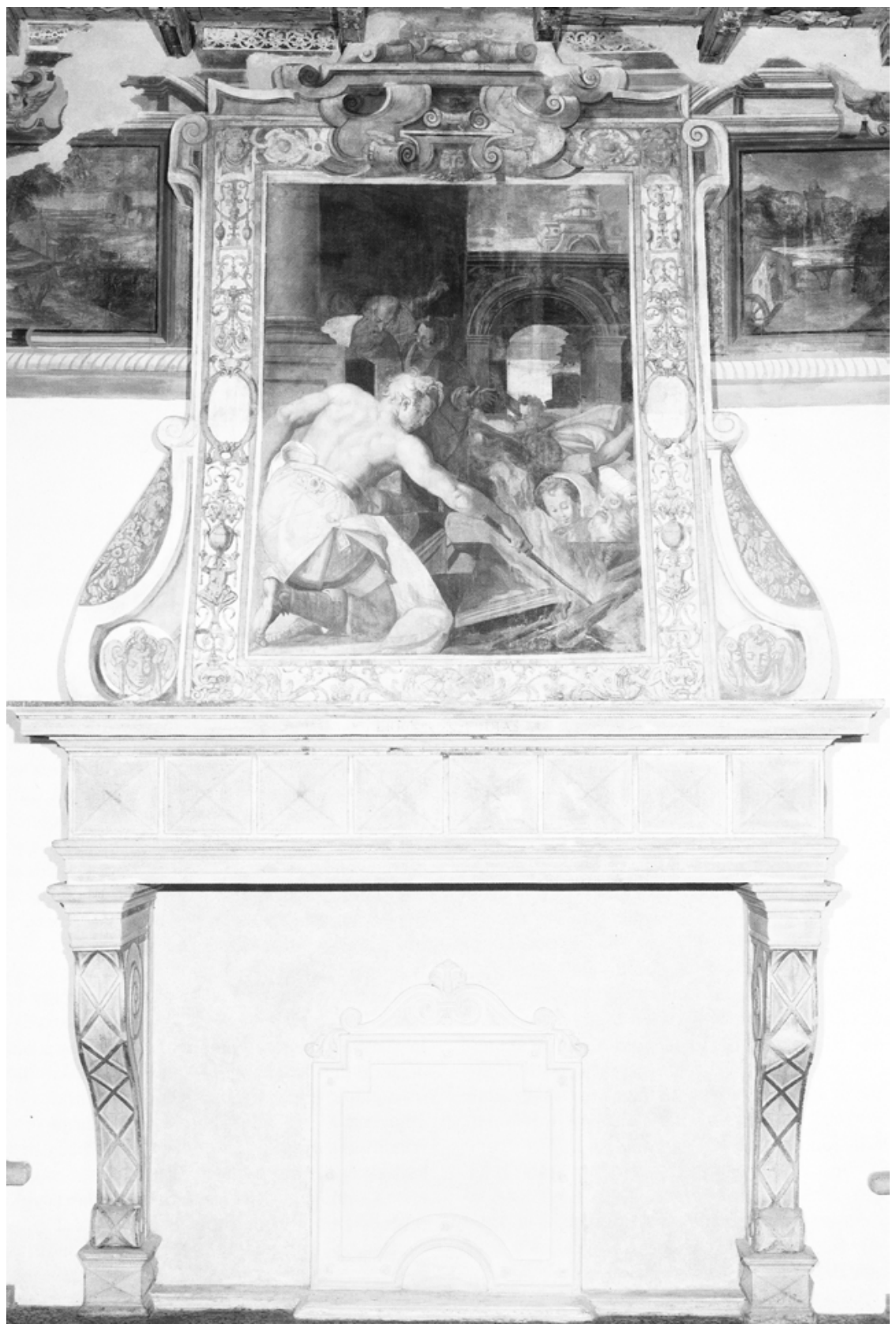

Abb. 35: Cesare Baglione (zugeschr.), Die Verbrennung der häretischen Bücher, Fresko, 1576-1578, Sala dell'Antico Testamento, Villa Guastavillani, Barbiano. 


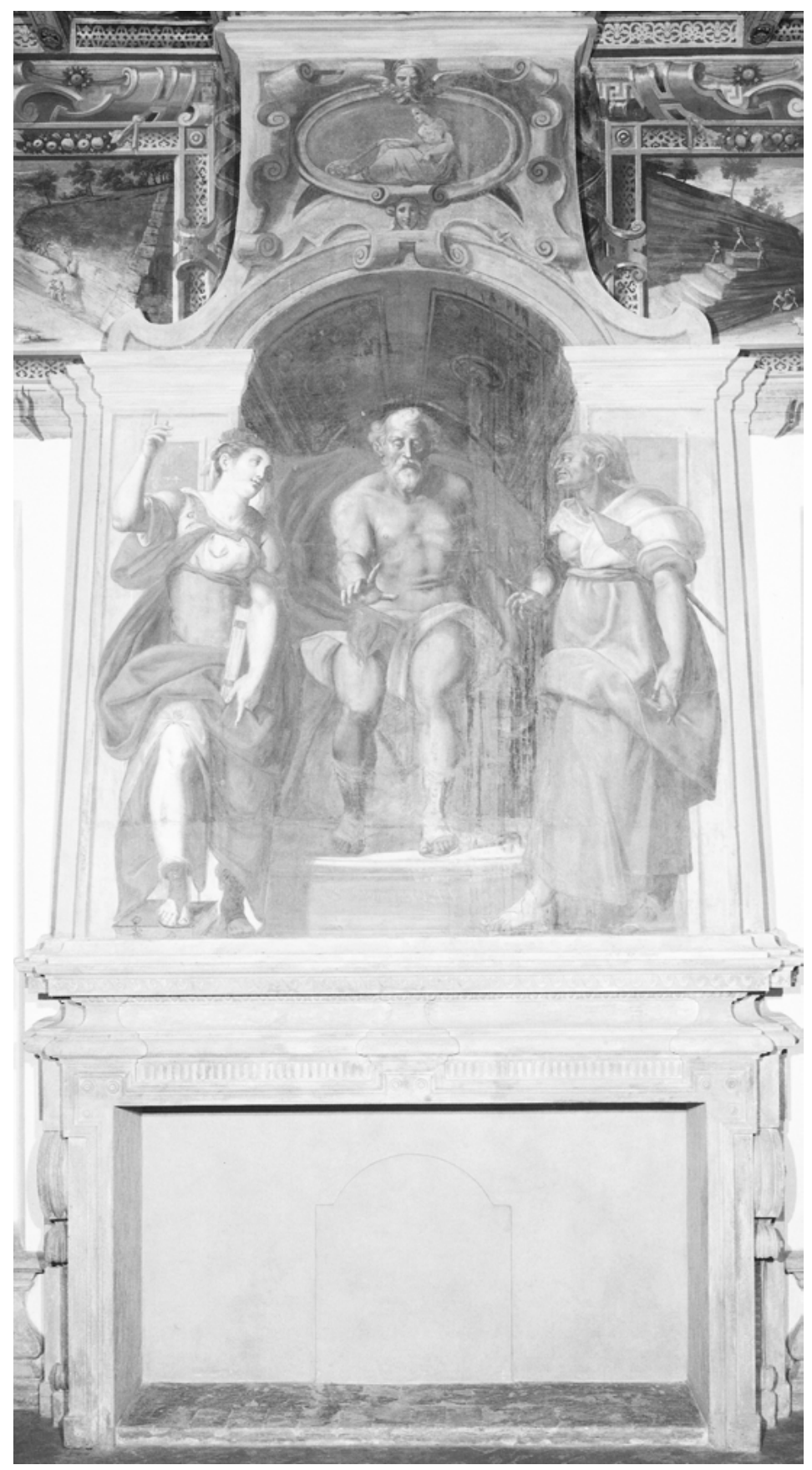

Abb. 36: Cesare Baglione (zugeschr.), Der Heiligen Eligius inmitten der Beredsamkeit und Notwendigkeit, Fresko, 1576-1578, Sala del Cardinale, Villa Guastavillani, Barbiano. 
Sabbato passato il Papa fece publicare et affegere per Roma il S.mo et Plenario Giubileo in stampa promosso nel Conc.ro passato per la per la questione di Fiandra, il quale si mandera per tutta la Christianità et qua si era comminciato a pigliare all'essempio di S.D.ne la quale [...] hoggi in san Pietro et feceli altari con grandissima divotione, faceva per tutto Processioni, et orationi delle quarant'hore dalle Confraternità, con essersi aperto il Crocifisso benedetto di san Marcello con molto concorrenza del Popolo. ${ }^{779}$

Rom nahm damit die Zentralstellung des Christianum Orbis ein, von wo aus sich die göttliche Barmherzigkeit auf die übrigen Erdteile - und damit auch auf die Spanischen Niederlanden - ausbreiten sollte. Die Kardinalskommission, der auch Filippo Guastavillani angehörte, vertrat die Überzeugung, dass die fidei catholice defensione in der „wahrhaften“ (vere) Ehrerbietung gegenüber der Eucharistie begründet sei. Die Verwaltung der übrigen Sakramente - allen voran die der Busse und der Taufe - war daher in einen engen Bezug zur eucharistischen Andacht gebracht worden. ${ }^{780}$ Die Feuerflamme, welche der heilige Eligius in der Sala del Cardinale der Villa Guastavillani vor den Augen des Betrachters segnet, stellt daher eine bildrhetorische Umwandlung des zentralen Stellenwerts dar, den das Eucharistiesakrament während der Friedensverhandlungen in den Spanischen Niederlanden einnahm. Mit der Spende dieses Sakramentes, dessen Verwaltung mit einer in Prozessionen sichtbar hervortretenden Andachtspraxis verknüpft wurde, sollten die relapsi in die römische Kirche wieder aufgenommen werden. Die reinigende Kraft des brennenden fuego revolto leitete sich theologisch aus dem heilsversprechenden Potential der Eucharistie ab. Diese Heilswirkung des Eucharistiesakraments, die sich aus dem zyklischen Durchlauf des Bildprogramms in der der Sala dell'Antico Testamento ergab, konnte entweder als direkte Einwirkung Gottes oder als ein auf die übrigen Erdteile vermitteltes Heil, dessen Quelle in Rom lag, interpretiert werden. ${ }^{781}$ Das Dekorationsschema der Villa Guastavillani stellt somit

779 BAV, Urb. lat. 1046, f. $289 r$.

780 ASV, Misc. Arm. VIII, 5, f. 11r-13r, hier f. 11v: Quare ex parte omnipotentis Dei omnes utriusque sexus Christifideles tam in Alma Urbe nostra quam in ceteris dicti christiani orbis partibus quo maiore possumus charitatis affectu requirimus, ut in Urbe videlicet, prima vel secunda hebdomada post primam dominicam procimi mensis augusti [...] ad Dominum, qui, cum iratus est, misericordiam facit et in tempore tribulationis peccata dimittit invocantibus eum, humili et contrito cordo ses convertant, et in utravis predictarum hebdomadarum confessori idoneo, ab ordinario approbato, peccata sua confiteantur ac quarta et sexta feriis necnon die sabati ieiunent, orationes devote habeant et elemosinas, qui illas dare potuerint, Christi pauperibus iuxta uniuscuisque devotionem erogent, demum proximo die dominico vere penitentes et confessi sanctissimum Eucharistiae Sacramentum omni reverentia suscipiant precesque pro fidei catholice defensione illiusque propugnatorum in dicto maxime bello prosperitate, impiorum atque hereticorum depressione, principum christianorum pace et populorum tranquilitate fundant. Sowohl der anonyme Discorso als auch die Relatione delli stati et governo di Fiandra aus BAV, Vat. lat. 7080, f. 230r-275v, resp. f. 212r-229v könnten diesbezüglich ebenfalls als Zeugnisse der Arbeiten der Kardinalskommission betrachtet werden.

781 Cesare Baglione hatte bereits in der Sala Davide des Palazzo Barbazzi in Bologna einen ähnlichen Friesaufbau dargestellt, weshalb es nicht unwahrscheinlich wäre, dass Guastavillani densel- 
ein anspruchsvolles Bildprogramm dessen, was die Kardinalskommission für die Wiederherstellung des Friedens in den Spanischen Niederlanden zu bewerkstelligen versuchte, dar. Die Figur des Heiligen Eligius in der Sala del Cardinale, der als Schutzpatron der Goldschmiede- und Hufschmiedezünfte gilt, verweist allegorisch darauf, dass ein Friede erst mit dem Eindringen der heilsspendenden Kraft der Eucharistie auch in die sozialen Schichten der Zünfte und Handwerker wiederhergestellt werden konnte. ${ }^{782}$

Im Zusammenhang mit der Ausstattung des Palazzo Apostolico und seines Verbindungskorridors zeigt die Bildprogrammatik in der Villa Guastavillani exemplarisch, wie die Heilswirkung der kurialen Sakramentsverwaltung bildsprachlich dafür eingesetzt werden konnte, das Sakrament der Eucharistie als Höhepunkt in einem sakramentalen Durchlauf der Kirchengeschichte zu offenbaren. Das Boncompagni-Pontifikat Gregors XIII. hatte bei den zeremoniellen Vorbereitungen zum anno santo den Vorrang der Eucharistie gegenüber den anderen Sakramenten erfolgreich demonstrieren können. Diese Suprematie der Eucharistie gegenüber den übrigen Sakramenten war auch eine wichtige Voraussetzung, um das Kurienzeremoniell ausserhalb des Palazzo Apostolico in den römischen Stadtraum hinaustragen zu können. Diese sakramentale Suprematie wurde in der Galleria delle Carte Geografiche des Palazzo Apostolico mit einer über der südlichen Stirnwand angebrachten Anamorphose inszeniert, die heute als verschollen gilt. Sie findet aber eine Erwähnung in Jean Tardes Erzählung über seinen Besuch der Galleria:

[...] nous avons vu [...] la galérie grégorienne, au bout de laquelle est un miroir qui réprésente un calice ave l'hostie, prenant telle image d'un tableau qui est audessous, sans que telle peinture y soit, mais c'est par un artifice de perspective. ${ }^{783}$

ben Baglione für die Ausmalung seiner eigenen Villa auf dem Barbiano beauftragt haben könnte. Zu Bagliones Fries im Palazzo Barbazzi vgl. Nunes 2017, S. 73-82; eadem 2013, S. 311-336; Boschloo 1984, S. 88-89. Die fundamentale Bedeutung der heilsspenden Kraft der Sakramente im Bildprogramm der Villa Guastavillani wäre ebenfalls mit dem Fresko über dem Kamin in der Sala dell'Udienza rechts neben dem Eingang im Erdgeschoss unterstrichen, bei dem es sich um Betseba im Bad nach Sam 11, 2-17 handeln könnte. Vgl. hierzu Armenini, Dei veri precetti della pittura, S. 201 sowie eine mögliche Exegese in Ambrosius, Apologia Prophetae David, III, 14: Quid igitur obstat quominus etiam Bethsabee sancto David in figura sociata fuisse credatur; ut significaretur congregatio nationum, quae non erat Christo legitimo quodam fidei copulata conubio [...] in qua nuda mentis sinceritas, et aperta simplicitas lavacri justificante mysterio, veri David et regis aeterni mentem traduceret, lacesseret charitatem?. Zit. n. PL, Bd. 14, Sp. 898.

782 Hall 1983, S. 281; BS, S. 1069-1074. Die Bedeutung der Zünfte für den Aufstieg der Calvinisten in den Spanischen Niederlanden zeigt sich durch die nach 1576 steigende Zahl an Ratssitzen, welche die Calvinisten mit Unterstützung der Zünfte in einzelnen Städten für sich zu beanspruchen begannen: Pollmann 2011, S. 107-111.

783 Tarde, A la rencontre de Galilée, S. 40. Diese Anamorphose dürfte denjenigen Besuchern, denen Gregor XIII. das Privileg erteilte, sich mit ihm in der Galleria unterhalten zu dürfen, nicht entgangen sein. Vgl. hierzu bspw. das avviso vom 23. Dezember 1583, welches den Besuch des Hochmeisters des Malteser Ritterordens aufzeichnete, in BAV, Urb. lat. 1049, f. 472r. Vgl. auch die 
Bislang blieb innerhalb der Forschung die Frage, welchem Dekorationssystem die Ausmalung des Gewölbes der Galleria delle Carte Geografiche folgte, unbeantwortet. Stattdessen bildete die Frage, inwieweit das Gewölbeprogramm mit einer bestimmten chronologischen Abfolge übereinstimmte, den Schwerpunkt der bisherigen Untersuchungen. Dabei wurde irrtümlicherweise vermutet, dass Cesare Baronio am programmatischen Bildentwurf beteiligt war. Der Freskenschmuck des Gewölbes in der Galleria zeigt aber vielmehr einen Prototyp dessen, was der Oratorianer Baronio mit seinen fast zehn Jahre später gedruckten Annales Ecclesiastici ebenfalls eindrücklich festhalten sollte, und zwar eine deutliche Rangordnung der Sakramente, die sich aus der historiographischen Entwicklung der Ecclesia Romana im Zusammenhang mit ihren Verwaltungspraktiken der Sakramente ableiten liess. In dieser sakramentalen Entwicklung der Kirche wurde dem Sakrament der Eucharistie die Suprematie über alle anderen Sakramente zugesprochen. Bereits die Konzilsväter in Trient hatten der Eucharistie wegen ihrer besonderen Identität mit dem Kreuzes- und Messopfertod Christi diese Herrschaftsgewalt über die anderen Sakramente zugesprochen. Kirchenhistoriographisch betrachtet bildete dieses Sakrament daher den Ursprung der gesamten Sakramentsverwaltung, über die zuerst die Apostel nach dem Kreuzestod Christi und dann später die römische Kurie verfügten. ${ }^{784}$

Die Galleria delle Carte Geografiche stellt einen besonderen Bezug zwischen Kartographie und kirchenhistoriographischer Szenenauswahl hinsichtlich der Konzipierung ihres Gewölbeprogramms her. Deren Mittelfelder wurden als scheinbare

Stelle in Lassels, Voyage of Italy, S. 39: „At first looking upon it, you see nothing but certain types or Figures of the Blessed Sacrament out of the Old Testament, but being placed directly under it, and looking upwards, you see all the foresaid Types and Shadows, prefiguring only the Body and Blood of our Saviour, in the holy sacrifice of the Altar." Danti hatte sich in seinem 1583 herausgegebenen Kommentar zu Vignolas Le due regole della prospettiva eingehend mit der geometrischen Konstruktion solcher Anamorphosen nicht nur auseinandergesetzt, sondern hatte selbst auch solche geschaffen, von denen eine dem Bildnis Gregors XIII. gewidmet war. Vgl. Vignola/Danti, Le due regole, S. 94-95.

784 Ann. Ecc., I, S. 160: Sed unde hoc illi, nisi a suis ipsorum patribus, Apostolis Domini, \& illi a Christo, id facere didicissent? Sed in his non immoramur [...] quibus nominibus maiores nostri consueverint sacram Eucharistiam nuncupare, quo ex ipsis nominibus, tanta res facilius congnoscatur, adducamus in medium. In primis, habito respectu ad fideles, qui eam accipientes Christo per omnia maxime uniuntur, eodem nomine, quo nos in praesentiarum utimur, Communionem seu Communicationem ab Apostolis illam esse dictam, fidem facit Paulus Apostolus, dum ad Corinthios scribens, haec ait: 'Calix benedictionis, cui benedicimus, nonne communicatio sanguinis Christi est?' (1 Kor 10, 16) Lucas item in Actis: 'Erant, inquit, perseverantes in doctrina Apostolorum, \& communicatione fractionis panis.' (Apg 2, 42) Insuper ob admirabilem ac ineffabilem rerum divinarum secretam quamdam coniunctionem a Graecis Mysterios, a Latinis vero Sacramentum inveniens nominatam, Tertullianus plane Eucharistiae Sacramentum appellat, \& alij post eum. Nomen vero Eucharistiae a gratiarum actione deductum, commune esse reperitur ex aequo Graecis ac pariter Latinis. Für die Stelle aus Tertullians De corona militis vgl. PL, Bd. 2, Sp. 79. 
Intersektion zwischen geographischer Ortslage und kirchenhistorischem Geschehen verwendet und wurden bisher aus dem Blickwinkel der kartographischen Anordnung an den Längswänden ausgelegt. Der weltliche Machtanspruch des Papsttums, auf den sowohl die Längswände der Galleria als auch die vorhin erwähnte Inschrift über dem Nordeingang verweisen, ergab sich vor allem aus dem Dekorationssystem des Gewölbeprogramms. Dieses Bildprogramm bezog sich auf die Verwaltungspraxis der Sakramente als heilsgeschichtliche Infrastruktur des eucharistischen Heilsgeschehens und wurde mit der Hegemonie der potestas papalis zu einer Einheit verbunden. Dieselbe Einheit zwischen einer territorialen Verwaltung und dem kurialen Hegemonieanspruch auf die Sakramentsspende hatte sich zuvor in der Ausmalung der Sala Bologna in nuce auf der Grundlage des Kirchenrechts manifestiert. ${ }^{785}$ Der Kardinalsbischof Gabriele Paleotti hatte in seiner 1578 gedruckten Istruttione anhand einer solchen Einheit ein umfangreiches Programm zur Verwaltung sowohl des bolognesischen contado als auch der Diözesanstadt selbst ausgearbeitet. In Paleottis Programm stellte agricoltura das Sinnbild eines atto governo d'Iddio dar:

\begin{abstract}
Et però i Pedicatori, che hanno la missione loro nelli luoghi della Diocese, dove per l'ordinario sono persone imperite di lettere, et che di continuo stanno occupate nelle fatiche, e lavorieri; devono havere sopra tutto questo giudicio di accommodarsi alla capacità loro, et predicare principalmente non per esercitare se stessi, come fanno molti, et riferire prediche composte ad altro fine; ma solo per giovare loro, et lasciando le cose inutili, et che potriano implicargli la mente, porgeli solo quel cibo, che possono digerire, accompagnandolo con alcuni esempij cavati da gli essercitij loro, che servono non solo à più facile intelligenza d'essi; mà ancora in gran maniera alla prattica della vita quotidiana [...]. Che sì come un terreno horrido, et incolto con l'industria, et diligente coltura diviene fruttifero, così con i buoni documenti, et disciplina si corregge la mala natura, et rendersi buona [...]. Che si come dalle biade si levano d'intorno gli spini, et male herbe, che le soffocano, così debbonsi dall'anime nostre fradicare le sconcie parole, et tutti i cattivi pensieri, che impediscono l'augumento nelle virtù [...]..$^{786}$
\end{abstract}

785 Pompeo Vizzani hielt diese hauptsächlich gegen das Banditentum gerichtete und daher notwendige Identität noch 1580 lebhaft aufrecht: „,...] i Cittadini, \& i Contadini tutti occupati a contrastare co' banditi, assassini, \& ladri di Campagna, che in grossissime squadre, sotto diversi capi, che sono indegni d'esser nominati; così di Guelfi, come di Ghibellini, sotto pretesto d'haver gravi inimicitie fra loro infestavano il paese; rubbandolo, assassinando ricchi, \& poveri; uccidendo grandi, \& piccoli; brugiando case, \& ville; taglieggiando i passeggieri, così paesani, come forestieri, \& facendo mille atre ribalderie; alle quali con tutto, che ogni giorno si fosse con essi alle mani; \& che assai volte fosse premiato largamente, chi uccidendogli portava le loro teste à Bologna; \& che le loro case fossero atterrate, saccheggiate, \& abbruggiate, non era però possibile di riparare: onde ne restava tutto il Contado afflitto, \& i Cittadini di mala voglia." Zit. n. Vizani, I due ultimi libri, S. 111.

786 Paleotti, Instruttione, c. 4v-5r. Bologna erwies sich mit diesem Programm der amiglioranza agricolturale sowie mit ihrem Appellativ la grassa als die buchstäblich fruchtbarste aller Diözesen im Kirchenstaat. Vgl. zu diesem seit dem Mittelalter gängigen Topos v. a. Münster, Cosmographie universelle, S. 162; Vizani, Descrittione della città, S. 30-31. 
Gabriele Paleottis Programm findet sich auch bildprogrammatisch in der malerischen Ausgestaltung der Villa Guastavillani mit der Betonung der grundlegenden Bedeutung der Sakramentsverwaltung wieder. Diese Grundlage der sakramentalen Verwaltungspraxis wurde nun auch auf das Gewölbeprogramm in der Galleria delle Carte Geografiche hinsichtlich der Verwaltung des Kirchenstaats durch die Kurie übertragen. Die zentrale Bedeutung, welche dabei der Heimatstadt des Boncompagni-Papstes zukam, wurde wiederum im Gewölbeprogramm der Galleria aufgenommen. Das grosse querrechteckige Feld, das sich in der Mitte des Gewölbescheitels und über der Landkarte der Bononiensis Ditio befindet, zeigt, wie Jesus die Weide der Lämmer (pasce oves meas) an Petrus übergibt. Dieses Bildfeld bildet den Höhepunkt der monochromen, in Ockertönen gehaltenen Opferszenen aus dem Alten Testament. An diesen Missionsbefehl schliessen sich die beiden Wallfahrtsorte von San Michele in Bosco und das Sanktuarium der Madonna di San Luca an. Über den beiden Fenstertüren sind zwei kirchenhistorische Szenen aus den Lebensbeschreibungen der beiden Stadtheiligen Bolognas - Dominikus und Petronius - aufgetragen. Es ist wahrscheinlich, dass bereits unter dem Boncompagni-Pontifikat die Szene des Missionsbefehls im Dekorationsprogramm für die Galleria delle Carte Geografiche vorgesehen war, zumal sich Gregor XIII. selbst bei seiner ersten Ernennung der neuen Kardinäle im Jahr 1572 ausdrücklich auf den Missionsauftrag aus dem Johannesevangelium bezogen haben musste (Jh 21, 15). ${ }^{787}$ Ähnlich wie die Längswände des Korridors, die eine Reihenfolge der Landschaften Italiens östlich und westlich des Apennins von Süden nach Norden anordnen, entfaltet sich der Zyklus der alttestamentlichen Szenen im Gewölbe aus den Büchern Genesis, Exodus und Leviticus in derselben Richtung der Galleria. Den Anfang dieser monochromen Opferszenen bildet das Dankopfer Adams (Abb. 37), auf welches bekannte Opferszenen von Kain und Abel (Gn 4, 3-5), von Noah (Gn 8, 20-21), von Abraham (Gn 22, 10-12), von Jakob (Gn 46, 1) und von Moses (Ex 3, 12) folgen. Den Abschluss dieser Serie, den die hochrechteckigen Bildfelder mit gesprengten Spitzgiebeln am Gewölberand bilden, die sich an die zerteilten Ohrenrahmen im Gewölbescheitel anschliessen, stellen die Darstellungen der Reinigung, des Reinigungsopfers und der Wiederaufnahme eines Leprakranken in die Stadtgemeinschaft dar. Die Szenen beziehen sich auf die Darbringung von Sündenopfern des Hohepriesters aus dem Buch Leviticus.

787 Maffei, Degli Annali di Gregorio XIII, I, S. 20: „[...] Venerabili Fratelli, e Diletti Figliuoli, e questo nuovo manto, che imposto ci avete, porta senza dubbio seco due pesi, l'uno formidabile eziamdio alle spalle degli Angeli stessi, di custori, e di pascere massimamente in tempi tanto pericolosi la universal greggia di Cristo Nostro Signore, l'altro superiore ad ogni umana facondia, di rendere le debite grazie dell'onorato giudizio, che avete fatto di noi.“ Dieses Fresko des Missionsbefehls wurde erst unter Urban VIII. durch Giovanni Francesco Romanelli ausgeführt. Jedoch wirkt es trotz allem als ein markanter Schlussstein der Thematik des Gewölbeprogramms. Zur Restaurierung unter Urban VIII. vgl. insbes. Pollak 1928-1931, Bd. 1, S. 388; Almagià 1952, S. 17-20, 386-387; Schütte 1993, S. 23-24; Franzoni 1994, S. 169-174. 
Bereits die Loggien Julius‘ II. enthielten Darstellungen der Taten Adams, Abels, Kains, Noahs, Abrahams, Jakobs und Moses'. Jedoch scheint ein anderer theologischer Gedanke sowohl für die Auswahl als auch für die Darstellung der Opferszenen in der Galleria delle Carte Geografiche leitend gewesen zu. In den Szenen, die aus den Büchern Genesis und Exodus entnommen wurden, wird der besondere Stellenwert des Altars als eigentlicher Ort, an welchem die Opferhandlugen stattfinden, hervorgehoben. Die letzten Szenen sind dem Buch Leviticus entnommen und stellen die Figur des Hohepriesters erstmals in einer Nachfolge der biblischen Väter Jakob und Moses vor. Diese Szenen der levitischen Opferrituale verweisen auf die Problematik, wie sich in der Darbringung von Sündenopfern aus dem Alten Testament ein biblisches mit einem kirchenhistorischen Verständnis der eucharistischen Heilsverwirklichung verbinden lässt. Die Sequenz der vierzehn Opferszenen in den Gewölberändern beginnt mit der Heranführung des Opferrinds (Abb. 38a) und endet mit der Reinigung eines Leprakranken und seine Wiederaufnahme in die Kirchengemeinde (Abb. 381). Entlang dieser Bilderfolge entfaltet sich eine spezifische Exegese der alttestamentlichen Sündenopfer anhand des Hebräerbriefes, in welchem das Sündenopfer des Hohepriesters als Präfiguration des Kreuzesopfers Christi fungiert. Über den beiden Darstellungen eines Brandopfers und eines Reinigungsbades wird schliesslich die Entstehung des Buss- sowie Taufsakramentes aus dem eucharistischen Opfer dem Betrachter vor Augen geführt. ${ }^{788}$ Die Bildprogrammatik der monochromen Szenen aus dem Alten Testament bestätigt mit dem Sündenopfer des Fürsten (Lv 4, 22-26) die Einsetzung der Sakramente der Taufe sowie der

Busse als Erneuerungsakte des Menschen in der Sündenvergebung. Die beiden Nachbarfelder ergänzen diese Bildformulierung mit den Figuren der Ecclesia und dem Bischof Nikolaus von Bari, die beide Stola und Cingulum tragen. Diese beiden Figuren verweisen somit auf die Verwaltungsmacht der beiden Sakramente seitens der Kirche und des Bischofsamtes. Das Pendant zu dieser Szene auf der linken Gewölbeseite bildet das Sündenopfer des gemeinen Mannes (Lv 4, 27-33) und zeigt ein Paar, wie es ein Schaf oder eine Ziege an den Altar heranführt (Abb. 38g-h). ${ }^{789}$

788 Die Forschung hat sich bislang nur der Auslegung dieser monochromen Ockerreliefs aus der Perspektive der Tridentiner Dekrete zum Messopfer (COD, S. 693-698) gewidmet. Vgl. v. a. Battisti 1999, S. 73-74; Fioriani 2005, S. 218-225; Pinelli 1994, S. 140-143; Cheney 1989, S. 35-36; Watts 2005, S. 191.

789 Die theologische Verknüpfung zwischen dem Sündenopfer und den beiden Sakramenten wird in Lauretus, Silvia Allegoriarum, S. 883-884, hergestellt: Hostia quoque pro peccato, est homo in baptismo \& poenitentia [...] Immolatur autem hostia pro peccato, ubi offertur holocaustum ut noverit homo se sanctificatum esse per peccati remissionem [...]. Die Szene im Gewölbescheitel zwischen dem roten Ohrenrahmen und dem dritten betonten Gewölbefeld zeigt die Versetzung des Hauses der Jungfrau in Loreto und könnte die Beteiligung des Kardinals Guastavillani am Gewölbeprogramm bestätigen. Guastavillani wurde nämlich 1580 zum Kardinalprotektor und governatore dieses Sanktuariums ernannt. Vgl. Serragli, La Santa Casa abbellita, S. 81 und die Inschrift der 
Die alttestamentlichen Szenen betonen in ihrem Bildnarrativ die Theologie des Eucharistiesakraments als Sündenopfer. Nach der Darbringung dieses Opfers am Altar und dem darauffolgenden rituellen Vollzug wird die sakramentale Kraft der Eucharistie auf die beiden weiteren Sakramente der Taufe und der Busse übertragen. Der monochrome Bilderparcours, der sich von Süden nach Norden entlang des Gewölbes der Galleria delle Carte Geografiche entfaltet, beginnt mit der Szene der Heranführung und stellt damit eine besondere Gemeinschaft mit dem Zeremoniell des Fronleichnamsfestes her. Die Übertragung des Sakraments wird als Darbringung des leiblichen Opfers ad ostium Tabernaculi („zum Eingang der Stiftshütte“), wo es „im heiligen Feuer“ (sacris ignibus) geopfert $(\operatorname{Lv} 4,3)$ wird, präsentiert. Die Szene des Brandopfers (Lv 4, 8-10) stellt somit eine Bildlösung dar, die den biblischen Text anhand des Kurienzeremoniells zum Fronleichnamsfest deutet (Abb. 39f). Über dem Altar, wo die Eingeweide des Opferrindes verbrannt werden, steigt ein dichter Rauch auf. An diesem rituellen Vollzug der Opferung sind vier Priester beteilig. Einer von ihnen hält das Herzorgan des Opfertiers über dem Altar. In der Bibelstelle werden aber weder das Herz noch die vier Hohepriester erwähnt. Die Beteiligung dieser vier Priester an der Verwirklichung des liturgisch-sakramentalen Heils kann demgemäss allein auf der Grundlage, die den praelatos assitentes während des für das Fest des Corpus Domini ausgearbeiteten Kurienzeremoniells zukam, erklärt werden. Der Zeremonienmeister Francesco Mucanzio erwähnt in seinem Tagebuch anlässlich des Fronleichnamsfests von 1578, dass zwölf scutifieri zwölf funalia gehalten hätten. Bis zu diesem Zeitpunkt teilten sich vier Kapläne und acht scutifieri diese zwölf Kerzen. ${ }^{790}$ Dem Eintrag des Zeremonienmeisters zufolge wurde im Kurienzeremoniell zu diesem Fronleichnamsfest daher das Augenmerk auf den rituellen Vollzug der sich um das Sakrament konstituierenden Liturgie des incensus gelegt. Mit der „entbrannten Hostie“ wird somit das Mysterium des Wesenswandels Christi und seines leiblichen Körpers anhand der diesem Leib dargebotenen cura schon bei der Prozession nach San Pietro vollzogen. ${ }^{791}$ Das Dekorationssystem im Gewölbe der Galleria delle Carte Geografiche vollzieht daher im Bildnarrativ der alttestamentlichen Szenen aus

Kirchenfassade, die über den beiden Seitentüren angebracht ist und vom Stemma des Kardinals begleitet wird: PHIL. CARD. VASTAVILLANO PROTEC.

790 BAV, Chig.L.II.30, f. 546r: [...] et elevato Sanctiss.mo Sacram.to remanserunt accensa funalia usque ad finem Missae, donec superveniunt Scutiferi Papae duodecim rubeis vestibus induti, totidem funalia accensa tenentes. Sed annis praeterritis fuit aliter factum, nam à principio Cappellani celebrantis quattuor tenerunt octo funalia, quae in fine tradiderunt octo scutiferis.

791 Ibid., f. 547r-v: [...] transacta Scala Regia versus Basilicam S. Petri, et ibi accepit biretum album, et in fine scalarum mitram simplicem auream. Baldachinum fuit delatum primo per Praelatos Assistentes deinde succesimò per alios ordine solito, pro ut vocabantur à quodam scutifero, qui eius rei curam gerebat. Haud scio an omnes officiales venerint, et fuerit ritè servatus ordo pro ut in schedula, seu Rotulo, quia hanc curam reliqui [...] qui dixit omnia benè processisse [...]. Cubicularij quoque secreti volebant incedere post Cantores, quod non permisimus. Cantores verò volebant ire inter Acolithos et Auditores Rotae, et alios officiales cottis, et Rocchettis vestitos, quod etiam prohibimus. 
dem Buch Leviticus diese rituelle Erfüllung und Einsetzung des Sakraments der Eucharistie gemäss den zeremoniellen Vorschriften zum Corpus Domini. Das Kurienzeremoniell zum Fronleichnamsfest stellte daher die Erfüllung dieses in der Eucharistie enthaltenen sakramentalen Heilsversprechens unabhängig von der Abendmahlstheologie dar. Das Bildprogramm im Verbindungskorridor zwischen der Belvedere-Anlage und dem Palazzo Apostolico entfaltet ebenfalls ein Narrativ, welches das Kurienzeremoniell für die Feier des Corpus Domini im Zusammenhang mit der sakramentalen Heilsrealität der Eucharistie aufnahm. Das Dekorationssystem des spassegio für die Galleria verweist demgemäss bewusst auf die kurienzeremoniellen Vorschriften zum Fronleichnamsfest, in deren Festapparat die Sakramentsverwaltung gemäss den kurialen Richtlinien einfloss.

Im Gewölbeprogramm der Galleria delle Carte Geografiche wird der zentrale Stellenwert der Eucharistie bildsprachlich artikuliert. Das Bildprogramm suggeriert sodann wie sich aus der sakramentalen Heilswirkung des allerheiligsten Sakramentes die Verwaltung sowohl der Taufe als auch der Busse ergibt. Das Kurienzeremoniell war in dieser Hinsicht richtungsweisend, denn in der rituellen Ausführung des Wesenswandels des obersten Sakramentes wurde zugleich der Ursprung dieses Mysteriums manifestiert. Die Galleria betonte somit nur das Mysterium der eucharistischen Transsubstantiation. Im Kurienzeremoniell für das Corpus Domini wurde entsprechend die Fürsorge sowie Pflege des Sakramentes ausgestaltet, indem dessen „Schiffshütte“ (tabernaculum) unter einem Baldachin von den $p a$ rafrenarios nach San Pietro getragen wurde. ${ }^{792}$ Dieser besondere Aspekt der Verlegung der Hostie stand im Vordergrund der spezifischen Szenenauswahl für das im Gewölbe verlaufende Bildprogramm. Die Episoden mussten daher in Bezug auf die Erfüllung des sakramentalen Heilsversprechens der Eucharistie ausgewählt worden sein. Die Darstellung des Marschalldienstes Kaiser Konstantins d. Gr., das die Mitte des ersten Gewölbeabschnitts vor dem ersten Gewölbefeld einnimmt, spricht deutlich die ursprüngliche Bedeutung des Kaisers als Stallknecht des römischen Bischofs an. In der darauffolgenden Szene wird ihm der Empfang des Taufsakraments gestattet (Abb. 39a \& 39b). Die kurienzeremoniellen Vorschriften, wie die Eucharistie beim Fest des Corpus Domini angemessen zu verwalten war, boten für das Dekorationssystem der Galleria delle Carte Geografiche einen geeigneten Prototypen dar. Neben Guastavillani konnten sich dadurch auch weitere Mitglieder der Zeremonialkongregation, allen voran die Kardinäle Sirleto und Antonio Carafa, an dessen bildprogrammatischer Umsetzung beteiligen. Die seit 1572 bestehende Zeremonialkongregation wuchs gemäss dem im Zeremonialtagebuch Mucanzios festgehaltenen Eintrag zur Sitzung vom 28. Mai 1577 auf

792 Ibid., f. 547r: „Ibi collocatus in Sede gestatoria, et decenter aptato, et firmato securè tabernaculo cum Sanctiss. corpore Christi super tabella ornata ad id composita serico purpureo cooperta delatus fuit per Parafrenarios adhuc capite detecto usque ad descensum scalarum [...]“. 
neun Kardinäle an. Diesen neun Kardinälen wurde die rituelle Ausarbeitung des Fronleichnamsfestes anvertraut. ${ }^{793}$ Die bildprogrammatische Ausstattung der Galleria delle Carte Geografiche nahm mit ihrem Bildnarrativ im Gewölbe somit eine wichtige Funktion innerhalb des Palazzo Apostolico ein, denn in diesem Bildprogramm wurde das Mysterium der Wesensverwandlung des Leibes Christi im Eucharistiesakrament entsprechend den kurienzeremoniellen Vorschriften zum Corpus Domini vorgestellt und auf die Verwaltungspraxis der übrigen Sakramente ausgeweitet. Das apostolische Gedenken an die Vita Christi, das die sakramentale Verwaltung der Eucharistie im „ungesäuerten Brot“ nach dem Kreuzes- und Messopfertod Christi auch im gemeinsamen Abendmahl der Apostel stets erneuerte, stand somit deutlich im Hintergrund. Die Bildprogrammatik in der Galleria delle Carte Geografiche blendet die Auslegung der Sakramentsverwaltung der Eucharistie in der apostolischen Kommemoration, der sich der Oratorianer Cesare Baronio im ersten Band seiner Annales Ecclesiastici anzunehmen begann, gänzlich aus. Der narrative Bilderparcours im Gewölbe des Verbindungskorridors zeigt keine Episode, in der die Einprägung der Eucharistie im „ungesäuerten Brot“ (azymus panis) dargestellt ist. Die Frage, wie das „ungesäuerte Brot“ angemessen auszulegen sei, blieb allein als kontroverstheologisches Problem offen. Cesare Baronios Annales stellen eine kirchenhistoriographische Lösung vor, indem der Oratorianer diese spezifische Verwaltungspraxis als Fortführung des sacrificium Christi in der apostolischen Einsetzung der Eucharistie betrachtet. ${ }^{794}$

793 BAV, Chig.L.II.30, f. 480v-481r: „Die 28 eiusdem fuit Congregat.o Rev.mos Dominorum Card. lium ad Reformationem caeremoniarum deputatorum de mandato Sanctiss.mi, cui interfuerunt novem Card.les videlicet Farnesius, Sermonetta, Gambara, Ursinus, Sirletus, Estensis, Medices, Sfortia, Caraffa et in ea tractatum de Praecedentia Camerariorum, seu Cubiculariorum extrà muros, sinè extrà Cameram cum Advocatis, et multa hinc inde deducta, aliquibus ex dd. Advocatis causam suam defendentibus. Item an Capitula Ecclesiarum Lateranensis, S. Petri, et S. Mariae Maioris deberent venire in Processione S..mi Corporis Christi proximi cum interventu S. D. N. facienda“. Zwei Schriften Guglielmo Sireltos könnten hierfür möglicherweise als Grundlage für die bevorstehenden Arbeiten gedient haben, nämlich seine De praestantia Basilicae S. Petri Apostoli Vaticanae aus BAV, Barb. lat. 2592, f. 41r-v sowie die an Carlo Borromeo adressierte Abhandlung über Santa Maria Magiore in BAV, Urb. lat. 859, f. 120r-124v. Für eine nähere Untersuchung dieser beiden Schriften Sirletos vgl. F. Malesevic, Holy Family and Sacred Palace. Zur besonderen Rolle Carafas während des Fronleichnamsfestes vgl. die Stelle aus Mucanzios Diarium in BAV, Chig.L.II.30, f. 546v: „[...] et praecedens ante Altare imposuit thus i duo thuribula absque benedictione ministrante Card.li Granvelano primo Praesbitero ex his qui ibi aderant, et genuflexus thurificavit SS.mus Sacram.to triplici ductu, deinde accepto Velo aureo circum circa à collo pendente de manibus Rev.mi D. Card. lis Caraffij tabernaculum cum Sanctiss. Sacramento accepit [...]“.

794 Ann. Ecc., I, S. 160: „Tunc \& Apostoli, quibus Dominus praecepit id ipsum facere in sui memoriam, sacerdotes sunt facti, atque ipsum sacrificium, quod offerrent, est ordinatum. Id Apostoli ipsi, id patres omnes, id traditio Ecclesiastica, ac ipsa Catholica fides ab ipso exordio nascentis Ecclesiae praedicavit, ac hactenus profiteri non definit. Atque ut de his singulis (quod instituti ratio postulat) breviter interea agamus: in huius sacramenti institutione, in primis considerandum est ipsum tempus. Cum enim ipsa prima die Azymorum, decimaquarta luna ad vesperam, cum Pascha secundum legis Moysi ritum ageretur, post esum agni sacra Eucharistia fuerit insti- 
Es ist daher unwahrscheinlich, dass Baronio am Entwurf des Bildprogramms für das Gewölbe der Galleria delle Carte Geografiche beteiligt war. In Baronios Darstellung der Sakramentsverwaltung und dessen Entwicklung in der Frühkirche, die in seinen Annales Ecclesiastici durchaus Gemeinsamkeiten mit dem Dekorationssystem der Galleria zeigt, wurde der rituelle Vollzug der liturgischen Verwaltungspraxis, wie ihn das Kurienzeremoniell vorschrieb, noch nicht beachtet. Das Bildprogramm der Galleria delle Carte Geografiche offenbart aber das Verhältnis zwischen einer kurienzeremoniellen Ausgestaltung der Sakramentsverwaltung und der kirchenhistoriographischen Rekonstruktion derselben anhand kontroverstheologischer Fragen. Der Kirchenhistoriographik fehlten bis zu diesem Zeitpunkt noch die Eigenschaften einer sich an den Massstäben des Kurienzeremoniells orientierten Verwaltungspraxis der Sakramente. Cesare Baronios Annales Ecclesiastici stellen somit eine Werkstatt der kirchenhistoriographischen Rekonstruktion einer Liturgik, die einer solchen Sakramentsverwaltung zu Grunde liegt, dar. Für den Oratorianer stand vornehmlich der rituelle Wandel der sakramentalen Verwaltungspraxis im Zentrum, weshalb er danach seine Kirchenhistorik allmählich an die kurienzeremoniellen Vorschriften zur Sakramentsverwaltung anzupassen begann. Baronio begann sich, wie noch gezeigt werden soll, eine profunde Kenntnis über die rituell vollzogene Erfüllung des sakramentalen Heilsversprechens der Eucharistie im Kurienzeremoniell zu verschaffen. Eine Grundlage dafür bildeten die im Boncompagni-Pontifikat stattgefundenen Reliquientranslationen, auf die ebenfalls im Gewölbeprogramm der Galleria mit den Darstellungen der Zurschaustellung des Turiner Leichentuches, der Überführung der Asche Johannes' des Täufers nach Genua und im Reliquienwunder des Bultes des Heiligen Januarius in Neapel verweisen wird. Allerdings sollte zuerst untersucht werden, wie das Selbstverständnis der Kurie mittels der Sakramentsverwaltung in den weiteren Ausgestaltungskampagnen des Palazzo Apostolico gestiftet wurde. Seit dem Tridentinum stellt dieses mittels der Sakramentsverwaltung erzeugte Selbstverständnis des päpstlichen Herrschaftsapparates im Boncompagni-Pontifikat Gregors XIII. eine in der Geschichte der römischen Kurie einzigartige Erscheinung dar.

\footnotetext{
tuta, nulla est dubitatio, esse confectam in Azymis, \& non in fermentato: quem etiam ritum servatum esse ab Apostolis, ac eorum successoribus, Epiphanius, quantumlibet [...] ipse dicat legitimum Pascha esse a Domino anticipatum, agens contra Ebionaeos haereticos, qui primi fuerunt Apostolorum temporibus (Ebion enim primus post Simonem magnum ab Ignatio recensetur haeresiarcha) testatur sic dicens: 'Mysteria autem faciunt ad imitationem sanctorum in Ecclesia, ab anno in annum per Azymos, hoc est non fermentatos panes.' [...] Si igitur illi ad imitationem sanctorum, in Ecclesia in Azymis Mysteria conficiebant (hoc enim nomine antiqui Eucharistiam nominabant) nulla est dubitatio, maiores omnes eumdem servasse ritum, ut in Azymis eadem Mysteria sacrosancta confecerint. Sed unde hoc illi, nisia a suis ipsorum patribus, Apostolis Domini, \& illi a Christo, id facere didicissent?“
} 


\subsection{Das Pfingstfest als zeremonieller Brennpunkt im Palast}

Der Palazzo Apostolico wurde nach dem zeremoniellen Vollzug des anno santo zunehmend gemeinsam mit dem römischen Stadtraum als Zentrum der heilsgeschichtlichen Erfüllung des christlichen Heilsversprechens inszeniert. Die Kurie nutzte das Jubeljahr 1575 in Bezug auf das Kurienzeremoniell als eine Zeit der heilsamen Erfüllung dieses Heilsversprechens und begann damit, den Apostolischen Palast sowohl gemäss den kurienzeremoniellen Richtlinien als auch anhand der heilsstiftenden Charakteristik des römischen Stadtraumes neu auszugestalten. Einzelne Dekorationsarbeiten im Palast waren vom städtischen Raum beeinflusst, während sich andere - wie die in der Galleria delle Carte Geografiche - ausschliesslich auf die kurienzeremoniellen Vorschriften zur Verwaltung der Sakramente stützten. Zudem stellte die Kurie des Boncompagni-Pontifikats Gregors XIII. mittels dieser Ausgestaltung des Palastes einen Dialog zwischen ihren eigenen Räumen und dem urbanen Stadtraum her. Dieser intensive Dialog, durch den das Kurienzeremoniell in die städtische Gesellschaftskonstellationen eindringen konnte, stellte die Grundlage für eine bildimmanente Stiftung Roms als Roma Sancta und damit als immerwährende Heilslandschaft auf dem Orbs Christianum dar. Die für die kurialen Ausmalungsarbeiten im Palazzo Apostolico tätigen Malerwerkstätten schufen zugleich Bildlösungen, die sich auch für die Ausgestaltung von bruderschaftlichen Oratorien besonders eigneten, wie es der Fall des Oratorio del SS. Crocifisso und der der Cappella del Rosario in Santa Maria sopra Minerva zeigten. Filippo Neris Kongregation des Oratoriums in Santa Maria in Vallicella hatte sich nach ihrer offiziellen Anerkennung ebenfalls in diesen Dialog zwischen Kurie und Roma Sancta einzufügen, um ihr weiteres Bestehen als Priesterversammlung gewährleisten zu können. Damit waren sich die Oratorianer des zentralen Stellenwerts der Bildproduktion für die Stiftung eines spezifischen Rombildes sowie der Bedeutung für ihre Kongregation bewusst.

Auch wenn die Kongregation erst in den 1580er Jahren die Dekoration einzelner Stiftskapellen im Langhaus von Santa Maria in Vallicella in Angriff nehmen sollte, hatte Cesare Nebbia, dem die Leitung über die Ausführung des Gewölbeprogramms in der Galleria delle Carte Geografiche anvertraut wurde, zwischen 1578 und 1579 sowohl eine Anbetung der Könige als auch ein Pfingstwunder für die Oratorianer in der Chiesa Nuova ausgeführt (Abb. 40, 41a \& 41b). ${ }^{795}$ Mit diesen beiden in Ölmalerei

795 ACR, A.V.14, f. 16r. Zur Autorschaft Nebbias vgl. auch Baglione, Vite, I, S. 373. Das Dokument nennt Porzio Ceva, Notar der Camera Apostolica, als den Stifter dieser Cappella dell'Epifania. Letzteres Ölgemälde Nebbias gilt heute als verschollen. 1598 wurde es gegen eines von Wenzel Cobergher ausgetauscht und dem Bildhauer Egidio della Riviera übergeben. Vgl. zu den beiden Tafeln Nebbias Barbieri/Barchiesi/ Ferrara 1995, S. 71-74, 136; Ferrara 1995, S. 109; Barchiesi 1995, S. 137. Die Zeichnung aus der Walker Art Gallery in Liverpool stellte Marciari 2002, S. 126-128 in Verbindung mit der verschollenen Tafel für die Chiesa Nuova. Vgl. auch Eitel-Porter 2004, S. 136. Ein Brief vom 21. Februar 1598, der an Giovanni Matteo Ancina adressiert ist, bezeugt einen noch gänzlich 
ausgeführten Tafeln profilierte sich der bis 1576 im Oratorium der Gonfalone-Bruderschaft tätige Nebbia als zentraler Maler, dem es gelang, die für die zeremonielle Ausgestaltung des Palazzo Apostolico verwendete Bildsprache spezifisch an die Bedingung der heterogenen Bildproduktion im römischen Stadtraum anzupassen. Sowohl die Cappella dell'Epifania in der Chiesa Nuova als auch Cesare Nebbias Fresken im Oratorium von San Marcello al Corso zeigen, wie die Überführung solcher für das kuriale Mäzenatentum verwendeter Bildlösungen in einzelne Bruderschaftsräume stattfand. Das Bildprogramm im Oratorio del SS. Crocifisso präsentiert einen zyklischen Freskenfries, dessen Szenen sich auf die bruderschaftliche Verehrung der in San Marcello al Corso beherbergten Kreuzesreliquie bezieht. ${ }^{796}$ Giovanni de‘ Vecchi, der zu diesem Zeitpunkt auch für die Freskierung der Langhauswände der Cappella del Rosario in Santa Maria sopra Minerva mit Szenen aus dem Leben der heiligen Katharina von Siena beauftragt war, stellte zwischen 1578 und 1579 - also zur selben Zeit als Nebbia sein Ölgemälde für die Chiesa Nuova herstellte - für die rechte Wand des Oratoriums neben der Chorwand ein Fresko der Zerstörung der Idole und die Suche nach dem Kreuz her. Die Darstellung der legendären Kreuzauffindung, mit dem der Freskenzyklus im Oratorio del SS. Crocifisso beginnt, ist weder in der italienischen Altarmalerei noch in der römischen Bildproduktion überliefert. Dieser Freskenschmuck stellt daher erstmals die Aufnahme einer im Breviarium Romanum enthaltenen Legende in die monumentale Wandmalerei dar. Da die Vorsteher der Bruderschaft und nicht wie herkömmlich der Kardinalprotektor derselben die Finanzierung dieses Dekorationsprojektes übernahmen, verzögerte sich die Fertigstellung von de Vecchis zweitem Fresko, das die Auffindung der Kreuze darstellte, um drei Jahre. ${ }^{797}$

Giovanni de‘ Vecchis Szene der Zerstörung der Idole teilt den Bildraum entlang eines zentralperspektivischen Loggienraumes in zwei Bereiche auf. Im Bildvordergrund wird Helena, die Mutter Konstantins d. Gr., gezeigt, wie sie die Zerstörung der heidnischen Kultstätte anordnet. Damit wird die Zerstörungsszene im Bildhintergrund mit der Szene im Vordergrund organisch verbunden. Dieselbe Verbindung nahm das Breviarum Romanum im officium der Kreuzauffindung vorweg, indem es davon berichtet, dass eine Venusstatue von den Heiden am Ort der Kreuzigung

unbeachteten Austausch zwischen Nebbia und der Kongregation: ACR, P.I.14, f. 14v: „[...] la lettera del S.r Cesare Nebia da Orvieto pittore, quale ha fatto le tavole et delli maggi et dello spirito santo in chiesa nostra, desidero che sia fidelmente consegnata“.

796 Nebbia war im Oratorio del SS. Crocifisso in der Werkstatt Girolamo Muzianos tätig, dem neben Tommaso de' Cavalieri die Ausmalung des Oratoriums am 3. Februar 1578 anvertraut wurde: ASV, Arciconfr. SS. Crocifisso in S. Marcello, P.I.58, f. 55r-v. Giovanni de' Vecchi unterzeichnete dann am 11. Juli desselben Jahres den Vertrag für die Ausmalung des Oratoriums. Der Vertrag ist abgedruckt in Henneberg 1974, S. 102-103. Zu Nebbias Anteil an der Ausmalung vgl. Eitel-Porter 2000, S. 613-623.

797 Pierguidi wies bereits darauf hin, dass die Wappen Giangiorgio Cesarinis, damals ein Vorsteher der Bruderschaft, sich auf den rahmenden Lisenen befinden. Vgl. Pierguidi 1999, S. 269. Zur Schwierigkeit der Finanzierung vgl. auch Henneberg 1974, S. 66-67; Heideman 1993, S. 156-157. 


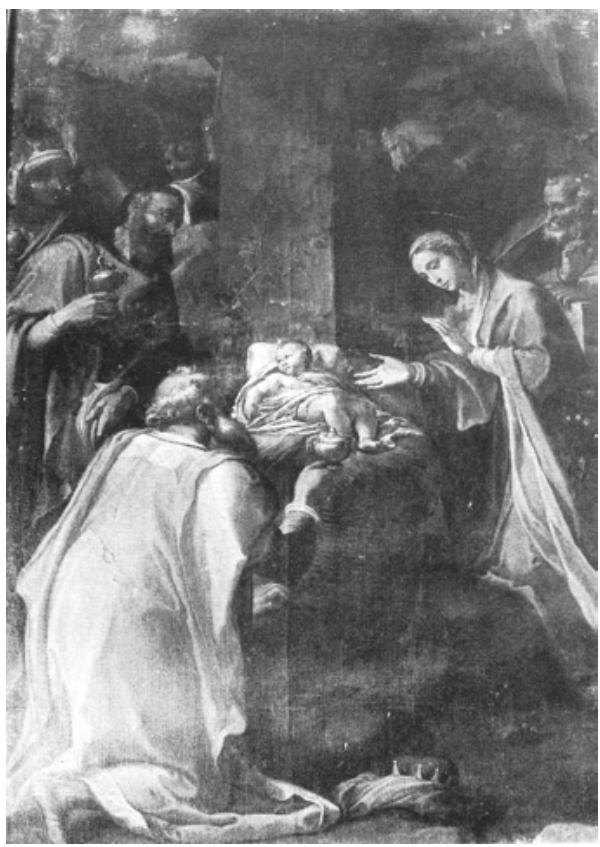

Abb. 40: Cesare Nebbia, Die Anbetung der Könige, Öl auf Leinwand, 1578, Cappella dell'Epifania, Santa Maria in Vallicella (Chiesa Nuova), Rom.

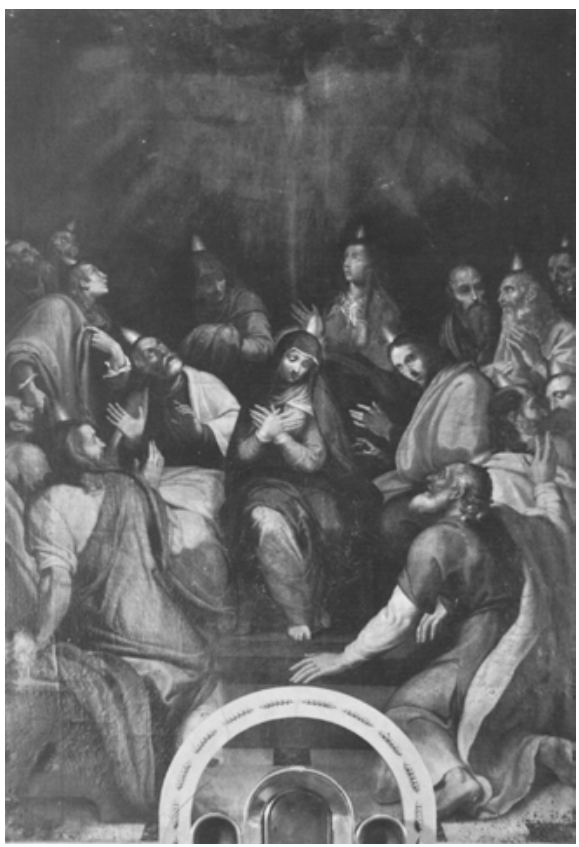

Abb. 41a: Cesare Nebbia, Pfingstwunder, Öl auf Leinwand, 1576, Cappella Oradini, Duomo di Perugia.

Christi aufgestellt wurde. ${ }^{798}$ Das liturgische officium legte die Kreuzesverehrung als eine besondere Form der Reliquienverehrung aus und hob sie als ein Mysterium, in dem das Heil, das Leben und die Wiederauferstehung Christi eingeschrieben sind, hervor. Das Bildprogramm im Oratorio del SS. Crocifisso entfaltet ein Narrativ, das sich aus weiteren liturgischen Momenten im Breviarum zusammensetzt und die

798 Brev. Rom. (MLCT, 3), S. 769: „[...] Helena Constantini mater in somnis admonita, conquirendae crucis studio Hierosolymam venit: ubi marmoream Veneris statuam in crucis loco a Gentibus collocatam ad tollendam Christi domini passionis memoriam, post centum circiter octoginta annos evertendam curavit [...] et in loco resurrectionis, inde Adonidis, hinc Iovis sublato simulacro. Nos autem gloriari oportet in cruce domini nostri Iesu Christi, in quo est salus, vita, \& resurrectio nostra: Per quem salvati, \& liberati sunt“. Daniele da Volterra hatte zwischen 1541 und 1548 in der Cappella Orsini, der Kirche von SS. Trinità dei Monti, im Gewölbe vier Szenen der Kreuzauffindungslegende dargestellt, die aber Helenas Anordnung der Zerstörung heidnischer Idole ausliessen. Die Cappella Orsini folgte demgemäss der von Paulino von Nola tradierten Überlieferung. Zur Orsini-Kapelle vgl. Vasari, Vite, VII, S. 53-54; Hirst 1967, S. 498-509; Davidson 1967, S. 553-561; Valone 1990, S. 79-87; Heussler 2006, S. 236-240, 365-366; Richter 2009, S. 192-195; Hansen 2013, S. 57-64. Zu den Legendversionen, die ebenfalls über das Venusheiligtum berichten - allen voran Gelasius/Rufinus, Sokrates und Sozomen - vgl. dann Drijvers 1991, S. 101, 103, 106, 114-115. 
Kreuzesreliquie als heilsames Zeichen betont. Im Bildnarrativ wird daher bewusst auf die sinnliche Betonung des Kreuzes als dulce lignum verzichtet. Dadurch wird dieser Reliquie mehr Gewicht in ihrer Bedeutung als signum des Kreuzes- und Messopfertodes Christi verliehen. ${ }^{799}$ In dem von Fabio Lando erwähnten Trattato wird berichtet, dass die Bruderschaft von San Marcello jedoch mit de' Vecchis Arbeitsweise unzufrieden war, da dieser zu langsam arbeitete. Rhoda Eitel-Porter formulierte anhand der überlieferten Vorstudien Cesare Nebbias die These, dass sich Nebbia noch vor Niccolò Circignanis Beteiligung an der Ausschmückung des Oratoriums gegen de' Vecchi behauptet habe. Nebbias Zeichnung der Aufrichtung des Kreuzes, die sich im Art Institute in Chicago überliefert findet, zeigt deutlich, wie diese neue Bildlösung $\mathrm{zu} \mathrm{de}^{6}$ Vecchis eigener Bildfindung in Konflikt stand (Abb. 42a \& Abb. 42b). ${ }^{800}$ Der mögliche Eintritt Nebbias in die im Oratorium der Bruderschaft des SS. Crocifisso tätige Malerwerkstatt, der noch vor Circignanis Ausführung des Kreuzwunders stattgefunden haben musste, kann im Zusammenhang mit den beiden für die Chiesa Nuova der Oratorianer hergestellten Tafeln betrachtet werden. Dadurch lässt sich belegen, wie eine neue und den kurialen Massstäben entsprechende Bildsprache in die Dekoration des Oratorio del SS. Crocifisso Eingang fand. Diese bildproduktive Sprache entstand im Umkreis der innerhalb des Palazzo Apostolico tätigen Künstlerwerkstatt und diente hauptsächlich dafür, die Bruderschaft des SS. Crocifisso und ihr Oratorium weiterhin an die Kurie zu binden. Diese Bindung war nämlich durch die prekäre Finanzlage prekär geworden. Seinen Anteil an der Dekoration im Oratorio del SS. Crocifisso hatte Nebbia nicht nur seiner Nähe zum Maler Girolamo Muziano zu verdanken, sondern auch seinen Beziehungen zum Fürsten von Acquasparta, Federico Cesi. Cesi, der ebenfalls innerhalb der Kongregation des Oratoriums fest eingebunden war, bewerkstelligte schlussendlich den Vertrag für Nebbias Beteiligung im SS. Crocifisso durch seine engen Beziehungen zur Bruderschaft von San Marcello al Corso. ${ }^{801}$

799 Dies hing vor allem mit der in den Statuten der Bruderschaft enthaltenen Vorschrift zusammen, das wundertätige Kruzifix von San Marcello das ganze Jahr über unter Verschluss zu halten. Das Kruzifix von San Marcello al Corso wurde den Gläubigen nur an den Festtagen der Kreuzauffindung und -erhöhung, an Karfreitag und an Fronleichnam, vorgeführt. Vgl. hierzu Delumeau 19571959, Bd. 1, S. 283.

$800 \mathrm{Zu}$ den Vorstudien Nebbias vgl. Eitel-Porter 2000, S. 620, 622-623. Die Zuschreibung der einzelnen Fresken an die entsprechenden Maler de' Vecchi, Nebbia und Circignani geht hauptsächlich aus Baglione, Vite, I, S. 128 (de' Vecchi), 117 (Nebbia), 42 (Circignani) hervor. In Bezug auf die chronologische Einordnung ihrer Entstehung vgl. Pierguidi 1999, S. 268-270; idem 2005, S. 30-31; idem 2012, S. 267-273; Negro 2001, S. 47-55.

801 Hinsichtlich des Zustandekommens eines Vertrags mit Nebbia für die Dekoration des Oratoriums vgl. Landos Auszug aus seinem Trattato in ASV, Arciconfr. SS. Crocifisso in S. Marcello, P.XIX.51: „Pigliata sopra di se l'amorevole Signor Ottavio Capranica trattò con il Signor Federico Cesi, e lo persuate a fare la seconda istoria quale fece M. Cesare d'Orvieto“. Vgl. auch Pierguidi 1999, S. 269. Obwohl die Zeichnung aus den Uffizi für Nebbias Fresko von Heraklius trägt barfuss 
Im Unterschied $\mathrm{zu}$ dem im Oratorio del SS. Crocifisso ausgeführten Bildprogramm, das von einer spezifisch im Breviarum Romanum enthaltenen Liturgie geleitet wurde und sich dadurch besonders für die bruderschaftliche Frömmigkeits- sowie Andachtspraxis eignete, waren die ersten Kapellendekorationen in der Chiesa Nuova der Oratorianer von den kurienzeremoniellen Vorschriften zu ausgewählten Festtagen im liturgischen Kalender bestimmt. Diese spezifische Auswahl von Bildsujets für die einzelnen Kapellendekorationen in der Chiesa Nuova hing einerseits damit zusammen, dass Filippo Neris Kongregation ihren Charakter einer Priesterversammlung aufrechterhalten wollte. Demgemäss lag die Predigtpraxis stets im Zentrum der bruderschaftlichen Zusammenkünfte der Oratorianer. Andererseits stellte die frühe Ausschmückung der einzelnen Kapellen in Santa Maria in Vallicella noch keine zusammenhängende Bildprogrammatik her, wie es in den Oratorien der Gonfalone-Bruderschaft und des SS. Crocifisso der Fall war. Die ersten errichteten Kapellen im Langhaus der Chiesa Nuova waren ausschliesslich zur privaten Nutzung ihrer Stifter gedacht. Bereits zwei Jahre nach dem feierlichen Abschluss des anno santo erkaufte sich der päpstliche Kämmerer Pietro Vittrici das Patronat der zweiten Langhauskappelle im rechten Seitenschiff der Chiesa Nuova. Die Einrichtung eines Altars wurde ihm mittels eines päpstlichen breve gestattet. ${ }^{802}$ Mit Cesare Nebbias Tafel der Anbetung der drei Könige verband diese erste in Santa Maria in Vallicella ausgeschmückte Kapelle eine auf das Mysterium der Fleischwerdung Gottes bezogene Andachtspraxis der Oratorianer mit den kurienzeremoniellen Vorschriften zum officium der Epiphanie.

Die Bildlösung Nebbias muss daher zusammen mit der Dekoration der Gewölbeapsis der Kapelle betrachtet werden. Dort wird mittig die Figur des Apostels Paulus gezeigt, der von den beiden Evangelisten Markus und Lukas flankiert wird. Nebbias Bildlösung für das Altarbild lehnt sich stark an das Frontispiz zur Legenda sanctorum trium regum des Johannes von Hildesheim an. In dem 1745 erstellen Inventarium bo-

das Kreuz um 1579 entstanden sein musste, konnte das Fresko nicht vor 1582 wegen der schwierigen Finanzierungslage, die ebenfalls de' Vecchis Arbeiten beeinflusste, ausgeführt werden. Zum Kunstmäzenatentum der Cesi, das in Rom hauptsächlich vom Kardinal Pierdonato vorangetrieben wurde, vgl. Nocchi 2015, S. 77-96. Zu den Beziehungen der Familie zu den Oratorianern dann Pastor 1893-1933, Bd. 9, S. 805; Bonadonna Russo 1970, S. 101-155; Cistellini 1989, Bd. 1, S. 288-292.

802 Vgl. zu den stuccature den Eintrag im Libro dell'entrata et uscita in ACR, C.I.24. Zur These, dass bereits mit der Dekoration der beiden ersten Kapellen von einem einheitlichen Bildprogramm ausgegangen werden sollte, vgl. Kummer 1993, S. 518-519. Kummer ging wie Graeve 1958, S. 234 und Zuccari 1981a, S. 106 von einem „einheitlichen, ikonographischen Programm aus“, für dessen Gestaltung er Filippo Neri selbst als Autor vermutete. Diese Auslegung stützt sich vor allem auf Baccis hagiographischer Überlieferung: Bacci, Vita, S. 61-62. Nebbias Tafeln griffen jedoch nicht Bildthemen auf, die vornehmlich aus dem repertoire des Rosenkranzes entstammten. Diese einheitliche Bildprogrammatik kam erst mit den um 1580 verfassten Conditioni cole quali si ha conceder le Cappelle auf: ACR, C.I.26. 


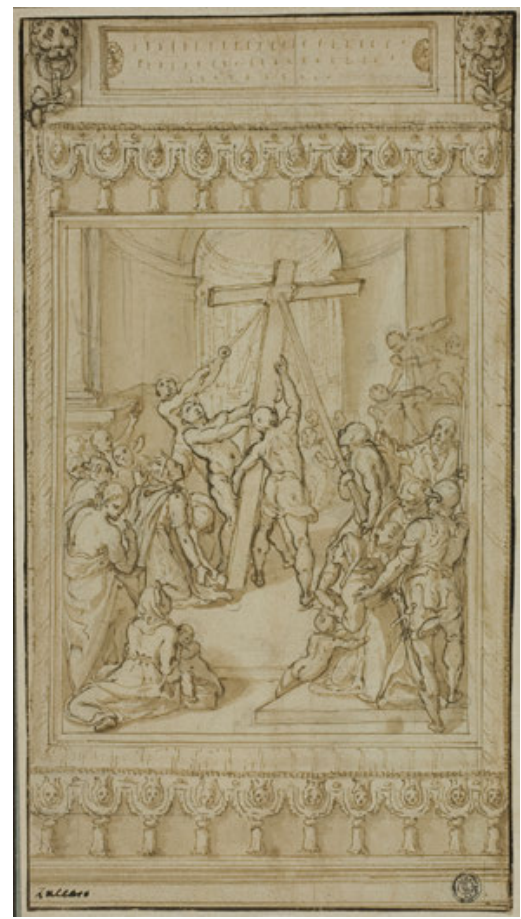

Abb. 42a: Cesare Nebbia, Die Kreuzeserhöhung, Federzeichnung in Brauntinte, 1579-1580, 29,7 × 16,4 cm, The Art Institute, Chicago.

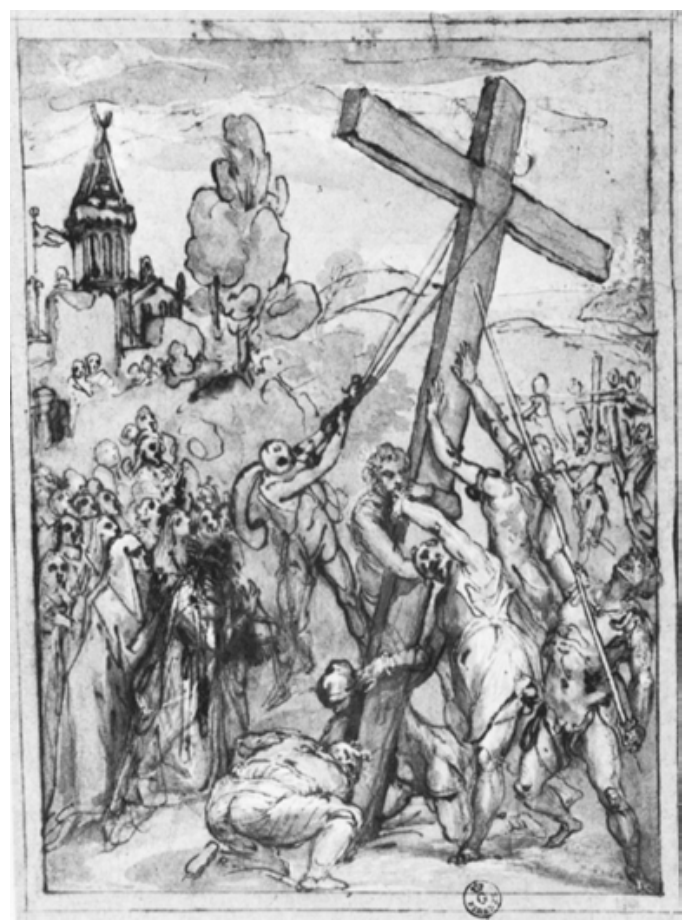

Abb. 42b: Giovanni de' Vecchi, Die Kreuzeserhöhung, Federzeichnung in Brauntinte, 1578-1579, 30,2 × 22,1 cm, Gabinetto Disegni e Stampe degli Uffizi, Florenz.

norum Filippo Neris fand sich eine gedruckte Ausgabe dieser Legenda aus dem Jahr $1490{ }^{803}$ Das Hochfest der Epiphanie zeichnete sich durch sein liturgisches officium als die Vorwegnahme des Mysteriums der Wiederauferstehung Christi nach seinem Kreuzes- und Messopfer in der Geburt aus. In den Feierlichkeiten zur Vigil wurde die heilsversprechende Sündenvergabe angekündigt, die sich im feierlichen Moment der Geburt Christi zu einer fleischgewordenen Heilsrealität verkörpert fand. Anhand des Römerbriefes wurde sodann das officium zur Epiphanie, wie es das Breviarium Romanum überlieferte, als eine liturgische Feier ausgelegt, bei welcher ein Mysterium des Bundes auf das Mysterium der Fleischwerdung folgte. Der Stern (stella) wurde somit als symbolische Vorsehung gedeutet, durch den die Ankunft der Heiligen Drei Könige,

803 ACR, C.I.39 (n. p.). Das Druckexemplar der Legenda des Johannes von Hildesheim findet sich dann in BVR, S.Borr.S.II.9. 
die sich anlässlich der Geburt des Gottessohnes an der Krippe von Betlehem um das Kind der heiligen Maria versammelten, schon verkündet wurde. ${ }^{804}$

Die Dekoration der ersten Stiftskapelle im Langhaus der Chiesa Nuova hob dementsprechend das Bedürfnis der Oratorianer, dem Priesterbund einen Charakter des Zusammenschlusses im Zeichen der Geburt Christi zu verleihen, hervor. Dieser Wunsch der Oratorianer, sowohl die liturgischen Feiern in ihrem Kirchenraum als auch ihre regelmässigen Zusammenkünfte im Oratorio piccolo als Ausdruck ihres Bundes zu kennzeichnen, ging ab 1578 nicht nur durch die steigende Zahl an Neulingen, sondern auch durch den feierlichen Besuch des Boncompagni-Papstes am 17. August, in Erfüllung. ${ }^{805}$ Drei Tage vor diesem Papstbesuch der Oratorianer und ihrer Chiesa Nuova berichtete Cesare Baronio in einem Briefschreiben an seinen Vater, dass er nun endgültig von San Giovanni dei Fiorentini nach Santa Maria in

804 Brev. Rom. (MLCT, 3), S. 228: „Veritatem dico in Christo Iesu, non mentior, testimonium mihi perhibente conscientia mea in spiritu sancto quoniam tristitia mihi magna est, \& continuus dolor cordi meo. Optabam enim ego ipse anathema esse a Christo pro fratribus mei, qui sunt cognati mei secundum carnem: qui sunt Israelitae, quorum adoptio est filiorum, \& gloria, \& testamentum, \& legislatio, \& obsequium, \& promissa: quorum patres, \& ex quibus est Christus secundum carnem: qui est super omnia deus benedictus in saecula (Röm 9, 1-5)“. Derselbe Bund wird auch in Eph 2, 11-22 ausgedrückt, der dann sowohl in Hildesheim, Legenda sanctorum trium maogrum (BVR, S. Borr.S.II.9), S. 17, als auch in der patristischen Exegese des Augustinus wieder auftaucht. Zur patristischen Verarbeitung dieser Theologie des Bundes vgl. DS 1960, Bd. 4/1, Sp. 869-871. Borromeo stützte sich in seiner 1584 überlieferten Predigt auf die Zeichenhaftigkeit des Sterns. Vgl. hierzu außer die in BAM, D 214inf., f. 71r-72r überlieferte Predigt auch Borromeo, Homiliae, III, S. 247-257. Zum Kurienzeremoniell des am 6. Januar jährlich stattfindenden Hochfestes vgl. den Eintrag in Mucanzios Zeremonialtagebuch in BAV, Chig.L.II.30, f. 582v-583r. Vgl. in diesem Zusammenhang auch Ann. Ecc., I, S. 67-69, wo ausschliesslich eine homiletische Exegese der entsprechenden Stellen bei Mt 2, 2-12 und Lk 2, 1-20 vorgenommen wird. Dadurch wird die Geburt Christi als Geburt eines Königs betont.

805 BAV, Chig.L.II.30, f. 552v: His diebus S. D. N. visitavit Ecclesiam novam S. Mariae in Valicella nuper Presbiteros Cong.nis Oratorij construetam, ad quam quotidie magis fideles utriusque sexus conveniunt propter bona opera dictos sacerdotum, qui verbo et exemplo rectam Christianam disciplinam ostendunt. Vgl. auch das avviso in BAV, Urb. lat. 1047, f. 302v. Die Präsentation des Oratoriums als eine einheitliche Priesterversammlung gegenüber dem Papst und der Kurie anlässlich dieses Besuchs wurde mit der Aufnahme von membri onorari, die als erste Laien betrachtet wurden und zentrale Aufgaben innerhalb der Priesterversammlung übernommen haben, bewerkstelligt. Antonio Sala, einem Familienangehörigen des Kardinals Borromeo, wurde ab 1577 „il governo di tutta la casa“ übertragen, obwohl er nur als clericus et frater nostrae Congregationis bezeichnet wurde. Vgl. hierzu Aringhis Lebensbeschreibung in BVR, O 60, f. 224r-228v; BAM, F 99inf., f. 69r; Primo processo, IV, S. 197, 160 sowie Virgilio Spadas Instituta Congregationis Oratorii in ACR, C.I.14, f. 27r-v: [...] et licet de illo tempore non essent laici, qui essent de corpore Congregationis, sed tantum mercede conducti, nihilominus eos dirigebant in viam Domini, et cum tali applicatione ut decreverint congregationi culparum eorundem interesse debere quatuor sacerdotes. Es handelte sich daher nicht um Laien (laicos), sondern um sogenannte famulos und daher um „Hausangestellte“, deren Mitgliedschaft gegenüber der kurialen Verwaltung legitimiert werden musste. Vgl. zu diesem Problem insbes. Cistellini 1989, Bd. 1, S. 232-233. 
Vallicella übergesiedelt sei. In diesem Brief berichtet Baronio auch über den Fortschritt der fabrica der Vallicella:

Hora per gratia del Signore habbiamo mutata stanza, e contrada, e non stiamo piu in Casa altrui, ma in Casa nostra; e per dir meglio in Casa della Madonna santissima Madre d'Iddio; dove al primo di questo mese nel giorno di San Stefano son venuto ad habitare insieme con Mes. Francesco Maria, e con Mes. Gio. Antonio nostro; et ho la meglior cammera di Casa, posta a tramontana; gl'altri verranno a mano a mano, secondo saranno in ordine le stanze, a Natale vi saranno tutti: perchè una parte della Chiesa sarra finita per posservi officiare. Il Papa con gl'altri vi han speso fin hora da settemila scuti, ne si è fatto ancora la terza parte: sarra una delle belle Chiese ce siano in Roma. Il suo titolo si è Santa Maria della Vallicella, il che mi fa ricordare di Santa Maria nostra di Valleradice, dove io ricevei la vita. Molto sto contento, trovarmi in servitio della Santissima Madre d'Iddio. La nostra fabrica è andara con tanta sollecitudine che ha fatto, e fa maravigliare tutta Roa; e speriamo nella Madonna Santissima, che andera da bene in meglio. [...] Del resto sforzamoci viver in tal modo, che ci sia il fine in desiderio. Perche veramente il morire, non è altro, se non andare alla vera patria, et al regno del quale siamo heredi. Viviamo bene, e lasciamo fare al Signore, et habbiamo sempre in desiderio la eterna che la temporal vita. ${ }^{806}$

Dieser Brief Baronios erlaubt es, die Fertigstellung von Cesare Nebbias Tafel in den Zeitraum zwischen August und Weihnachten des Jahres $1578 \mathrm{zu}$ datieren. Die Tafel war somit für die ersten gemeinsam gefeierten officia der Oratorianer in der Chiesa Nuova gedacht. Baronios Erwähnung der päpstlichen Spesen für die neue Kirche von Santa Maria in Vallicella, die sich bis 1578 auf insgesamt 7000 scudi beliefen, deutet nicht nur darauf hin, dass sein Brief ebenfalls in das Jahr 1578 datieret werden kann. Das Schreiben zeigt ebenfalls deutlich, dass Baronio zum Zeitpunkt des Einzugs in das neue Haus der Oratorianer einem kurialen Prälatenkreis gedient haben muss. ${ }^{807}$

806 BVR, Q 46, f. 47v. Die Widmung der Kirche von Santa Maria in Vallicella auch an den heiligen Gregor d. Gr. hatte für Baronio ebenfalls eine wichtige Bedeutung. Er konnte sich noch daran erinnern, dass er vor sechs Jahren (1572) am Festtag der heiligenGottesmutter selber von seiner Krankheit geheilt wurde. Vgl. hierzu den Eintrag in BVR, Q 63, f. 291v: SS. Gregorium papam suscipimus patronum, cuius reliquiae quodam miraculo ad me pervenerunt: in die eius liberatus a morbo, sub eius famulatu perpetuo mansi. Am 3. Februar 1577 feierte der Kardinal Alessandro de' Medici die erste Messe in der neuen Kirche der Oratorianer, nach welcher der Boncompagni-Papst einen Plenarablass erliess. Vgl. hierzu v. a. Gallonio, Vita Filippo Neri, S. 144. Das Ereignis wird nicht im Tagebuch des Zeremonienmeisters Mucanzio erwähnt, da sich an diesem Tag die Zeremonialkongregation im Haus des Kardinals Morone traf: BAV, Chig.L.II.30, f. 456v-458r.

807 Die Kosten für die Kirche der Oratorianer können aus Ciappi, Compendio, S. 17-18 rekonstruiert werden, der die Spesen um die Mitte des Jahres 1576 auf 5000 scudi beziffert, zu denen bis Januar 1577 weitere 1000 scudi hinzukamen. Vgl. hierzu das avviso vom 19. Januar 1577 in BAV, Urb. lat. 1045, f. 22r. Weitere Kosten häuften sich dann im Juli 1578 in Bezug auf den Tod des Kardinals Giovan Paolo Della Chiesa an, wofür das päpstliche breve, Ut Ecclesiae, vom 24. Juli desselben Jahres der Vallicella Silbergeschirr und weitere Ausstattungsgegenstände abkaufte: ACR, A.V.16 (n. p.). Sirleto selbst hatte Tarugi noch 1576110 scudi „per limosina in soccorso de la nostra fabrica de la chiesa di S.ta Maria in Vallicella“ ausbezahlt. Das Briefschreiben Tarugis befindet sich 
Der besondere Charakter der Oratorianer als einer in sich geschlossenen sodalitas von Priestern, deren Tätigkeiten noch institutionell und damit kirchenrechtlich zu formulieren waren, wurde in der Ausschmückung der vierten Kapelle im rechten Langhausarm betont. Diese Kapelle stiftete der Pisaner Vincenzo Lavaiana, die er laut einer Beschreibung der Kirche aus dem Jahr 1625 auch ausmalen liess. In einer Inschrift wird das Jahr 1579 als Datum der Fertigstellung der Lavaiana-Kapelle, für die Cesare Nebbias zweite Tafel der Ankunft des Heiligen Geistes gedacht war, festgehalten. ${ }^{808}$ Obwohl Nebbias zweites Altarbild heute als verschollen gilt, kann die Zeichnung aus der Walker Art Gallery in Liverpool als Vorstudie zum Ölgemälde betrachtet werden (Abb. 43). Die Bildlösung Nebbias für dieses Altarbild legt nahe, dass sich der Maler an die herkömmliche Bildtradition der Darstellung des Pfingstfestes anlehnte. Nebbia musste somit die für das im Gewölbe der Sala dei Paramenti des Apostolischen Palastes angefertigte Vorstudie zum Pfingstfest Girolamo Muzianos gekannt haben. Die Darstellung zeigt die Apostel, die sich unter der Taube des Heiligen Geistes und um die Zentralfigur Mariens versammeln. Dieselbe Figurenanordnung übernahm Cesare Nebbia für seine zweite Tafel, die er für die Oratorianer in Santa Maria in Vallicella ausführte. Muzianos Bildsprache, die für die zeremonielle Ausgestaltung des Palazzo Apostolico verwendet wurde, wurde durch seinen Werkstattmitarbeiter Nebbia in den römischen Kirchen verbreitet. Nebbia grenzte allerdings in seiner Vorstudie das Pfingstgeschehen weit stärker auf die kreisförmige Gruppierung der Figuren ein als Muziano dies in seiner Bildlösung für die Sala dei Paramenti tat. Marciari vermutet, dass es sich bei der Tafel in der OradiniKapelle im Duomo von Perugia um Nebbias zweite Tafel für die Vallicella gehandelt haben könnte. Eitel-Porter weist aber überzeugend darauf hin, dass dieses Altarbild für die Kapelle in Perugia spätestens 1576 ausgeführt wurde, da die Kapelle bereits seit 1573 als Grablege für Giulio Oradini - den Bruder des Auftraggebers - dienen musste. ${ }^{809}$ Bislang beurteilte die Forschung das zweite Altarbild Nebbias für die

in ACR, C.I.37, f. 587r. Die Cappella Ceva soll zusammen mit ihrer Stuckdekoration im Jahr 1580 fertiggestellt worden sein, wie es auch eine Inschrift belegt: PNTIVS CEVA NICIENSIS/ VIVENS SACELLVM ORNAVIT. DOTAVIT/ SEPVLCRVM. QVE. SIBI. POSTERISQVE. SVIS. ELEGIT/ ANNO. DOMINI. M.D L XXVIII. Zit. n. Forcella, Iscrizioni, IV, S. 156 (Nr. 373).

808 Zur Inschrift vgl. Forcella, Iscrizioni, IV, S. 146 (Nr. 333): D.O.M./ VINCENTIVS LAVAIANVS PISANVS SIBI ET/ VIRGINIAE CIAMPOLO VXORI POSTERIS/ QVE SVIS P. C. ANNO DOM./ M.D.L.X.X.I.X. Die Nachricht, auf welche ebenfalls Hess 1967, Bd. 1, S. 364 Bezug nimmt, liegt in ACR, A.V.14, f. $21 r$ vor. Kummer 1987, S. 122-123 zweifelte an der Glaubwürdigkeit der Ausmalung der Kapelle, welche die Nachricht aus dem Jahr 1625 überliefert. Anscheinend war Lavaiana ebenfalls innerhalb der Camera Apostolica als ihr depositario generale sowie provveditore gem. ASR, Soldatesche e galere 1431-1841. Castel S. Angelo, b. 27 tätig.

809 Marciari 2002, S. 127 folgt der in Kat. Roma 1995a, S. 527 aufgestellten Vermutung Zuccaris, dass das Altarbild Nebbias 1598 entfernt und an dessen Stelle eine Tafel des Wenzel Cobergher angebracht wurde. Zu dieser Tafel vgl. Segreto 1993, S. 278-296. Hinsichtlich des Altarbildes in Perugia vgl. insbes. Eitel-Porter 2009, S. 52-53. 


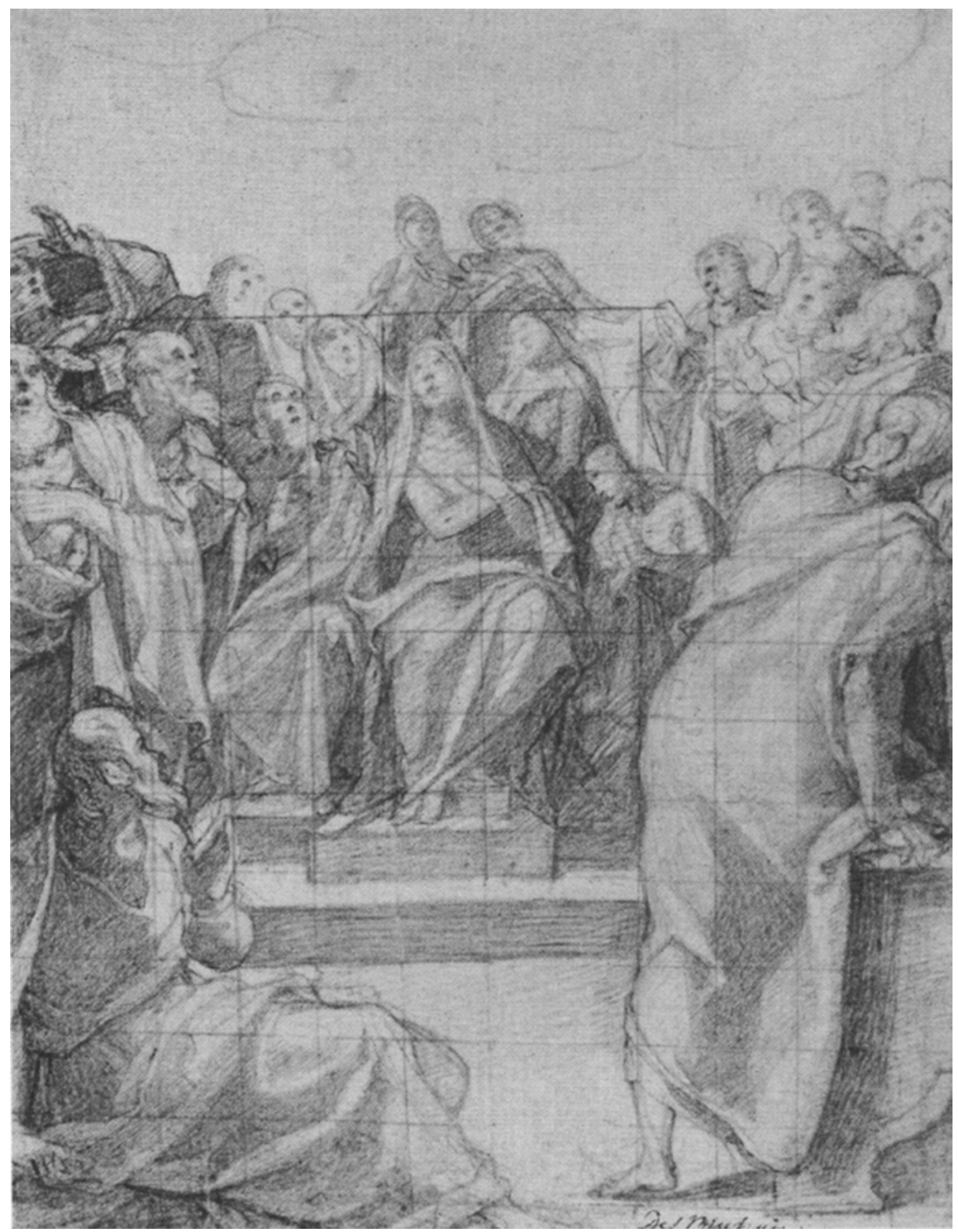

Abb. 43: Cesare Nebbia, Das Pfingstwunder, Kreidezeichnung in Rot, 1577-1578, 26,4 x 17,6 cm, Walker Art Gallery, Liverpool. 
Chiesa Nuova als eine sich bewusst an die Spiritualität der Dominikaner anlehnende Programmwahl. Gemäss dieser Deutung hätte sich die liturgische Ausstattung der Kirche der Oratorianer bereits eine bildprogrammatische Umsetzung des Rosenkranzes, wie es die Cappella del Rosario in Santa Maria sopra Minerva vorführte, vorgenommen. Diese Einigkeit im Bildprogramm der Langhauskapellen der Chiesa Nuova lässt sich jedoch erst ab den 1580 verfassten Conditioni cole quale si ha concede le Cappelle nachweisen. ${ }^{810}$

Da die Entstehung der Tafel Nebbias nicht in diesen Zeitraum einer bildprogrammatischen Einheit der Dekoration in den Langhauskapellen fällt, kann deren Bildinhalt unabhängig von den Rosenkranzgeheimnissen gedeutet werden. Cesare Nebbias Pfingstfest zeigt mit seiner Anlehnung an Mucanzios Gewölbefresko in der Sala dei Paramenti eine Ausrichtung der liturgischen Nutzung dieser Kapelle gemäss den kurienzeremoniellen Richtlinien für diesen Festtag. Diese liturgische Anbindung an das Kurienzeremoniell erlaubte es Cesare Baronio später, die Kongregation der Oratorianer zu einem verlängerten Arm des Kurienapparates zu gestalten. Filippo Neri sollte hingegen mit der Fassung der ersten Dekrete ab 1580 seine Priesterversammlung noch weiter von diesem starken Einfluss des päpstlichen Herrschaftsapparates zu distanzieren versuchen.

Cesare Nebbias Pfingstfest in der vierten Langhauskapelle im rechten Seitenschiff der Chiesa Nuova folgt einer klaren Bildsprache, mittels welcher das Hochfest als Versammlung der Apostel um die Figur Mariens, über der sich die Spendekfraft des heiligen Geistes ausgiesst, vorgeführt wird und damit mit dem in der Apostelgeschichte überlieferten Zeitpunkt der Gründung der Ecclesia (Apg 2, 1-4) in Übereinstimmung gebracht wird. Ein weiteres Blatt Nebbias, das 1979 in London versteigert wurde, zeigt dieselbe Anlehnung an Girolamo Muzianos Fassung für die Sala dei Paramenti. Die Komposition unterscheidet sich in Bezug auf Figurengestik und -aufstellung deutlich von der Tafel im Duomo von Perugia. In der Vorstudie - sowie dann vermutlich im fertiggestellten Altarbild für die Chiesa Nuova - blicken alle dargestellten Figuren auf die herabfallende Taube des Heiligen Geistes. Nebbias Version für die Cappella Oradini in Perugia hingegen betont die mittig sitzende Mariengestalt in ihrer Demutshaltung mit ihrem gesenkten Kopf. Einzig der rechts unten kniende Jünger aus dem Bildaufbau in der Vorstudie stimmt mit derselben Figur im Altarbild für die Cappella Oradini überein. Sie ist eine immer wieder in Muzianos Bildkomposition anzutreffende Figur, die auch in der Studie einer Apostelgruppe aus dem Istituto Nazionale per la Grafica erscheint. ${ }^{811}$ Die Anlehnung an

810 ACR, C.I.26 (n. p.). Vgl. auch die bereits erwähnte Dichiarazione della pianta von 1625 in ACR, A.V.14, f. 17r. Vgl. auch Barbieri/Barchiesi/Ferrara 1995, S. 160; Ferrara 1995, S. 108; Bonadonna Russo 1968, S. 136; Zuccari 1981a, S. 106; Verstegen 2015, S. 43-65.

811 Prosperi Valentini Rodinò 1993, S. 28-30; Eitel-Porter 2009, S. 52. Die Zeichnung Muzianos diente als Teilstudie für die Himmelfahrt Mariens in der Kirche von San Luigi dei Francesi, welche Matthieu Cointrel in Auftrag gab und welche Muziano in den frühen achtziger Jahren schuf. 1592 
Muzianos Bildsprache für die Sala dei Paramenti scheint für die ersten Dekorationskampagnen in der Kirche der Oratorianer richtungsweisend gewesen zu sein, denn sie sollte die Anbindung der Priesterversammlung an die römische Kurie betonen. Das officium des Pfingstfestes, wie es im Breviarium Romanum festgehalten wird, war ausschliesslich auf die Ankunft des Heiligen Geistes über „alle Schüler“ Jesu (omnes discipuli) ausgerichtet, ohne dabei eine Unterscheidung zu treffen, ob mit den discipuli die Apostel oder Priester gemeint sind. ${ }^{812}$ Eine solche Unterscheidung sollte sich in der kurienzeremoniellen Ausmalung der beiden Sala dei Paramenti im Palazzo Apostolico anbahnen, die 1577 fertiggestellt wurde und in der ebenfalls der institutionelle Gründungsmoment der Ecclesia im Pfingstfest betont wird. Die beiden Räume im Apostolischen Palast, die auch als Anticamera und Camera del Concistoro Segreto bezeichnet werden, befinden sich im ersten Stockwerk des mittelalterlichen Teils des Palastes, der sich über dem Cortile del Pappagallo befindet und auf das Pontifikat Nikolaus' III. zurückgeht. Die Sale dei Paramenti befinden sich somit auf demselben Geschoss wie die Cappella Paolina, die Sala Regia, die Sala Ducale, die Camera della Falda und die sogenannte Galleriola des Appartamento Borgia. Diese Räume grenzen an die Westfassade der vatikanischen Loggien über dem Cortile di San Damaso an. Die Doppelbenennung der Sala dei Paramenti lässt vermuten, dass die beiden Räume der zeremoniellen Bekleidung sowohl des Papstes als auch der Kardinäle vor den liturgischen Feiern dienten. Aus den Plänen für die Papstwahlen der zweiten Hälfte des Cinquecento kann weiter entnommen werden, dass der Raum am nördlichen Ende - die Sala del Pappagallo inferiore - auch für die Konsistorien genutzt wurde. ${ }^{813}$ Das Kurienzeremoniell des consistorio secreto sah unter anderem

erwarben es die Mönche der Kirche von San Paolo fuori le mura und installierten es in derselben Basilika, in der die Tafel 1823 verbrannte. Zwei Stiche überliefern das Gemälde und ein ricordo Muzianos dieses Bildes wurde am 8. Juli 2004 in London bei Sotheby's versteigert (Öl auf Leinwand, 154 x 107.5 cm, Nr. 155). Vgl. Kat. Roma 1993, S. 216; Bertolotti, Artisti lombardi a Roma, Bd. 1, S. 121; Loire 1993, S. 123; Lieure 1924-1929, Bd. 2, S. 15; Strinati 1980, S. 45-46.

812 Brev. Rom. (MLCT, 3), S. 464-469. Während der Feierlichkeiten für die Vigil hatte das Breviarium dann den Ritus der Aufnahme der catechumenos folgendermassen aufgenommen: „Dum per sacratissimum crucis signum vos suscipit in utero sancta mater ecclesia, quae sicut \& fratres vestros cum summa laetitia spiritualiter pariet nova praeles futura tantae matris, quosque per lavacrum sanctum regeneratos verae luci restituat congruis alimentis“. Zit. n. ibid., S. 464-465. In diesem Verständnis musste es sich hierbei bereits um den Ritus der Spende des Sakramentes der Firmung gehandelt haben, welches gem. Apg 1, 4-8; Lk 3, 15-22 und Tertullian, De Baptismo in PL, Bd. 1, Sp. 1331-1334 als Taufe verstanden wurde.

813 Sacrorum caeremoniarum (1573), 75v: „Secretum Consistorium celebratur in aula aliqua palatij Apostolici remotiori, hodie cameram Papagalli appellant [...]“. Vgl. auch Moroni, Dizionario, Bd. 7, S. 17, 238-239 resp. ibid., Bd. 28, S. 154-155. Zur Palastarchitektur unter Nikolaus III. vgl. Rzuletzt Monciatti 2005, S. 115-158. Die Acta Camerarii aus dem Konsistorialarchiv nennen die Sala dei Paramenti (aulae paramentorum) ebenfalls als Ort, an dem das Konsistorium tagte. Vgl. hierzu bspw. das Dokument aus ASV, Archivio Concistoriale. Acta Camerari, 11, f. 112v für das Konsistorium vom 
die Wahl neuer Kardinäle vor. Während der ersten sechs Jahre des BoncompagniPontifikates wurden nur vier Kardinäle ernannt. Am 21. Februar 1578 und fuori d'ogni opinione, wie es ein avviso berichtet, ernannte Gregor XIII. neun neue Kardinäle. Dem Eintrag im Tagebuch des Zeremonienmeisters Mucanzio zufolge fand diese Ernennung in der Sala di Costantino statt, während die Sale dei Paramenti dementsprechend als anticamera concistorij genutzt wurden. Dadurch traten die beiden Sale dei Paramenti in einen spezifisch zeremoniellen Zusammenhang mit dem Raum, in dem die Kardinalsernennungen durchgeführt wurde. Dieser Zusammenhang zwischen Sale dei Paramenti und Sala di Costantini spiegelte sich auch in der bildproduktiven Ausgestaltung des ersten Raumes. ${ }^{814}$

Die für diese Dekoration entrichteten Zahlungsbelege erlauben es, die Vergoldung der Decke und die Installation von Girolamo Muzianos Pfingstfest zwischen dem 8. und dem 20. Dezember $1577 \mathrm{zu}$ datieren. Die letzte Zahlung für den Abbau des Gerüsts erfolgte am 21. Dezember desselben Jahres. Die feierliche Einweihung der beiden Sale

3. Oktober 1571. Aus den Zahlungsaufträgen in ASR, Camerale I. Giustificazioni di Tesoreria, b. 5, fasc. 21 kann für den 2. November 1576 festgestellt werden, dass sich das Konsistorium damals in der Sala di Costantino abgehalten wurde - wahrscheinlich wegen der in den beiden Sale dei Paramenti begonnenen Ausmalungsarbeiten. Der erste Zahlungsbeleg für die Dekoration wurde am 9. November 1576 entrichtet: ASR, Camerale I. Tesoreria Segreta, 1304, f. 174r. Hinsichtlich der zeremoniellen Konsistorialordnung des concistoro publico vgl. wiederum Sacrarum caeremoniarum, c. 74r-v: „Quia publicum consistorium frequenter noniavim, $\&$ in posterum naniacuri sum: opereprecium videt ordinem \& modum ipsius consistorij explicare. In palatio Apostolico apud S. Petrum tres aulae sunt Pontificales, quas in conclavi contineri superi diximus: Prima omnium maxima pro consistorio publico ornari solet quin Reges, aut Regij Legatis sunt excipiendi, canonizattionum etiam causae in ea parant, in tertia aula recipiunt Legationes aliorum principum, \& rerum publicarum, cum ad venerandus Summum Pontificem veniunt publicantur novi Cardinales“.

814 Für die Kardinalsernennung vom 21. Februar 1578 vgl. das ein Tag später verfasste avviso in BAV, Urb. lat. 1046, f. 54 r sowie den Eintrag im Tagebuch Mucanzios in BAV, Chig.L.II.30, f. 516r$519 v$, bes. f. 518v-520r: „Notanda sunt plura circa hunc actum. Primo de ingressu Card.lis novi, qui debuisset secundum aliquos ingredi antè faciem Pontificis per medium Quadraturae sedilium Rev. mos Card.lium quia debuisset singulos Card.les antiquos in eos locis stantes adire, et eis inclinatus gratias agere, pro ut toto tempore Pij Papae V factum fuit et etiam in creatione Rev.mos Card.lium S. Sixti, et Vastavillani, quod ego Papae sum testatus. Collega meus contrarium asserebat, et aliqui Cardinales ei adhaerebant, sed parum erant memores moderni usus. Unde Papa nos redarguit, quod inter nos disentiremus; sed non est mirandum, cum haec sit Caeremonia nova, nec in libro Caeremoniali comprehensa, ubi non dicitur quod Card.les statim electi ingrediantur Consistorium secretum, ut expiant Biretum rubeum. Imò prius et tempore Pauli Papae III Card.les creabantur in Consistorio, quo finito Papa mittebat ad eos biretum rubeum absque ut vocarentur prius nequae ad Consistorium, imò nequae ad Palatium licet Pontifices antè Paulum 3.umvariè abservarerint [...]. Die igitur sequenti quae fuit Sabbathi 22 eiusdem habitum fuit Consistorium publicum in Aula ubi haberi solet pro Ducibus, et Cardinalibus in Palatio Apostolico. [...] Praestita obedientia per Card. les in Consisorio, et incepta propositione Causae per Advocatum, duo primi Diaconi factis debitis reverentijs Papae et Cardinalibus exierunt ex dicta Aula Consistorij ad Cappellam Sixtis, ubi Cardinalis novus Cappa violacea indutus expectabat“. Zu dieser Kardinalswahl vgl. insbes. dann Pastor 1893-1933, Bd. 9, S. 163-164. 
dei Paramenti fand gemäss den Tagebucheinträgen Mucanzios an Weihnachten 1577 statt. ${ }^{815}$ Das Dekorationsprogramm dieser beiden Räume im Palazzo Apostolico hatte erstmals Taja beschrieben. Dabei bedauerte er vornehmlich den schlechten Zustand der Ausmalung. Zudem nahm Taja keine Bestimmung der Bildsujets vor, ausser derjenigen, die im Zyklus der Passionsgeschichte Jesu vorkamen:

Questa decente, e vistosa stanza, con opportuno focolare all'usanza atica, resta ornata nel soffitto di grand' intaglio di scorniciature, coprto d'oro [...] Questa fregiatura, ripartita in varie istoriette, è dipinta a buon fresco con non ordinaria risolutezza. Io non posso qui indicare i soggetti precisi, che si esprimoni, e dan tema a queste istoriette per ritrovarsi adesso alla pittura sfregiata, annegrita, ed annebbiata dalla polvere estremamente [...]. Perchè questa sala de' Paramenti non si vede per lo più, che addobata di ricca tapezzeria, è bene di avvertire, come nell nude pareti sua laterali, in tutte quattro le parti resta dipinta di sei quadretti eguali in ragionevole proporzione. Sono due per facciata a modo di quadri appesi sopra del muro, con entro alcune istorie della passionedie Gesù Cristo, condotte a fresco a terretta gialla, di ragionevole composozione, e di buon disegno, le quali restano adorne per di fuori da maschere, da grotteschi, e da figurine. Tutta questa dipintura di fregiature, di cornicione, e chiariscuri sulle pareti fu condotto da que' medesimi Maestri uniti insieme, i quali sotto la direzione di Marco da Faenza [...]. I soffitto di questa gran sala, ripartito di vaghi intagli, e da corniciami, illustrati d'oro, fù nel campo di mezzo, che si estende per ampio spazio, dipinto da Girolamo Muziani, pittor Bresciano coll'istoria della venuta dello Spirito Santo in figure oltre la grandezza del naturale, ed in numerosissima quantità. ${ }^{816}$

815 BAV, Chig.L.II.30, f. 505v-506r: „Finita Missa, et data benedictione, ac lecto Evangelio deposuit Sanctitas Sua Pallium super Altari. Card.les deposerunt Paramenta in locis suis, et acceperunt Cappas. Dico Diaconi vero Assistentes una cum Diacono Evangelij redierunt cum Papa parati sed sine mitris, quod hic recte fit, non sic in Vesperis. Nota quod die hesterna fuerunt ornatae duae Aulae nuper instauratae aureisque laquaribus, et picturis pulcherrimis compositae et distinctae. Quae sic optatae omnibus placuerunt, et Sanctitas Sua universo ora collaudata fuit ob haec, et alia praeclara opera quibus in dies Palatium Apostolicum illustrat“. Eine präzisere Beschreibung der Einweihung gibt die Stelle im Zeremonialtagebuch aus BAV, Vat. lat. 12286, f. 420v folgendermassen wieder: „Nota q.d hesterna die fuerunt pannis ornatae duae aulae nuper instauratae aureisq. laquearibus et picturis pulcherrimis compositae, et distintae quae p. plures menses $\mathrm{du}(\mathrm{m})$ aptarentur usui esse non potuerunt ed id circo Papa dum opus fuit parari se pro cappellis vel consistorijs diversis in locis id fecit, satis incommode. Hae(c) autem aulae sic aptatae omnibus placuerunt et S.tas Sua universo ore collaudabat, ob hec, et altra preclara opis, in dies palatiu(m) Ap(osto)licum illustrat(ur). Possent vocari dictae aulae illa ubi ordinatio fit consistoriu(m), et ubi in lacuna depicta ut Immago Pentecoste Aula Consistorij Secreti. Altra v(er)o eid(em) coniuncta anticammera consistorij seu aula paramentor(um) ubi card.les parantur“. Die Zahlungsbelege an die in den Sale dei Paramenti beteiligten Künstlerwerkstätten befinden sich in ASR, Camerale I. Tesoreria Segreta, 1304, f. 174r, 185r, $188 r, 192 r, 193 r \&$ ibid., 1305, f. 46r, 61r, 67v, 71r, 83r, 83v.

816 Taja, Descrizione, S. 79-81. Die beiden Räume wurden jedoch zehn Jahre nach Tajas Descrizione restauriert: ASV, Palazzo Ap., Computisteria, 346, Nr. 24. Gemäss dieser Beschreibung setzte sich die Malerwerkstatt aus Giovanni Battista Lombardelli, Giovanni Battista della Marca, Paris Nogari und anderen maestri subalterni zusammen. Vgl. auch Chattard, Nuova descrizione del Vaticano, II, S. 77, 167, der neben den von Taja erwähnten Malern noch Raffaellino da Reggio aufführt. Die Künstlerwerkstatt lässt sich anhand Baglione, Vite, I, S. 78 rekonstruieren. Folgende Maler werden dabei erwähnt: Paris Nogari, Giovanni Battista Lombardelli und Marco da Faenza. Die Dekorations- 
Aus dieser Beschreibung Tajas folgt, dass bei der Ausgestaltung der Sale dei Paramenti eine einheitliche Künstlerwerkstatt tätig sein musste und deren Leitung Girolamo Muziano unterstand. Sein Mitarbeiter, der Tischmeister Ambrosio Bonacini, bereitete für das an der Decke in rechteckigem Format angebrachte Pfingstfest eine Vorstudie vor, die im Cabinet des Dessins des Louvre aufbewahrt wird (Abb. 44). Einer am 10. Januar 1579 entrichteten Zahlung zufolge war Muziano auch für die Herstellung der cartoni per i mezzanini del concistoro und ihrer Umsetzung in Freskenmalerei zuständig. Damit mussten die Szenen im Fries unterhalb seines Pfingstfestes gemeint gewesen sein und die ausgewählten Szenen aus dem Alten mit entsprechenden Episoden aus dem Neuen Testament verschränken. ${ }^{817}$

Das Bildprogramm dieses Gemäldefrieses musste sich somit stark an das von Muziano ausgeführte Pfingstfest und dessen spezifischer Bildsprache angelehnt haben. Der Bilderschmuck in der zweiten Sala dei Paramenti, die auch als anticamera für das concistorium segretum genutzt wurde, entfaltet zudem ein Bildnarrativ, das die Predigtpraxis der Apostel in ein Zeremoniell der Ernennung von Priestern und Diakonen bibelexegetisch einflechtet. Die erste Freskengruppe im Fries zeigt die Predigt Moses vor dem Volk Israels (Ex 19) und die Bergpredigt Jesu (Mt 5, 17). Beide Szenen werden von allegorischen Figuren des Glaubens und der Religion um das päpstliche Triregnum eingerahmt. ${ }^{818}$ Auf dem gegenüberliegenden Wandkompartiment finden sich die Szenen der Berufung der Leviten (Ex 30, 30) und die Wahl

kampagne für die Sale dei Paramenti steht für die kunsthistorische Forschung deshalb an einem entscheidenden Übergang der Leitung der malerischen Ausgestaltung des Palazzo Apostolico, weil anscheinend der Nachfolger Lorenzo Sabatinis, sein Sohn Mario nämlich, sich spätestens seit dem 31. März 1578 nicht mehr in Rom befand und damit seine Rolle als Leiter der Dekorationen im Palazzo nicht mehr innezuhaben schien. Vgl. zur problematischen Rolle Mario Sabatinis diesbez. Rodolfo 2010, S. 220-222; eadem 2012, S. 21-22.

817 ASR, Camerale I. Tesoreria Segreta, b. 1306, f. 54v: „Giovan Pietro Mangili et sono per le tele datte per impannate delle stantie nove per le stantie di belvedere dove si fanno gli agnus dei, et per la stantia dove Hieronimo Muttiano fa li cartoni alli mezzanini del Concistoro et cinque sportelli alle camere de S. Santità et per far strazzi per nettare li candelieri d'argento“. Vgl. auch den Zahlungsbeleg vom 11. Januar 1578 an denselben Muziano für sein Pfingstfest in ibid., b. 1305, f. 50r: „E a di detto scudi ducento di moneta de mente de N. S. e ordine dell'Illustrissimo Cardinale Guastavillani pagati a Hieronimo Mucano pittore al qual si sono pagati per resto et intiero pagamento del quadro della Istoria del spirito santo da lui fatto per servitio de la sala del concistoro". Zur Mitarbeit Bonacinis vgl. Tosini 1999, S. 267; eadem 2008, S. 398-399; Hochmann 2004, S. 387. Ein handschriftlich festgehaltener Entwurf des Bildprogramms im Fries findet sich in BAV, Vat. lat. 7031, f. $277 r-278 v$.

818 Bildreproduktionen der Fresken in den Sale die Paramenti finden sich in Rodolfo 2010; dies. 2012. Zurzeit bereitet der Verfasser eine kritische Edition der Commentaria in Acta Apostolorum Cesare Baronios vor, in denen sich auch Bildreproduktionen des hier behandelten Dekors in den Sale die Paramenti finden werden: F. Malesevic, Reinventing the Apostolic Community. A Critical Edition of Cesare Baronio's "Commentaria in Acta Apostolorum“ (in Vorbereitung) sowie ders., Ritualizing the Apostolic Palace. The Cappella Paolina during the Boncompagni Pontificate of Gregory XIII (in Vorbereitung). 
der sieben Diakone (Apg 6, 1-7). Ihre Auswahl wird in einer anonymen Schrift zum Entwurf des Bildprogramms dadurch erklärt, dass die „Wahl der Bischöfe der Geschichte Mose entspräche, als er den Priester Aaron ernannte und weihte“. ${ }^{819}$ Die dritte Episodengruppe im Fries der zweiten Sala dei Paramenti stellt den Sieg Josuas gegen Amalek in Refidim (Ex 17, 8-16) und Petrus und Johannes vor dem Hohen Rat (Apg 4, 1-22) dar. Sie sind den beiden Szenen der Offenbarung - der Aufrichtung des Zeltes durch Moses (Ex 40, 34-38) sowie der Aussendung der zwölf Jünger (Mk 6, 7-13) - gegenübergestellt und beenden somit den Freskenzyklus.

Die Episoden im Fries der zweiten Sala dei Paramenti nehmen in spezifischen Momenten zentrale Bezüge zum Gewölbefresko Muzianos auf. Dem Pfingstfest wird dadurch eine entscheidende Bedeutung als Versammlung aller Apostel und Jünger Jesu in dem Moment, in dem sich die heilsspendende Kraft des Heiligen Geistes über sie ausgiesst, zugeschrieben. Der Bilderzyklus im Fries betont daher dieses besondere Fest der Apostel und Jünger Christi im Hinblick auf den Stellenwert, der diesem Hochfest im Kurienzeremoniell 1578 eingeräumt wurde. Das Bildprogramm kann zugleich als eine spezifische Exegese dieser zeremoniellen Bedeutung des Pfingstfestes verstanden werden. Der Zeremonienmeister Mucanzio hielt in seinem Tagebuch fest, dass für die Pfingstvigil in der Cappella Paolina am Altar silberne Statuen von sieben Aposteln aufgestellt worden seien. Zusammen mit den sechs weiteren aus Silber gegossenen Apostelstatuen sollten sie die Zahl der dreizehn Jünger Jesu vollständig repräsentieren. ${ }^{820}$ Das Kurienzeremoniell hatte damit be-

819 BAV, Vat. lat. 7031, f. 277r: „All'eletione de vescovi converebbe l'historia di Moyse quando instituì e consacrò sacerdote Aronne“. Aliprando Caprioli fertigte 1599 einen Stich der ersten Episode an.

820 BAV, Chig.L.II.30, f. 539v-540r: „In Altari fuerunt additae Statuae argenteae Apostolorum septem ultrà sex, quae apponi solent, quas S. D. N. nuper conflari, et construi fecit, ut complerent numerum tredecim Apostolois et certè fuerunt ab Aurificibus pulchrè compositae et fabrefactae, sed pro prima nicae in Altari non fuerunt satis commodè aptatae, unde non poterant omnino ritu consueto thirificari, nam Crux quae in medio Apostolorum Petri et Pauli poni solent, remansit cooperta Imagine B. Petri culpa aliquorum, qui plus sapore nolunt, quam sapere oporteat. Regulariter enim observatur in Cappella Papae ut Imago S. Pauli ponatur in dextero latere Crucis, Sancti Petri verò in sinistro, pro ut de hac re opusculum edidi S. D. N. Gregorio XIII dicatum, et ideo antequam Papa ad Cappellam pervenisset, feci dictas Imagines SS. Petri, et Pauli commutare, et collocare modo praedicto. Papa thurificata Cruce, et Imaginibus Pauli primo, deinde S. Petri, thurificavit etiam caeteras imnes Imagines Apostolorum, quae ibi erant“. Dass es sich hier um die Cappella Paolina gehandelt haben musste, in welche die Vigil gefeiert wurde, kann anhand eines auf das Jahr 1580 zu datierenden Stichs Federico Zuccaris aus der Albertina belegt werden, in welchem die beiden Statuen der Apostelfürsten den Altar flankieren. Dieselben Statuen wurden dann ebenfalls am Tag des Pfingstfestes am Hauptaltar in San Pietro aufgestellt. Vgl. den Eintrag in ibid., f. 541r: „Papa descendit ad faldistorium, et genuflexit pro ut heri in Vesperis ad principium hymnis. Imagines argenteae Apostolorum fuerunt ità collocatae, ut sex anterior et respicerent versus solum Papae reliquae septem versus Populum. Inter utrasque erant septem Candelabra aurata magna, et in eorum medio Crux ampla cristallina, in qua aiunt includi de ligno Crucis Domini Nostri Jesu Christi, et fuit omnibus aspectu iucundum, et magnificum“. 
reits für das officium der Vigil eine deutliche Auslegung des Pfingstereignisses vorgestellt, wonach mit den discipuli Christi eindeutig die Apostel gemeint waren. Damit schloss es bewusst eine Auslegung der Ankunft des Heiligen Geistes als Priesterversammlung, wie es Cesare Nebbias Pfingstfest für die Cappella Lavaiana der Chiesa Nuova der Oratorianer tat, aus. Diese Vorstellung, dass die Heilskraft der Kirche mittels des Heiligen Geistes allein auf die Apostel übertragen werde, fand im Kurienzeremoniell zum Pfingstfest von 1578 ihre institutionelle Begründung. Das Bildnarrativ auf den Wandabschnitten unterhalb des Frieses in der zweiten Sala dei Paramenti legte die entsprechenden Stellen der Apostelgeschichte aus, in denen die Nachfolger Christi selbst die von Jesus eingesetzten Sakramente verwalteten. Gemäss dieser kurienzeremoniellen Bestimmung, die sich im Bilderschmuck der Sale dei Paramenti spiegelt, sind die Apostel als eigentliche Träger der evangelischen Botschaft zu betrachten. Das christliche Heilsversprechen ist demgemäß sowohl in der von den Aposteln selbst praktizierten Sakramentsverwaltung als auch in ihren Martyrien enthalten.

Die kirchenhistoriographische Bedeutung dieses Hochfestes zeichnete sich daher aus der Unterscheidung zwischen apostolischem und priesterlichem Verständnis der Ecclesia ab. Die entsprechende Auslegung des in der Apostelgeschichte enthaltenen Pfingstfestes konnte daher entweder als Mandatsübergabe an die Priester (sacerdos), wie sie auch in der protestantischen Theologie nach Luther vertreten wurde, verstanden werden, oder als ein an Pfingsten gestiftetes Regiment der Apostel, das vom Heiligen Geist geleitet (gubernans) wird und dadurch die Kirche des neuen Zeitalters gründet. Gemäß dieser kurienzeremoniellen Auslegung wurde mit dem Pfingstfest eine neue Ordnung der Apostel in der Ecclesia nach Christus gegründet. Cesare Baronios Annales Ecclesiastici artikulieren bewusst diese kurienzeremonielle Interpretation des Pfingstereignisses. Aus der kirchenhistorischen Rekonstruktion des Oratorianers Baronio ergibt sich im rituellen Vollzug der Pfingstliturgie ein spezifischer Charakter der Kirche als Ecclesia Romana. Das Pfingstzeremoniell verleiht demnach der Kirche ihre sichtbaren Wesenszüge einer apostolischen - und nicht priesterlichen - Versammlung. ${ }^{821}$

821 Baronius, Ann. Ecc., I, S. 214-215: „Cum igitur illic cum ceteris congregati essent Apostoli, Petrus Apostolorum princeps, cuius curae commissi ceteri videbantur (dixerat enim Dominus ad illum: Et tu aliquando conversus confirma fratres tuos) ut Ecclesiae afflictate, \& Iudae proditoris perditione concusse consuleret, de substituendo aliquo ex discipulis in locum illius perditi homini concionem habuit. Pastoralem Petri solicitudinem, ac pervigiliae non tantum gregis [...] Petrus \& non Iacobus, tamquam ferventior, \& velut is, cui discipulorum praesidentia commissa erat. Cum vero Petrus perorasset: statuerunt (inquit Lucas) duos, Ioseph, qui vocabatur Barsabas, qui cognominatus est Iustus, \& Matthiam: \& cum orassent dederunt fortes eius; \& cecidit fors super Matthiam, \& annumeratus est cum undecim Apostolis. [...] Quod vero ad fortem pertinet, quam super illos duos dederunt Apostoli [...] Praedicta insuper occasione, quod Apostoli quae eligerent, fortiti sint, irrepsit aliquando in Christianos genus quoddam fortilegij, quod honesto nomine diceretur [...] sed a sanctis patribus, ecclesiasticis sanctionibus ab Ecclesia Dei procul reiectum est: Sed eam licentiam 
Die kurienzeremoniellen Bestimmungen zu dem im Jahr 1578 durgeführten Pfingstfest hatten im Zusammenhang mit der Ausmalung der beiden Sale dei Paramenti den Palazzo Apostolico zum rituellen Brennpunkt dieses officium erklärt. Das Pfingstfest hatte damit eine eigenständige liturgische Spezifik innerhalb des Kurienzeremoniells verliehen bekommen, indem der apostolische Versammlungscharakter der Kirche mit den zeremoniellen Vorstellungen der Ecclesia Romana gleichgesetzt wurde. Unmittelbar nach dem anno santo setzte innerhalb der Kurie eine Entwicklung ein, die alle im Breviarium Romanum enthaltenen liturgischen officia in deren kurienzeremoniellem Verständnis auslegte. Die kuriale Praxis der Sakramentsverwaltung unterschied sich damit deutlich von derjenigen, welche die Oratorianer bei ihren Priesterversammlungen in der Chiesa Nuova pflegten. Während nämlich die Oratorianer bewusst die heilsgeschichtliche Einlösung des christlichen Heilsversprechens in der priesterlichen Verwaltung der Sakramente sehen wollten, begann die Kurie nach dem anno santo ihre alleinige Gewalt über die sakramentale Heilsökonomie zu beanspruchen. Dafür bediente sie sich des im Kurienzeremoniell erkennbaren Vorstellungswandels der Ecclesia, gemäss welchem die Kirche als Apostel- und nicht als Priesterversammlung ausgelegt wurde. $\mathrm{Zu}$ diesem zentralen ekklesiologischen Gedanken musste der Oratorianer Cesare Baronio ab 1576, aber noch bevor er in die Vallicelliana einzog, der Kurie verholfen haben. Seine Zusammenarbeit mit ausgewiesenen Kurienprälaten - vornehmlich jenen der Indexkongregation - bewirkte ein profundes Neuverständnis dessen, wie sich das römische Kurienzeremoniell als Summe einer spezifisch patristischen Auffassung liturgischer officia und deren rituellen Vollzugs im Zeremoniell zu entwickeln begann. Dadurch wurde ab dem Boncompagni-Pontifikat Gregors XIII. ein neuer Pfad auf dem Weg zu einer den Massstäben der Kurie angemessenen Kirchenhistoriographik vorbereitet. Die Resistenz, die eine solche Kirchengeschichte gegenüber den theologischen Anfechtungen seitens der Protestanten besitzen sollte, lag hauptsächlich in einer Erzählung der Entwicklung der Ecclesia Romana gemäss der Apostelgeschichte, die dann von der Patristik weitergeführt wurde und in das Stadiumder Heiligen und Märtyrer überleitete. Dabei stützte sich eine solche Kirchenhistorik

non nisi ante adventum Spiritus sancti“. Zum lutherischen Verständnis des Pfingstfestes vgl. insbes. WA 46, S. 401-402; WA 49, S. 442-446; ibid. 41, S. 605-607. Vgl. diesbez. dann Mumme 2015, S. 174-177. Vgl. entsprechend dann auch die Stelle in Ecc. Hist., I, Sp. 243-244: „Pentecostes non sit mentio ab Evangelistis. Erat autem festum, in quo memorio legis divinae promulgatae in monte Synai recolebatur, die nimirum quinquagesimo à Pesah festo. Nam totidem ab egressu populi Israelitici, donec ad eum montem venissent, dies intercesserant: unde \& nomen accepit. Observatum autem esse magno studio, apparet ex historia Actorum 2. Ubi etiam novam Pentecosten Christus cum discipulis suis, effuso in ipsos spiritus sancto, visibiliter, \& accensis linguarum de miraculorum donis celebrat. Actestatur ea historia, plurimos tum homines Hierosolymis fuisse. Vocatur autem festum hebdomaddarum, ac praecipitur observandum à Deo“. 
vornehmlich auf die kurienzeremonielle Auslegung der römischen Liturgik, wie sie im Missale und im Breviarium Romanum überliefert wurde. Cesare Baronios Annales Ecclesiastici stellen demgemäss noch vor dem offiziellen Rituale Romanum eine kirchenhistoriographisch bestätigte Ritensammlung dar, welche die römische Liturgik kennzeichnet. 